
ROYAL ONTARIO MUSEUM

LIFE SCIENCES

CONTRIBUTIONS

160

\section{ANALYSIS OF MORPHOLOGICAL AND BEHAVIOURAL EVIDENCE FOR THE PHYLOGENY AND HIGHER CLASSIFICATION OF TRICHOPTERA \\ (INSECTA)}

Henry E. Frania

Glenn B. Wiggins 
(C) 1997 Royal Ontario Museum

All rights reserved. No part of this publication may be reproduced, stored in a retrieval system or data base, or transmitted, in any form or by any means, electronic, mechanical, photocopying, or otherwise, without the prior written consent of the publisher.

First published in 1997 by the Royal Ontario Museum, 100 Queen's Park, Toronto, Ontario M5S 2C6.

Publication date: 15 June 1997

ISBN 0-88854-420-0

ISSN 0384-8159

\section{Canadian Cataloguing-in-Publication Data}

Frania, Henry Edward, 1951-

Analysis of morphological and behavioural evidence

for the phylogeny and higher classification of Trichoptera (Insecta)

(Life sciences contributions, ISSN 0384-8159; 160)

Includes bibliographical references and index.

1. Caddisflies - Phylogeny. 2. Caddisflies -

Classification. 3. Caddisflies - Morphology.

I. Wiggins, Glenn B. II. Royal Ontario Museum.

III. Title. IV. Series.

QL516.F72 $1997 \quad 595.745138 \quad$ C97-930775-9

\section{ROYAL ONTARIO MUSEUM PUBLICATIONS IN LIFE SCIENCES}

The Royal Ontario Museum publishes books on a variety of subjects in the life sciences, including Life Sciences Contributions, a numbered series of original scientific publications. All manuscripts considered for publication are subject to the scrutiny and editorial policies of the Academic Editorial Board, and to independent refereeing by two or more persons, other than Museum staff, who are authorities in the particular field involved.

\section{ACADEMIC EDITORIAL BOARD}

Chair: Chris McGowan

Members (Science): D. H. Collins, T. A. Dickinson, R. D. James

Members (Art \& Archaeology): L. Golombek, P. Kaellgren, P. L. Storck

\section{Manuscript Editor: R. D. James}

Production Editor: Andrea Gallagher Ellis

Henry E. Frania is a Postdoctoral Associate in the Entomology section of the Centre for Biodiversity and Conservation Biology, Royal Ontario Museum.

Glenn B. Wiggins is Curator Emeritus in the Entomology section of the Centre for Biodiversity and Conservation Biology, Royal Ontario Museum.

The Royal Ontario Museum is an agency of the Ontario Ministry of Citizenship, Culture and Recreation.

Cover: The cover illustration shows a last-instar larva of a species of the caddisfly genus Ochrotrichia, family Hydroptilidae. The phylogenetic relationships of the Hydroptilidae are enigmatic.

Printed and bound in Canada 


\section{Contents}

Abstract 1

Introduction 1

Materials and Methods 2

Specimens Examined and Study Techniques 2

Character-State Data and Phylogenetic Techniques 3

Morphology of Larvac 6

Changes Between Larval Instars 6

Head 6

Thorax 15

Abdomen 20

Morphology of Adults 27

Head 27

Thorax 30

Abdomen 31

Results of Numerical Phylogenetic Analyses of the Morphological Data 36

Evaluation of Alternative Hypotheses of Relationships for Trichoptera Based on Morphology 41

Issues about Spicipalpia 41

Issues about Annulipalpia 44

Issues about Integripalpia 46

Evolution of Larval Construction Behaviour and the Phylogeny of Trichoptera 48

Higher Classification of Trichoptera 54

Acknowledgements 57

Appendix 58

Literature Cited 62 



\title{
Analysis of Morphological and Behavioural Evidence for the Phylogeny and Higher Classification of Trichoptera (Insecta)
}

\begin{abstract}
Higher-level relationships of the families of Trichoptera, and in particular those of the Rhyacophilidae, Hydrobiosidae, Glossosomatidae, and Hydroptilidae, are examined using numerical phylogenetic techniques on 70 morphological characters from larvae and adults. Data concerning larval construction behaviour are examined in this way as well, and are considered also from a biological perspective. Both the morphological and behavioural data provide strong support for monophyly of the Annulipalpia (s.s.) and the Integripalpia (s.s.), and for overall primitiveness of the families of Spicipalpia (Rhyacophilidae, Hydrobiosidae, Glossosomatidae, Hydroptilidae). Our analyses do not support monophyly of Spicipalpia, or inclusion of Spicipalpia within the Annulipalpia (s.l.). There is some morphological evidence indicating that the Glossosomatidae, Hydrobiosidae + Rhyacophilidae, and Annulipalpia (s.s.) constitute a monophyletic group; there is equivocal morphological evidence that the Hydroptilidae and Integripalpia (s.s.) are sister groups. In contrast, behavioural data provide evidence that the Integripalpia and Annulipalpia are sister groups, as are the Glossosomatidae and Hydroptilidae.

Under these circumstances, we propose a classification of three coordinate suborders in the Trichoptera: Spicipalpia, Annulipalpia, and Integripalpia, recognizing that the Spicipalpia may not be a monophyletic group. Within Annulipalpia, we recognize the Philopotamoidea and Hydropsychoidea; within Integripalpia, the infraorders Plenitentoria and Brevitentoria; and within Brevitentoria, the Leptoceroidea and Sericostomatoidea, again with the qualification that, based on our analyses, the Brevitentoria and Leptoceroidea may not be monophyletic groups.

Cool running waters are inferred from available evidence to be the ancestral aquatic habitat for Trichoptera. This hypothesis is consistent with the fact that all families of Spicipalpia construct closed semipermeable cocoons, and addresses the problem of osmotic regulation met by groups of insects colonizing aquatic habitats.
\end{abstract}

\section{Introduction}

A primary source of contention in the literature about the systematics of Trichoptera concerns the placement of the closed-cocoon-making caddisfly families Rhyacophilidae, Hydrobiosidae, Glossosomatidae, and Hydroptilidae. There are three aspects to the problem: whether these four families constitute a monophyletic group; how as a group or individually they are related phyletically to other Trichoptera; and how they should be classified.

Some contemporary workers follow Martynov (1924, 1930), who recognized two suborders in Trichoptera:
Annulipalpia and Integripalpia, the former composed in part of the fixed-retreat makers, the latter the portable-case makers. Martynov placed the Rhyacophilidae (including Hydrobiosidae and Glossosomatidae) and the Hydroptilidae in Annulipalpia, together with the fixedretreat makers. Weaver $(1983,1984)$ and Weaver and Morse (1986) considered the four families in question to form a monophyletic group within Annulipalpia (= Vericloacia of Weaver 1983, 1984), the infraorder Spicipalpia, and to be the sister group of the fixed-retreat makers, the 
Curvipalpia (Fig. 1). This arrangement conformed to that of Schmid (1980), except that Schmid placed the Hydrobiosidae with the fixed-retreat makers.

Lepneva (1964) placed the four families with some of the fixed-retreat makers in the superfamily Paleochaetoidea, and the other fixed-retreat makers, Ecnomidae, Polycentropodidae, and Hydropsychidae (including Arctopsychinae) in the Neochaetoidea.

Ross (1967) recognized the Annulipalpia and Integripalpia but placed the closed-cocoon-making Rhyacophilidae (including Hydrobiosidae), Glossosomatidae, and Hydroptilidae in Integripalpia with the portable-case makers (Limnephiloidea), and considered them to have evolved in that sequence. Ross (1967) erected a paraphyletic group, the Rhyacophiloidea, to contain all the closed-cocoon makers (Fig. 2).

Wiggins and Wichard (1989) followed Weaver and Morse (1986) in considering the Spicipalpia (including Hydrobiosidae) to be monophyletic, but introduced new behavioural evidence raising the possibility that the Spicipalpia have a sister-group relationship with the Annulipalpia + Integripalpia (Fig. 3). Consequently, they proposed a classification granting equivalent subordinal status to the three lineages. Weaver (1992a, 1992b) criticized the proposals of Wiggins and Wichard (1989); Wichard (1991) and Wiggins (1992) provided rebuttals.

To try to resolve the controversy about the phylogeny and higher classification of Trichoptera, we restudy the morphological characters that have been used in the past to support one phylogenetic arrangement or another, and add a number of new characters. We then analyse the data using numerical phylogenetic methods, and compare the resulting cladograms with phylogenies inferred previously. Our results are discussed largely in terms of the hypotheses of Ross (1967) and Weaver (1983, 1984) because these authors have documented the evidence for their arrangements more than others have done. We then examine the issue further using recent findings concerning construction behaviour of larval Trichoptera (Bohle and
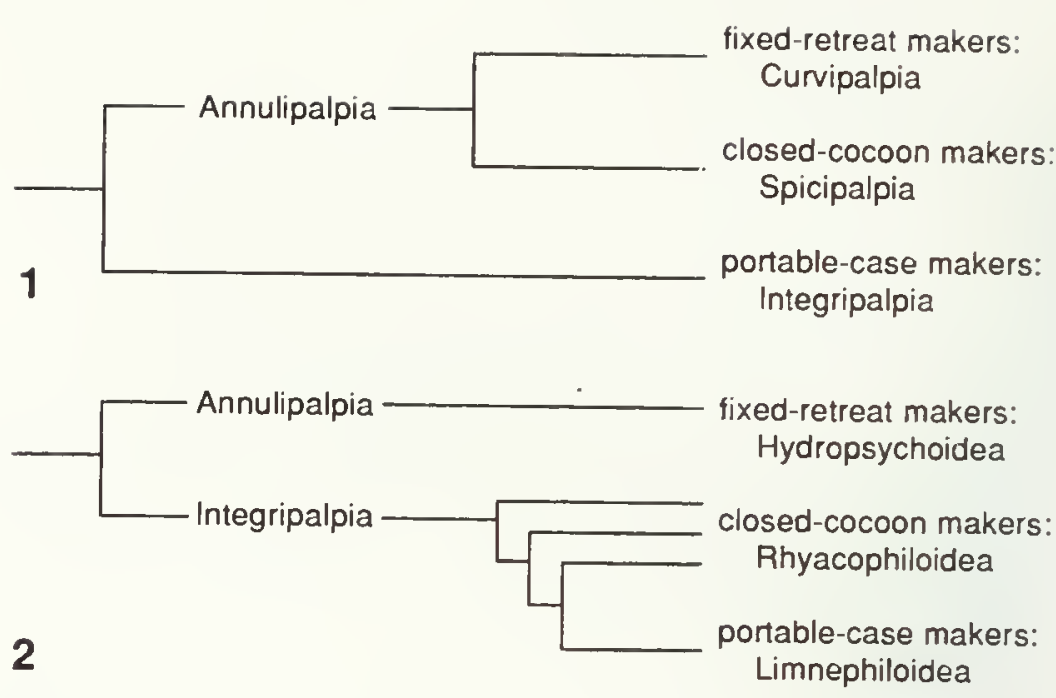

3

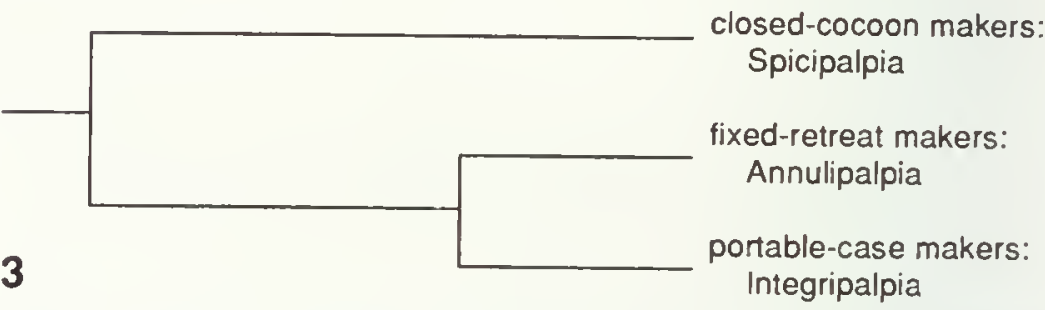

Figs. 1-3. Three conlemporary hypotheses of phylogeny for Trichoptera, showing the classification based on each. 1. Weaver and Morse (1986). 2. Ross (1967). 3. Wiggins and Wichard (1989), Wichard (1991).

Fischer, 1983; Wiggins and Wichard, 1989). Finally, we provide a working classification for Trichoptera that in our opinion best reflects present understanding of evolutionary relationships among the families, while promoting stability for general use.

Throughout the text, we classify and refer to the Rhyacophilidae, Hydrobiosidae, Glossosomatidae, and Hydroptilidae collectively as the suborder Spicipalpia, a group with equivalent rank to the suborders Integripalpia and Annulipalpia (Wiggins and Wichard, 1989). Within Integripalpia we continue to recognize and refer to the Plenitentoria and Brevitentoria of Weaver $(1983,1984)$, which are equivalent to the limnephilid and leptocerid branches of Ross (1967). Our rationale for these positions is provided in the section on classification at the end of our paper.

\section{Materials and Methods}

\section{SPECIMENS EXAMINED AND STUDY TECHNIQUES}

Larvae and adults of genera in 35 families of Trichoptera were examined (an asterisk indicates that only the adults were identified to species): Rhyacophilidae, Rhyacophila fuscula (Walker); Hydrobiosidae, Atopsyche sperryi Denning*; Glossosomatidae, Agapetus illini Ross, Glossosoma nigrior Banks, Protoptila tenebrosa (Walker)*; Hydroptilidae, Palaeagapetus nearcticus Banks, Agraylea sp.; Philopotamidae, Dolophilodes dis- tinctus (Walker), Chimarra obscura Walker; Stenopsychidae, Stenopsyche griseipennis McLachlan.; Hydropsychidae, Arctopsyche grandis (Banks), Diplectrona modesta Banks, Hydropsyche betteni Ross, Macrostemum zebratum (Hagen); Ecnomidae, Ecnomus tenellus (Rambur); Psychomyiidae, Psychomyia flavida Hagen*, Paduniella nearctica Flint; Xiphocentronidae, Xiphocentron numanus Schmid*; Polycentropodidae, Nyctiophylax affinis (Banks)*; Dipseudopsidae, Phylocentropus placidus (Banks); Phryganeidae, Yphria californica (Banks). 
Phryganea cinerea Walker; Phryganopsychidae, Phryganopsyche latipennis (Banks); Plectrotarsidae, Plectrotarsus tasmanicus Mosely-adults, P. gravenhorsti Kolenati-larvac; Brachycentridae, Brachycentrus occidentalis Banks; Limnephilidae, Dicosmoecus atripes Hagen, Pseudostenophylax uniformis (Betten), Limnephilus indivisus Walker, Apatania arizona Wiggins; Gocridae, Lepania cascada Ross, Goera stylata Ross; Uenoidac, Neophylax concinnus McLachlan; Neothrenmma alicia Banks*; Lepidostomatidae, Lepidostoma vernale (Banks); Tasimiidac, Trichovespula macrocera Schmid; Limnocentropodidac, Limnocentropus himalayanus Martynov-adults, L. rectus Kimmins-larvae; Kokiriidac, Kokiria miharo McFarlane; Beraeidae, Beraea fontana Wiggins; Sericostomatidae, Gumaga nigricula (McLachlan); Calocidac, Caenota plicata Mosely; Helicophidae, Alloecella grisea Banks; Molannidae, Molanna flavicornis Banks; Odontoceridac, Psilotreta indecisa (Walker), Pseudogoera singularis Carpenter, Atriplectides dubius Mosely*; Philorheithridae, Austrheithrus dubitans Mosely; Helicopsychidac, Helicopsyche borealis (Hagen); Calamoceratidae, Heteroplectron californicum McLachlan; Leptoceridac, Mystacides interjecta (Banks); Anomalopsychidae, Anomalopsyche minuta (Schmid).

Various genera of Lepidoptera and Mecoptera were also studied for purposes of outgroup comparison: Lepidoptera: Micropterigidae, Epimartyria auricrinella Walsingham, Micropteryx calthella L.-adults only; Eriocraniidae, Dyseriocrania griseocapitella (Walsingham)—adults only; Psychidae, Solenobia sp.; Incurvariidae, Adela sp.—adults only; Mecoptera: Panorpidae, Panorpa sp., Brachypanorpa sp.

Specimens preserved in alcohol or dry were dissected, cleared in $\mathrm{KOH}$, and examined in glycerine using a compound as well as a binocular dissecting microscope. Larval antennae were also viewed using a scanning electron microscope. Living specimens, when available, were preserved and cleared in lactic acid.

\section{CHARACTER-STATE DATA AND PHYLOGENETIC TECHNIQUES}

After an initial survey of external and internal sclerotized structures, a data set was assembled comprising 40 multistate (= 64 binary) larval and 30 multistate ( $=45$ binary) adult morphological characters (Appendix; Table 1). Characters were polarized by outgroup comparison with Lepidoptera and Mecoptera. Characters are referenced in the text by number (e.g., Appendix, character 5) and the character states by a small letter; for character-state trees with branches, all of the character states on one branch were assigned letters sequentially (e.g., 5a, 5b), and then the first character state on the other branch was assigned the next letter in capitals and a small letter indicating the character state immediately ancestral to it (e.g., 5Ca).
We analysed the data using numerical phylogenetic techniques, with additive binary coding of the characters. The larval and adult data were analysed separately and then together. We employed two widely used techniques: parsimony analysis and compatibility analysis. In parsimony analysis an attempt is made to construct one or more phylogenetic trees that minimize the total number of character-state changes implied by that arrangement of the taxa, irrespective of whether the changes are derivations of the trait or reversals to the primitive condition. This procedure was carried out using the HENNIG86 computer program (version 1.5, J. S. Farris). All characters were weighted equally, and a hypothetical outgroup taxon was included having the ancestral condition for all character states. The search for minimum-length trees was carried out using the command sequence " $\mathrm{m} *$ bb", and the order in which the taxa appeared in the data set was changed once to determine if there were other islands of trees of minimum length (Maddison, 1991). We found that most branches of each tree obtained were supported only by characters that were homoplasious under that arrangement of the taxa. We then did compatibility analyses in order to find those arrangements of the taxa that are supported by the maximum possible number of uniquely derived characters. In compatibility analysis homoplasious characters are ignored when constructing the tree, and no consideration is given to the total number of character-state changes over the entire tree. The CLINCH computer program (version $6.2, \mathrm{~K}$. Fiala) was employed for these analyses, which were done only on the combined data set. Some parts of the arrangements obtained using compatibility analysis were unresolved; no effort was made to resolve the polytomies because the trees were sufficiently resolved for our purposes.

We then did another parsimony analysis on the combined larval + adult data, this time using the successive weighting procedure in HENNIG86 ("xsteps w" command). Each of the arrangements that we obtained using this procedure consisted for the most part of a mix of the groupings obtained when the characters were weighted equally, and when the data were analysed using compatibility analysis. For this reason, we do not consider them further.

We had doubts about the ancestral condition of some characters. The polarity of all of these traits was changed and the analyses were done again.

Arrangements of the taxa were compared numerically in terms of the number of character-state changes (tree length), the tree consistency index (minimum number of character-state changes under any arrangement of the taxa divided by the number of changes under a given arrangement), and the number of character states that are uniquely derived under that arrangement. 
TABLE 1. Distribution of morphological traits of larvae (1-40) and adults (41-70) of selected genera of Trichoptera.

Nc = no logical comparison.

Character
Genus

Rhyacophila a a b a Ec a a a a a a b a a a a a a Atopsyche a a b a Ec a a a a a a b a $\quad \mathrm{a}$ a

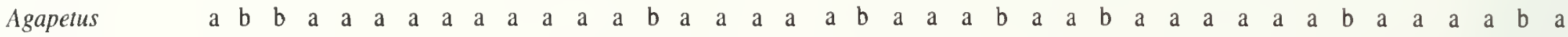

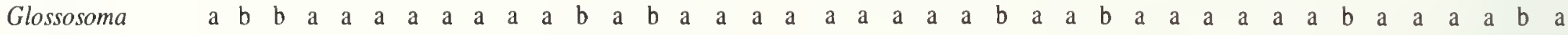

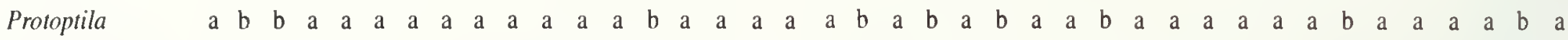
Palaeagapetus b c a a $\mathrm{Ca}$ a $a$ a $a$ a $a$ b $a$ a $a$

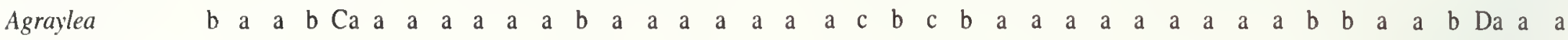
Dolophilodes a a b a b a a a a a a a a a a a a a a a Chimarra a a b a b a a a a a a a a a a a a a a a a a

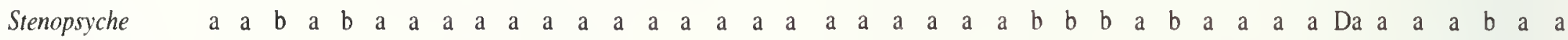

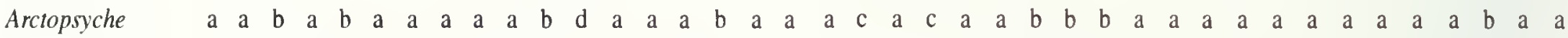
Diplectrona a a

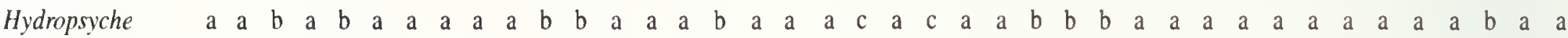
Macrostemum $a \mathrm{~b} \quad \mathrm{~b}$ a Ecnomus

Psychomyia

Paduniella

Xiphocentron

Nyctiophylax

Phylocentropus

Yphria

Phryganea

Phryganopsyche

Plectrotarsus

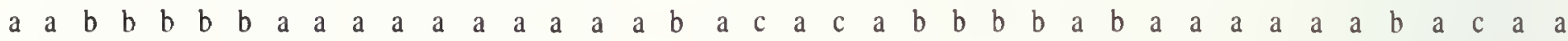

Brachycentrus

Dicosmoecus

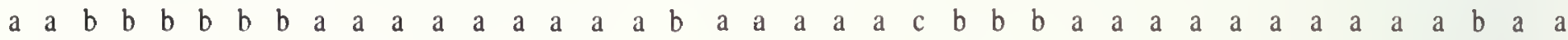
a $a$ b $b$ b b b b a a a a a a a

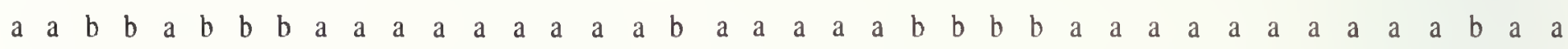

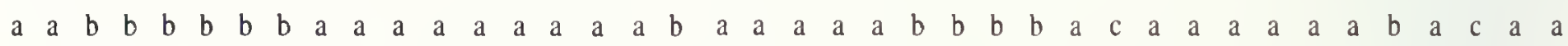
$a$ a $b$ b b b b b a a a a a a a a a b a a a a a b b b b a c a a a a a a a a c Ca a a a a a a a a a a b a a b b b a b a a a a b a a a a a b c Ca

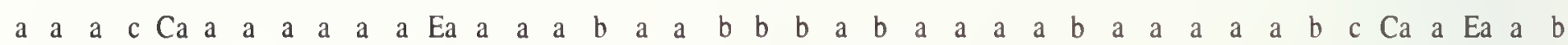

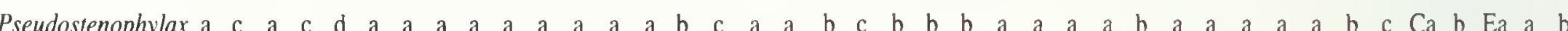
Limnephilus Apatania a b a c Ca a a a a a a Ea a a a b a a b c b a b a a a a b Da a a a a b b Ca $a$ a c a c Ca a a a a a a Ea a a a b a a b b b a b a a a a b Da a a a a b c Ca $a$ a c a c Ca a a a a a a Ea a a a b a a b c b b b b a a a b a

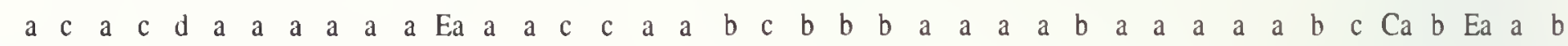
Neophylax Lepania

Goera

Neothremma

Lepidostoma

Limnocentropus

Trichovespula

Kokiria

Beraea

Gumaga

Caenota

Alloecella

Molanna

Psilotreta

Pseudogoera

Atriplectides

Austrheithrus

Helicopsyche

Heteroplectron

Mystacides

Anomalopsyche

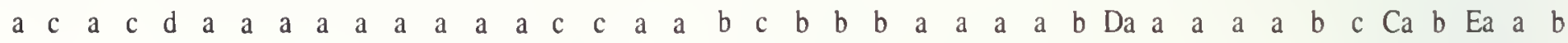

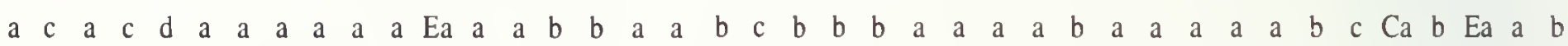

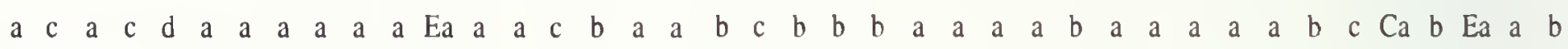

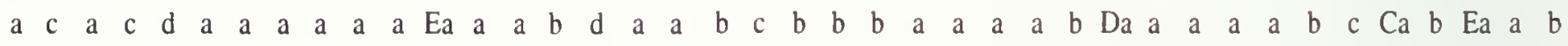
a $c$ a $c$ d a a a a a a Ea a a $c$ d a a $\quad$ b $c$ c b b b b a a a b a

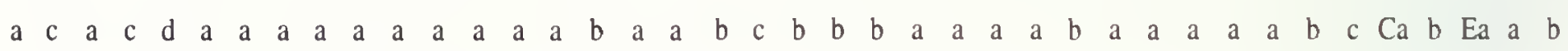
a c a c Ca a a a a a a Ea a a c b a a b c b b b a a a a b a a a a a b b Ca a b a $c$ d a a a a a a Ea a a a b a a a c b b b a a a a a a a a a a b b Ca $a$

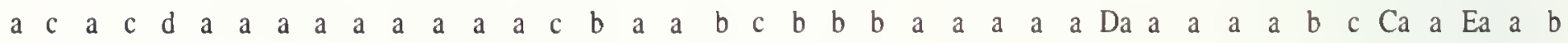
a a a c Ca a a a b b a Ea b a a b a a $a$ b b b b a a a a a $e$ a $a$ a $a$ b c Ca a a a c Ca a a a a a a Ea b a b b b a $a$ c $b$ a b a a a

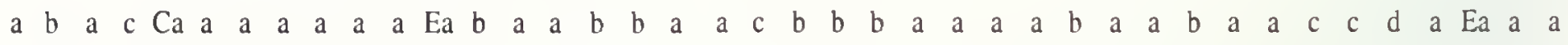
a c a c Ca a a a a a a Ea b a c b b a a c b a b b a a a b a a b a a c c Ca a Ea a a

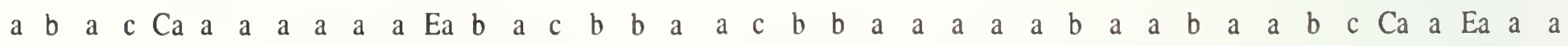
$a \quad b \quad a \quad c C a$ a $a$ a $b$ b a Ea b a b b a a a c b a b a a a a a $e$ a a a a b c Ca a Ea a a a b a c Ca a a a a a a a a a c b a a a c b b b a a a a b a b a b a b c Ca a Ea $a$ a $c$ a $c$ Ca a a a a a a a a a c b a a a c b b b a a a a b a b a b a

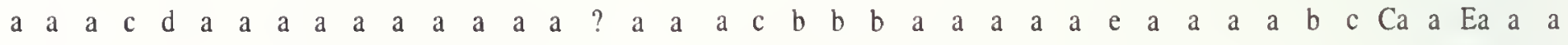
a b a c Ca a a a a a a a a a a b a a a c b b b a a a a b a a a a a b c Ca

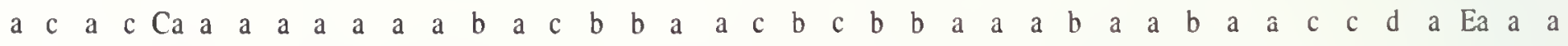
a c a $c$ Ca a a a a a a a a a c b a a a c b a b a a a a b Da a b b a b c Ca a Ea $a$ a a a a c Ca a a a a a a Ea b a a b a a a c b a a a a a a b Da a b a a b c Ca a Ea a a

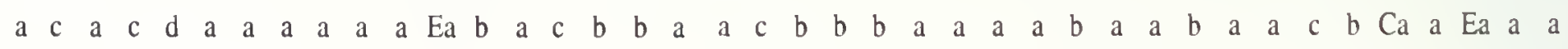


Character

414243444546474849505152535455565758596061626364656667686970

Genus

Rhycophila a a a Aropsyche

Agapetus

Glossosoma

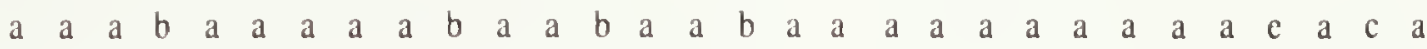

Protoprila

Palaeagaperus

Agraylea

Dolophilodes

Chimarra

Stenopsyche

Arctopsyche

Diplecirona

Hydropsyche

Macrostemum

Ecnomus

Psychomyia

Paduniella

Xiphocentron

Nyctiophylax

Phylocentropus

Yphria

Phryganea

Phryganopsyche

Plectrotarsus

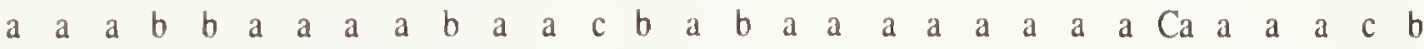

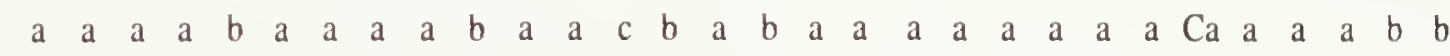

Brachycentrus

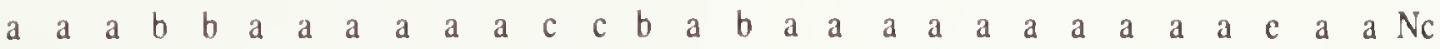

Dicosmoecus

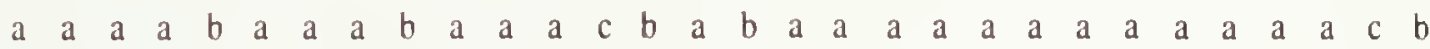

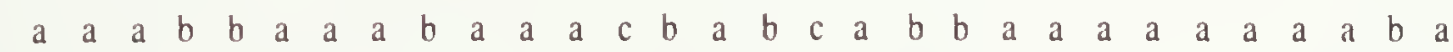
a a a a a b a a a b a c c c b b a a a

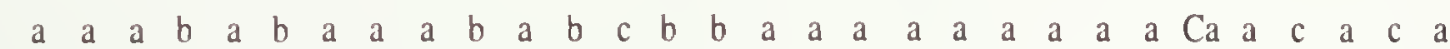

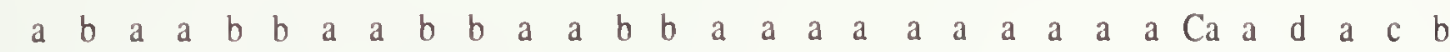

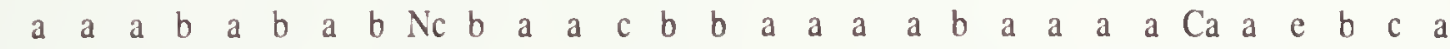

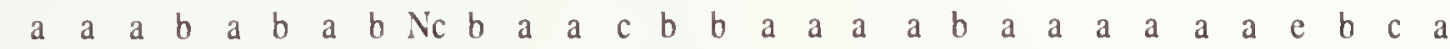

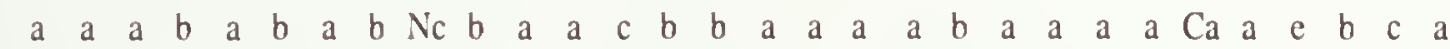

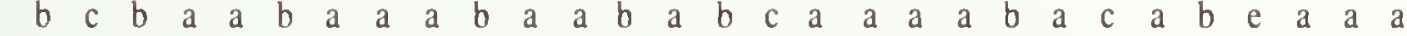

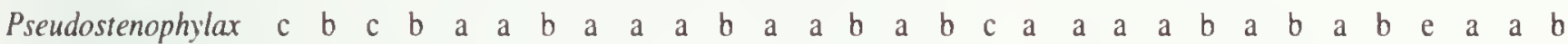
Limnephilus Apatania Neophylar Lepania

Goera

Neothremma

Lepidostoma $a \quad a \quad a \quad b \quad b \quad b \quad a \quad b \quad N c a$

Limnocentropus a $a$ a $b$ a $b$ a $b$ Nc $a$ a $a$ Trichovespula

Kokiria

Beraea

Gumaga

Caenota

Alloecella

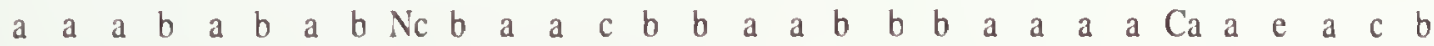
a a Fa b a a a b Nc a a a c b b a a a b a a a a a a a d a b b $a$ a $a \quad b \quad a \quad b \quad a \quad b \quad N c a$ Molanna

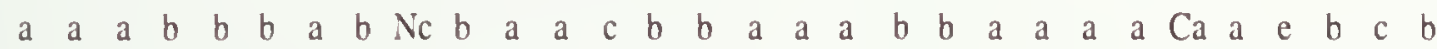
$a \quad a \quad a \quad b \quad b \quad b \quad a \quad b \quad N c a$

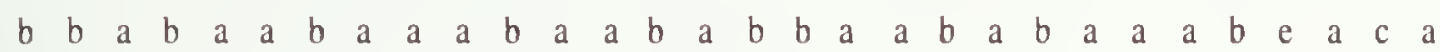

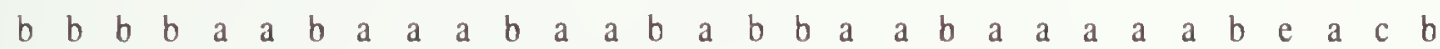

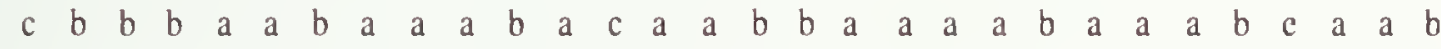
$b \quad b \quad c \quad b \quad a \quad a \quad b \quad a \quad a \quad a \quad b \quad a \quad a \quad a \quad a \quad b \quad c \quad a \quad a \quad b$ ? ? a a a b e a $c$

Psilotreta

Pseudogoera

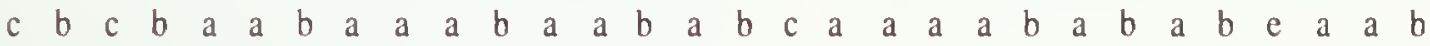

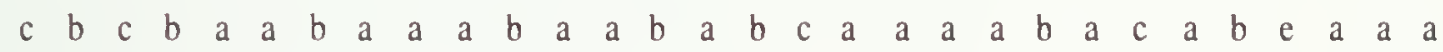

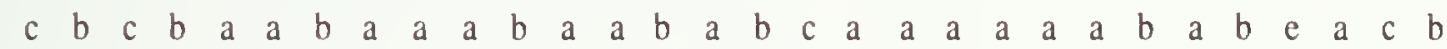

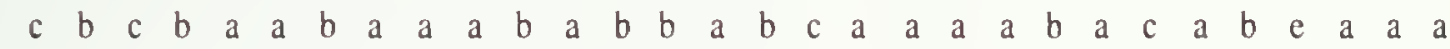
$c \quad b \quad c \quad b \quad a \quad a \quad b \quad b \quad N c a$

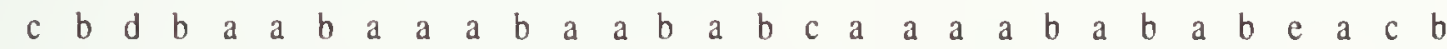
Atriplectides $c a c b a$ a $b$ b Austrheithrus

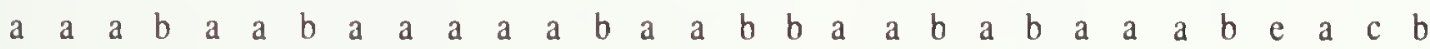

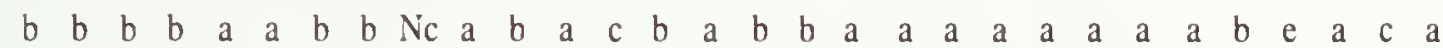

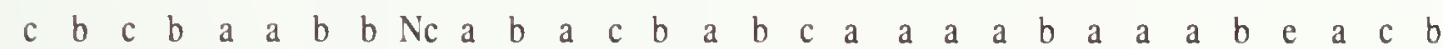
a a $a \quad b \quad a \quad a \quad b \quad b \quad N c$ a $a$ a $c$ b Helicopsyche Heteroplectron

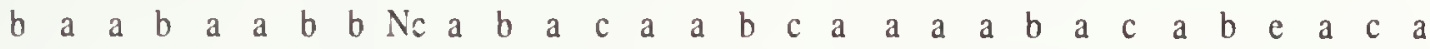
Mystacides

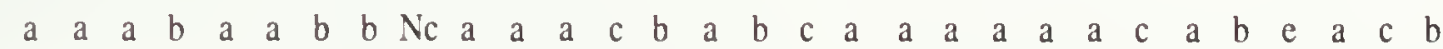

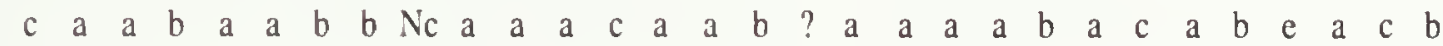

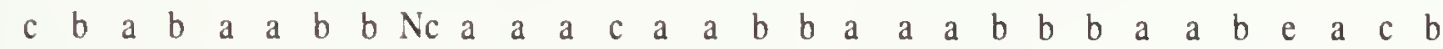

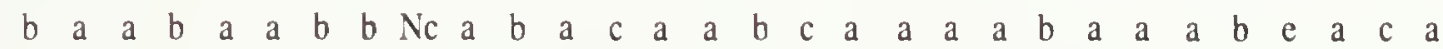
$a$ a $a \quad b \quad a \quad a \quad b \quad b \quad N c a$ $b \quad b \quad a \quad b \quad a \quad a \quad b \quad b \quad N c a$ a a a b a a b b Nc a b a c b a b ? a $a$ a $a$

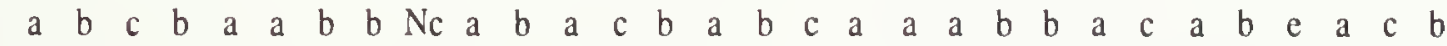
Anomalopsyche

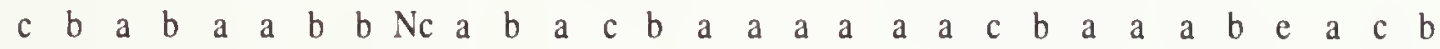

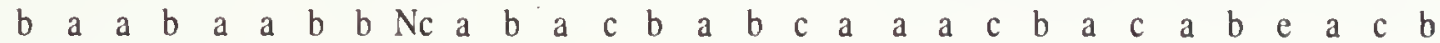

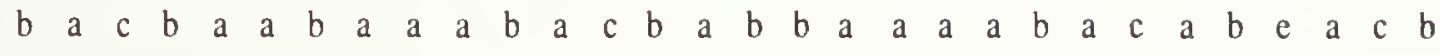




\section{Morphology of Larvae}

\section{CHANGES BETWEEN LARVAL INSTARS}

For the majority of Trichoptera the most marked changes from the early instars to the mature fifth-instar larva are an increase in the absolute size of the larva, and in the number of setae, and of the gills (where they occur). Changes in body proportions, orientation, and morphology are usually relatively slight. Larvae of Hydroptilidae (including Palaeagapetus) are an exception because they exhibit hypermetamorphosis: the first four instars are campodeiform and free-living, the last instar is suberuciform and constructs a case. Associated morphological changes include hypertrophy of the abdomen and modifications in form of the body and appendages.

Among Mecoptera, Lepidoptera, and Trichoptera, hypermetamorphosis is otherwise confined to two derived families of Lepidoptera (i.e., Epipyropidae and Gracillariidae, Davis 1987b). Thus, hypermetamorphosis is clearly a derived condition in Trichoptera (Appendix, character 1). The question of whether characters in the first four or in the last instar represent the plesiomorphic condition in Hydroptilidae is addressed in the discussion about the anal prolegs and in the section concerning the phylogenetic analyses.

\section{HEAD}

\section{Head Orientation}

The head of most Trichoptera larvae is held either in a horizontal position with the mouthparts directed forward (prognathous), or in a more vertical position with the mouthparts directed ventrally (hypognathous). Nielsen (1948:177) considered the prognathous condition to be primitive for Trichoptera, noting that "closing of the head capsule" is generally thought to be a consequence of prognathism. The occipital foramen of all Trichoptera is closed by the hypostomal bridge (Hinton, 1963; Kristensen, 1984b). Typically in prognathous insects (Denis and Bitsch, 1973), including primitive Lepidoptera (Kristen-sen, 1984b), the craniocardinal articulation is located considerably posterad of the mandibular articulation, but in all Trichoptera the two points of articulation are contiguous, a characteristic of hypognathous insects (Kristensen, 1984b). Kristensen (1984b) concluded that although the ancestral Lepidopteran was "supposedly" prognathous, the posterior position of the craniocardinal articulation is a derived condition for Lepidoptera.

It could be inferred from the conclusions of Nielsen (1948) and Kristensen (1984b) that in the common ancestor of Trichoptera and Lepidoptera the head was prognathous and the craniocardinal and mandibular articula- tions were contiguous. However, larvae of most Mecoptera are hypognathous, and in these the mandibular and craniocardinal articulations are contiguous (as in Trichoptera), while in the prognathous Nannochoristidae (Pilgrim, 1972, fig. 5), the craniocardinal articulation appears to be far behind the mandibular articulation (as in Lepidoptera); moreover, a hypostomal bridge is present. Stehr (1987) noted that in hypognathous Lepidoptera larvae the epicranial suture is long relative to the frontoclypeus, while in prognathous larvae the suture is much shorter. There is no relationship in larvae of Trichoptera between length of the epicranial suture and head orientation (figures in Wiggins, 1977).

Weaver $(1983,1984)$ suggested that the ancestral Trichopteran was hypognathous, but did not present any evidence. We consider the matter unresolved. A further difficulty is posed by the Glossosomatidae. Weaver (1983, 1984) tacitly and Hickin (1967) explicitly assigned the prognathous condition to this family. Badcock (1963) stated that in the Glossosomatidae the head is held anteroventrally, and thus this family exhibits an intermediate condition with respect to head orientation; the head is similarly oriented in the Hydroptilidae. Because of the problem of establishing the plesiomorphic condition for head orientation in Trichoptera, and the difficulty of explicitly defining this trait, we refrain from using it as a character in our analyses.

\section{Antenna}

Antennal location. Larvae of Trichoptera have the antenna located laterally between the base of the mandible and the eye. In larvae of Rhyacophilidae, Hydrobiosidae, most Hydroptilidae and Annulipalpia, and some Integripalpia (e.g., Phryganeidae, Korkiriidae, Beraeidae, some Odontoceridae (Atriplectides) and Leptoceridae), the antennae are located at or very near to the anterior margin of the head. More precisely, the antennae are separated from the anterior margin of the head capsule by less than one-half the diameter of the antennal foramen. We refer to this condition as far cephalad. In Glossosomatidae, some Hydroptilidae, Macrostemum (Hydropsychidae), and various families of Integripalpia (mostly Plenitentoria), the antennae are located more posteriorly (i.e., separated from the anterior margin of the head capsule by between onehalf to twice the diameter of the antennal foramen). This is the cephalad position. Finally, in Palaeagapetus and in various families of Integripalpia (mostly Brevitentoria) the antennae are about as close to the eye as to the anterior margin of the head (i.e., separated from the anterior margin of head capsule by more than twice the diameter of the antennal foramen). We refer to this condition as caudad. 
Larvae of Mecoptera and most Lepidoptera have the antennac located far cephalad. The antennae of Micropterigidae are located cephalad (Davis, 1987a, fig. $26.28 \mathrm{e}$ ), which presumably is correlated with the long antenna in this family (see below). Thus, we consider the far cephalad position to be ancestral in Trichoptera, as did Ross (1967:178) and Krafka (1923). Interpretation of this trait as a character transformation series is straightforward (Appendix, character 2).

Structure of the antenna. We have identified seven types of antennac in larval Trichoptera; Denis (1984a) recognized all of these except the first and fifth types.

Ptilocolepine type. The antennae of Palaeagapetus (Hydroptilidac: Ptilocolepinae) are onc-segmented. The segment is cylindrical, the sides are sclerotized, and the apex has two large basiconic sensilla medially (sinnesstäbchen or sensory rods of Niclsen, 1942; apical papillae of Ross, 1967; tubercles Tm and T1 of Denis, 1984a) and one long trichoid sensillum (seta of Nielsen, 1942) laterally (Figs. 4, 6a).

Glossosomatid type (type III of Denis, 1984a). The Glossosomatidae have vestigial antennac. These consist of a slightly raised membranous area bearing two large basiconic sensilla medially, and two long trichoid sensilla laterally, one on each side of the basiconic sensilla (Figs. 5, 6e; Denis, 1984a, pl. Ill, figs. $4,6)$.

Hydropsychid type (type I of Denis, 1984a). The Philopotamidae, Stenopsychidae, and most Hydropsychidae have antennae like the Glossosomatidac, except that in most taxa there are two long and one shorter trichoid sensilla laterally (Fig. 6f; Denis, 1984a, pl. I, figs. 4-6; pl. II, figs. 1-4). The antennae of Macrostemum (Hydropsychidae) have two trichoid sensilla; these are about as long and in the same position as the longest two trichoid sensilla in Nyctiophylax (Polycentropodidae, Fig. 6g).

Psychomyiid type (type II of Denis, 1984a). The antennae of Psychomyiidae, Ecnomidae, Polycentropodidae, and Dipseudopsidae are like that of the Glossosomatid type, except that there is just one large basiconic sensillum medially, and two long and one short trichoid sensilla laterally (Fig. 6g; Denis, 1984a, pl. I, figs. 1-3; pl. II, figs. 5-6; pl. III, figs. 1-3).

Xiphocentronid type. The Xiphocentronidae have antennae like the Glossosomatidae, except that there is just one large basiconic sensillum medially.

Rhyacophilid type (type IV of Denis, 1984a). The Rhyacophilidae and Hydrobiosidae have antennae of the Glossosomatid type, except that there is just one trichoid sensillum; it is large and located between the two basiconic sensilla (Fig. 6h; Denis, 1984a, pl. I, fig. 8; pl. III, fig. 5).
Limnephilid type (type $V$ of Denis, 1984a). The Integripalpia and Hydroptilinae (Hydroptilidae), like Palaeagapetus, have antennae of one segment. The shaft is cylindrical and the sides sclerotized; the apex has one large basiconic sensillum (Fig. 6b), or this sensillum is not evident (Figs. 6c-d). One long trichoid sensillum arises either peripherally at the apex or subapically, or this sensillum is absent (Figs. 6b-d; Denis, 1983, pl. 3, figs. c-i; 1984a, pl. I, fig. 9).

The antennae also have several very small conical basiconic sensilla (organes coniques of Denis, 1984a), and some campaniform sensilla (sensorial pits of Niclsen, 1948). Denis (1984a) reported that Trichoptera generally have two very small conical basiconic sensilla, but these are missing in later instars of some Limnephilidae, and in all instars of certain others (Denis, 1984b). We have observed three conical sensilla in SEM preparations of last-instar larvae of Glossosoma nigrior (Figs. 5a-b). Nielsen (1948) reported that in Hydroptilidae the number of campaniform sensilla varied from zero (Hydroptila) to four (Ithytrichia). Usually there are at least two, which are located side by side at the outer edge of the antennal foramen or on the basal clevation surrounding the foramen (Figs. 4-6).

The antennae of most larval Lepidoptera consist of three segments; segments I and II are fully developed, III is reduced; segment I may have up to four campaniform sensilla; II usually has a campaniform sensillum on the side of the segment, and the apex usually bears two long trichoid sensilla of unequal size, and three or four basiconic sensilla, of which two are large, one is small and sometimes resembles a trichoid sensillum, and the fourth (if present) is minute; the apex of III usually has a large styloconic sensillum, and one large and two small basiconic sensilla (Dethier, 1941). The antennae of Micropterigidae are made up of three elongate segments; the apical segment bears a long stylelike sensillum (Davis, 1987a, figs. 26.28-26.29), and there appear to be campaniform sensilla on each segment, including a pair laterally at the base of segment I. Larvae of Agathiphagidae have antennae of one segment, with various types of sensilla at the apex (Kristensen, 1984b, fig. 5). Antennae of Mecoptera consist of three segments, with numerous campaniform sensilla on segments I and II, and with several small trichoid sensilla at the apex of segment III (Dethier, 1941).

\section{Hypothesis of Evolution of Caddisfly Antennae}

Antennae of three segments are part of the lepidopteran groundplan (Kristensen, 1984b); given the condition in Mecoptera, and in Diptera, which generally have one to three segments (W. Hennig, cited in Teskey, 1981), three antennal segments is undoubtedly the ancestral condition for Amphiesmenoptera. Accordingly, the number of anten- 

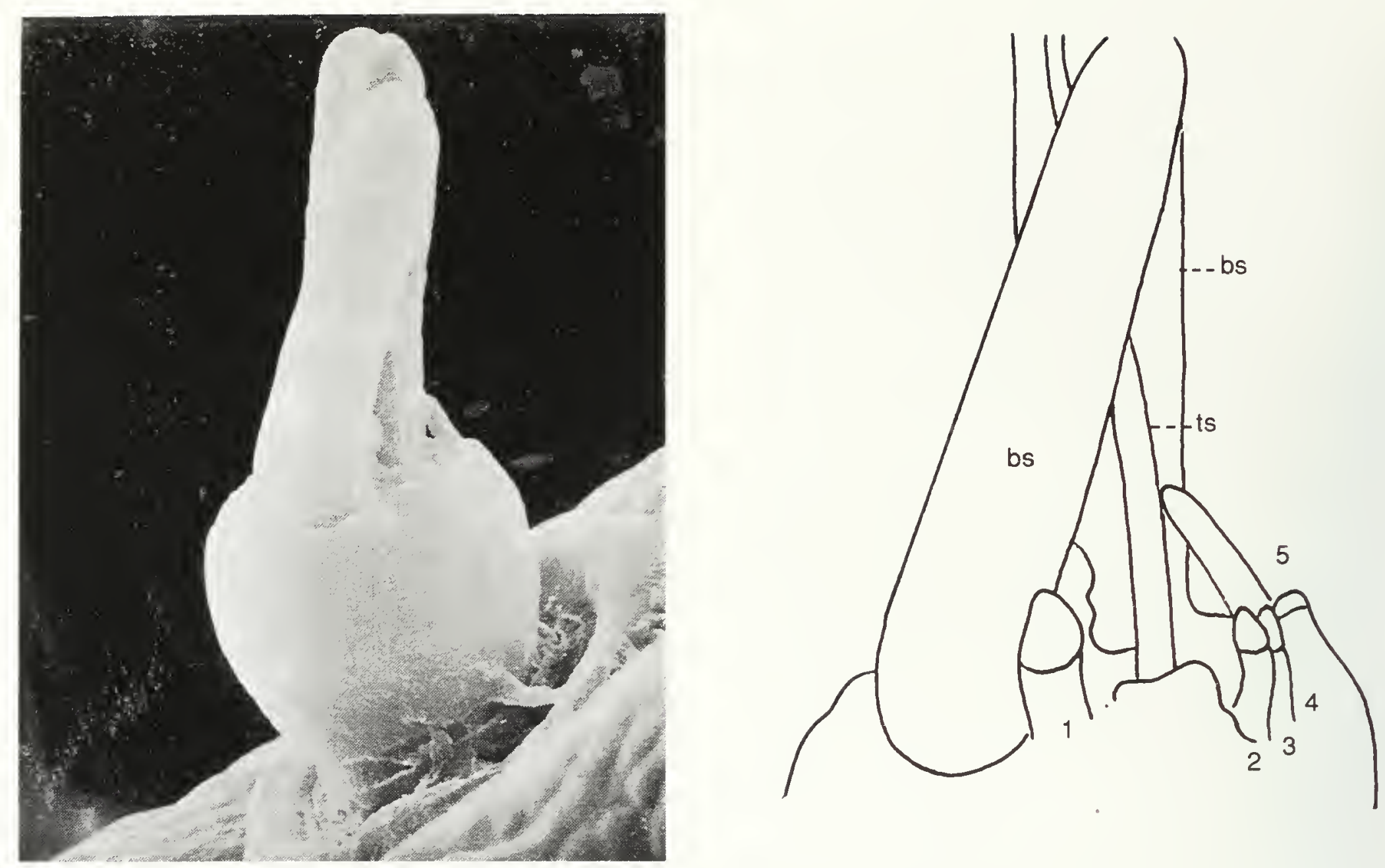

$4 a$
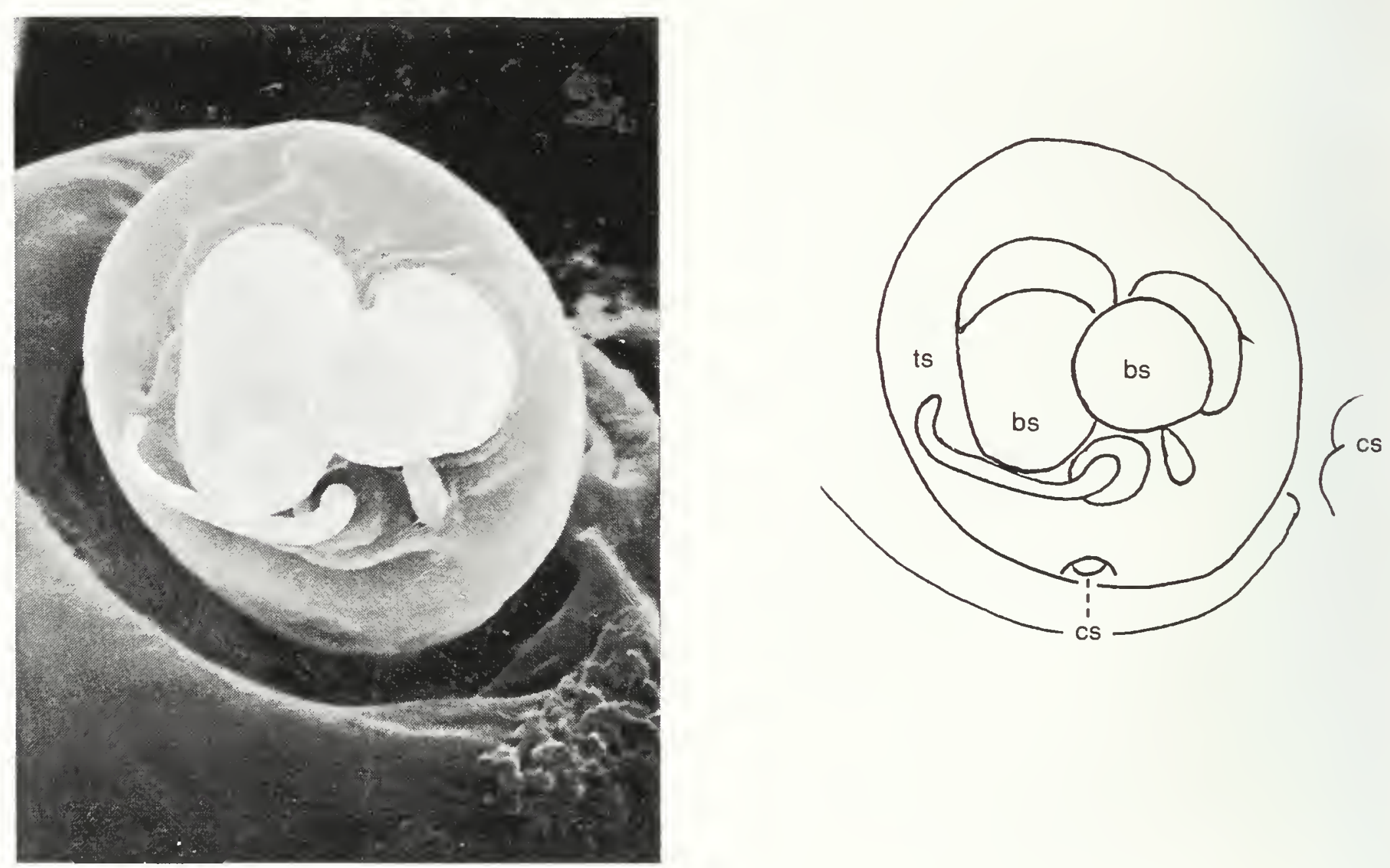

$4 b$

Fig. 4. Palaeagapetus nearcticus, left antenna of larva, scanning electron micrographs: (a) lateral aspect, (b) posterodorsal aspect. Abbreviations: bs, large basiconic sensillum; $c s$, campaniform sensillum; $t s$, trichoid sensillum; $I-5$, various other sensilla. 

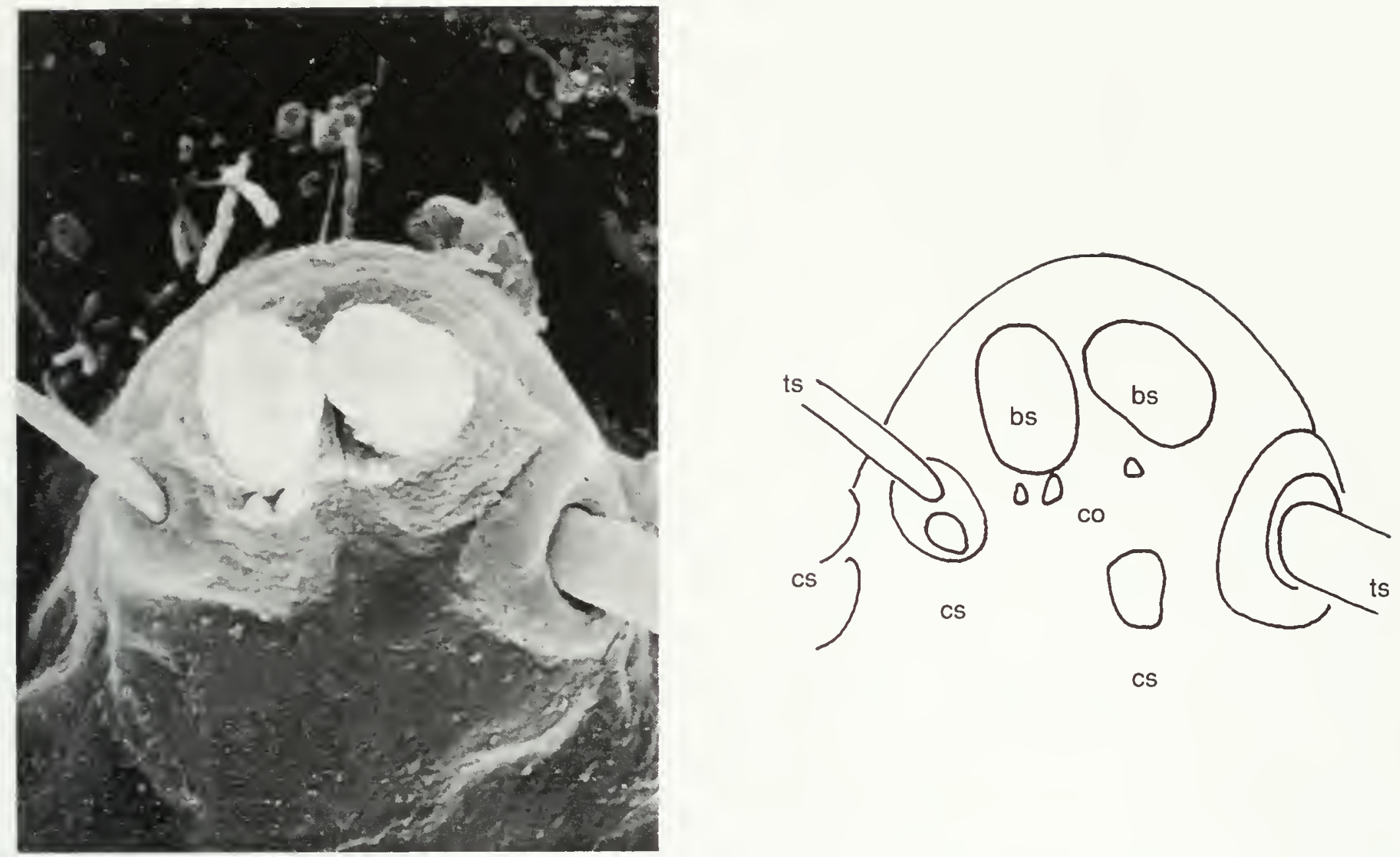

CS

$5 a$
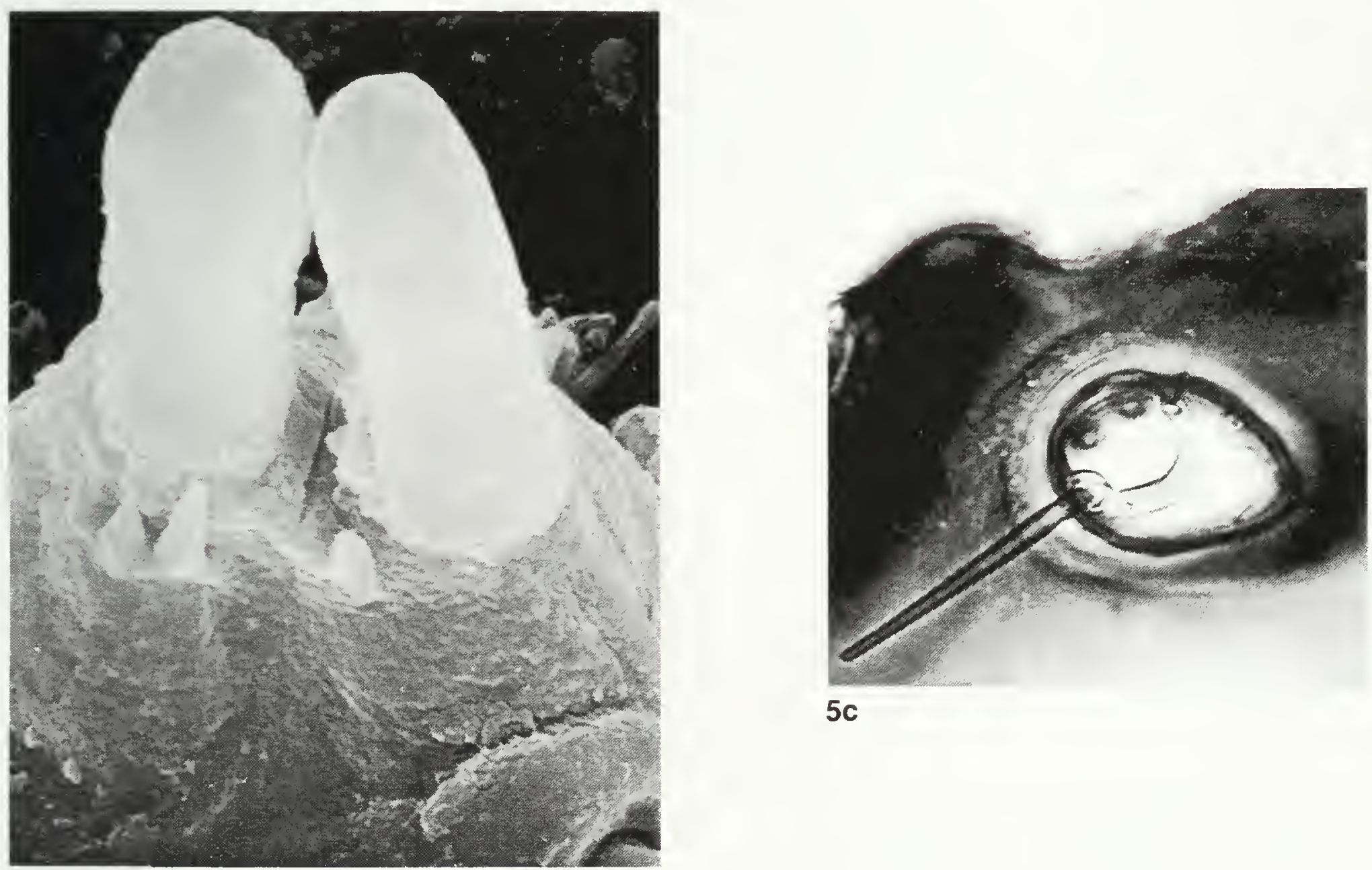

$5 c$

$5 b$

FIG. 5. Glossosoma nigrior, larval antenna, posterolateral aspect: $(a-b)$ right antenna, scanning electron micrographs, $(c)$ left antenna, photomicrograph. Abbreviations: $b s$, large basiconic sensillum; $c o$, coniform sensilla; $c s$, campaniform sensillum; $t s$, trichoid sensillum. 


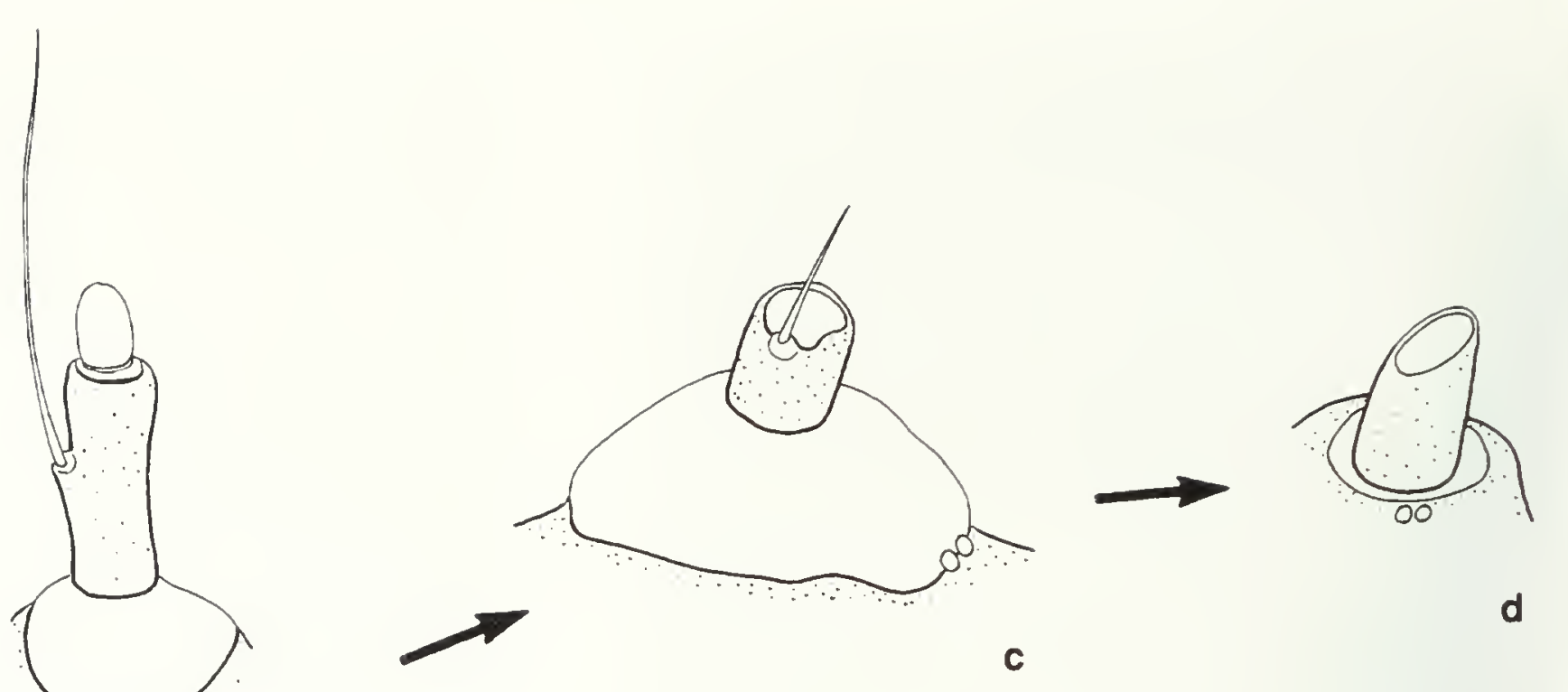

b

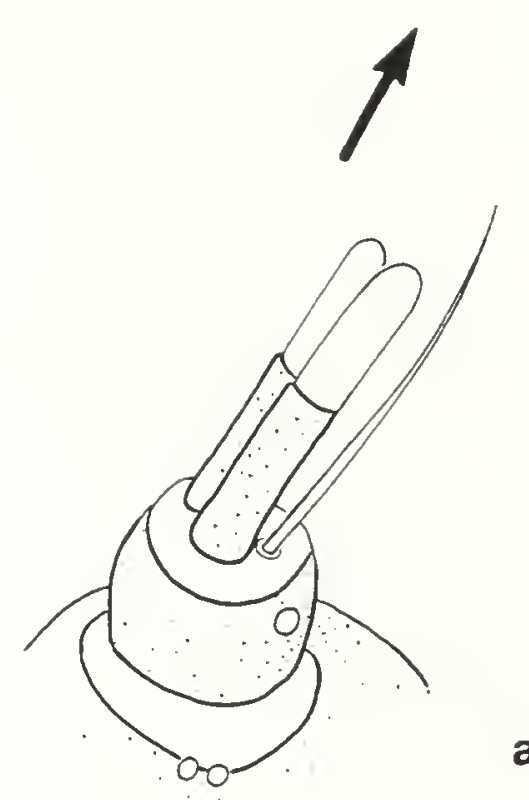

a
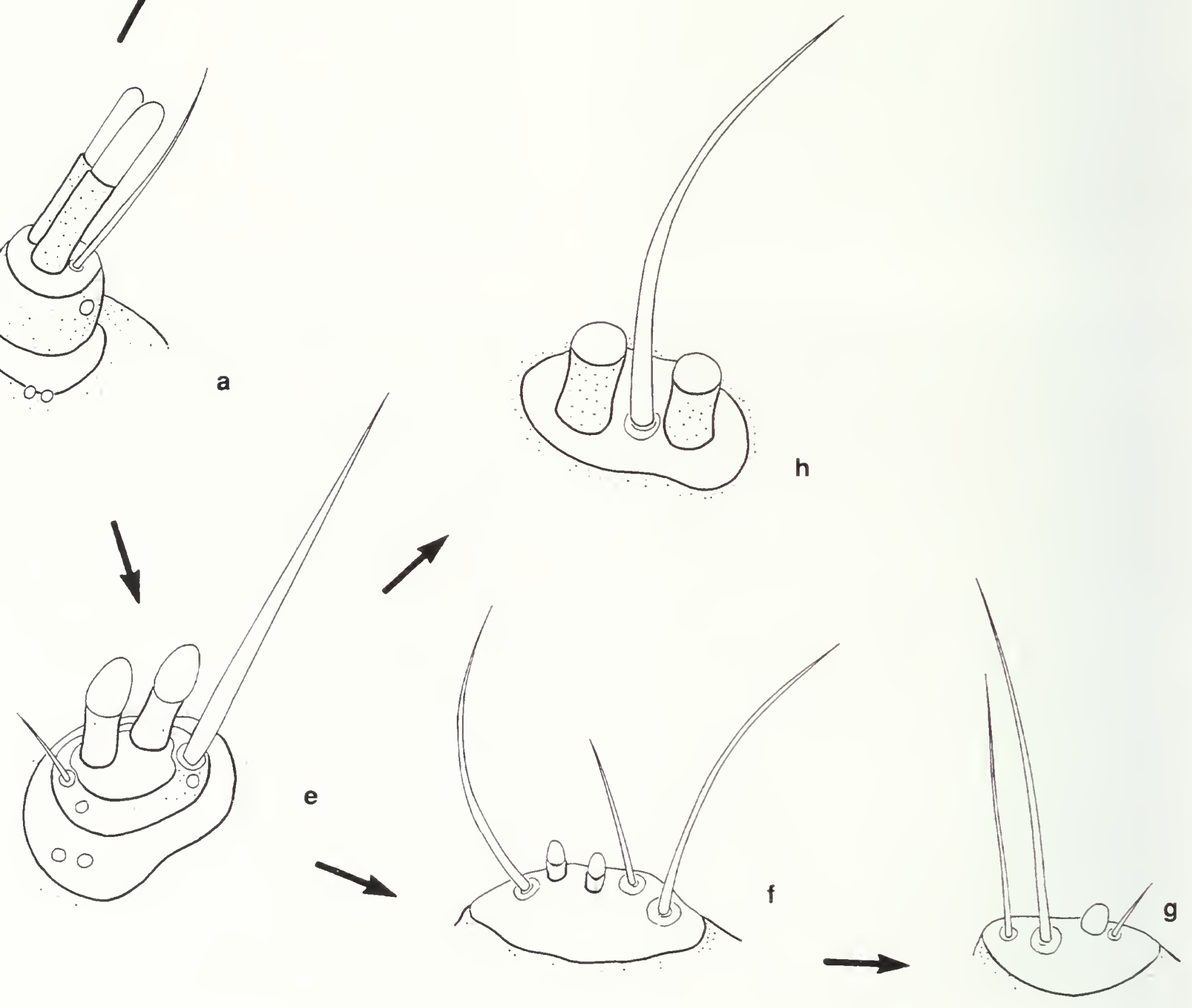

6

FIG. 6. Character transformation series for antennal structure in larvae of Trichoptera: (a) Palaeagapetus nearcticus, (b) Hydroptila sp.. (c) Phryganea cinerea, (d) Limnephilus indivisus, (e) Glossosoma nigrior, $(f)$ Stenopsyche griseipennis, $(g)$ Nyctiophylax sp., $(h)$ Rhyacophila fuscula: $(a, f)$ left antenna, $(b-e, g-h)$ right antenna; $(a-e)$ posterodorsal aspect, $(f-h)$ posterior aspect. 
nal segments in larval Trichoptera has been reduced to onc. Two lines of evidence indicate that the presence of one well-developed antennal segment is plesiomorphic for caddisflics (Denis, 1984a): in all other panorpoids there is at least one fully developed antennal segment; and in the embryo of Stenopsyche griseipennis (Stenopsychidac), the antennac undergo considerable reduction in size in the third to last developmental stage (Miyakawa, 1973). The antennae also become reduced in Neophylax concinnus (Uenoidae), only to increase in size again when the embryo emerges from the chorion (Patten, 1884).

As for which segments have been lost in Trichoptera, there is a general correspondence in number and location of sensilla on segment Il of the typical lepidopteran antenna with that of caddisflies, especially Palaeagapetus (Hydroptilidae) and Glossosomatidae. The two large basiconic sensilla and the trichoid sensillum at the apex of the antennal segment in Palaeagapetus appear to correspond to the two large basiconic sensilla and one of the trichoid sensilla on segment II in most Lepidoptera. We have observed five other much smaller sensilla in Palaeagapetus (Fig. 4), three of which could correspond to the other trichoid sensillum and the two smallest basiconic sensilla present in the typical Lepidopteran. The campaniform sensillum on the side of the antennal segment in Palaeagaeptus could be homologous to that present on the side of segment II in most Lepidoptera. The pair of campaniform sensilla at the edge of the antennal foramen are probably homologous to the pair that we observed at the base of segment I in Epimartyria (Micropterigidae). The antennae of Agapetus fuscipes (Denis, 1984a, pl. III, figs. $4,6)$ comprise two long trichoid sensilla, two large and two very small basiconic sensilla, and a pair of campaniform sensilla. In Glossosoma nigrior there is a third very small basiconic sensillum and four campaniform sensilla.

Antennal segments II and III of micropterigid moths are long, slender, and uniformly tapered, and the typical complement of sensilla at the apex of these segments is missing. It is unlikely that these traits are primitive for Lepidoptera, because then segment III would have been reduced and the sensilla on segments II and III would have developed independently in Lepidoptera and Trichoptera. Kristensen (1984b) indicated that the long antennae of Micropterigidae could be an autapomorphy "correlated with the unusual retractibility of the head in these larvae."

We conclude that antennal segments I and III have been lost in all Trichoptera, while II has been strongly reduced in the Glossosomatidae, Rhyacophilidae, and Annulipalpia. The original complement of sensilla in Trichoptera consisted of two large and at least two very small basiconic sensilla, two trichoid sensilla, and as many as four campaniform sensilla. The antennae of Glossosomatidae are usually entirely membranous, but in Glossosoma nigrior a lightly sclerotized ring is located within the membrane (Fig. 5c). The two trichoid sensilla and two of the campaniform sensilla arise on the ring, which is presumably the remnant of segment II. Besides loss of antennal segment Ii, other changes that have taken place are increases or decreases in the number and size of trichoid sensilla, and reductions in the number and changes in size of the large basiconic sensilla. The plesiomorphic number and positions of the campaniform sensilla and very small basiconic sensilla remain unclear, and these traits are not included in our phylogenetic analysis, nor is the size of the sensilla.

Nielsen $(1942,1948)$ considered the type of antenna in the Rhyacophilidae and Glossosomatidae to be primitive for Trichoptera. According to Nielsen, in Hydroptilidae one of the two large sensory rods (basiconic sensilla) present in Rhyacophilidae and Glossosomatidae migrated to the tip of the other rod, and a seta (trichoid sensillum), and sometimes a sensory pore (campaniform sensillum) also migrated onto the second sensory rod (this seta arises on the side of the antennal segment in many hydroptilids). There are several arguments against Nielsen's hypothesis. The strongest is that in Palaeagapetus there are two large basiconic sensilla at the apex of the antennal segment. If Nielsen's interpretation were correct, it would be necessary to infer that in Palaeagapetus one sensory rod migrated to the tip of the other rod and then divided in two. Sccondly, nothing resembling the Rhyacophilid or Glossosomatid type of antenna is found in the other panorpoid orders. Finally, Denis (1984b) reported that in the hydroptilid Stactobia caspersi the trichoid sensillum is at the apex of the segment in the first instar, "while the basal article becomes elongated above the insertion of [this sensillum]" in the last instar. Thus, contrary to Nielsen, location of the trichoid sensillum on the side of the antennal segment is apomorphic with respect to an apical position for this sensillum. Nielsen $(1942,1948)$ further proposed that in most Limnephilidae one of the two sensory rods has been lost. In support of this contention Nielsen illustrated (1942, fig. 121C) a structure next to the antenna of Stenophylax nigricornis, which he interpreted as the distal part of one of the two sensory rods present in Agapetus. We were unable to observe such a structure in $S$. nigricornis. Ross (1967) also interpreted the antenna of larval Trichoptera to be represented by either one or two papillae (= sensory rods of Nielsen, 1942). Krafka (1923) proposed that presence of a single antennal segment was primitive for Trichoptera, but gave no details.

Denis (1984a) considered the presence of three trichoid sensilla and two large basiconic sensilla to be primitive for Trichoptera, and concluded that the Hydropsychid type most closely corresponds to the ancestral condition in Trichoptera, and the Limnephilid type was derived from an "ancestral form" of the Rhyacophilid type. However, his conclusion (Denis, 1984a) that the Hydropsychid type 
is closest to the ancestral condition in Trichoptera contradicts his suggestion that a well-developed antennal segment is plesiomorphic for the order (see above). Our conclusion that originally there were two rather than three trichoid sensilla is based on outgroup comparison. Although some Lepidoptera have more than two trichoid sensilla on segment II, the additional ones are located proximally on the side of the segment rather than apically (Dethier, 1941). We do agree with Denis (1984b) that a well-developed antennal segment and presence of two large basiconic sensilla are primitive for Trichoptera.

In our interpretation, no extant Trichopteran exhibits all the groundplan characters; Palaeagapetus and Glossosomatidae come closest. We propose that the Ptilocolepine and Glossosomatid types were derived independently from the ancestral type (Fig. 6). The Limnephilid type was derived from the Ptilocolepine type. The Rhyacophilid and Hydropsychid types were derived independently from the Glossosomatid type, and the Psychomyiid type evolved from the Hydropsychid type. Based upon our hypothesis, it is most parsimonious to infer that the Xiphocentronid type was derived either from the Glossosomatid type through loss of one of the large basiconic sensilla, or from the Psychomyiid type through loss of a trichoid sensillum.

To summarize, our hypothesis is that the antennae in Trichoptera have been modified through losses of segments I and III from the three-segmented type held to be plesiomorphic for Lepidoptera. The single peglike antennal segment in Hydroptilidae and Integripalpia has been reduced further to a very small membranous area in Glossosomatidae, Rhyacophilidae, Hydrobiosidae, and Annulipalpia. Except in Glossosomatidae, there have also been increases or decreases in the number of trichoid sensilla and changes in their position, and loss of one of the large basiconic sensilla.

Character transformation series reflecting our hypotheses for reduction of antennal segment II (Appendix, character 3), number of large basiconic sensilla (4), and number and location of large trichoid sensilla (5) are used in the phylogenetic analysis.

\section{Eyes}

Based upon a survey of a limited number of taxa, Paulus and Schmidt (1978) concluded that the larva of the ancestor of Amphiesmenoptera had seven contiguous stemmata on each side of the head, each stemma with three primary pigment cells (Mantelzellen). These authors then proposed that in Integripalpia the number of stemmata has been reduced to six through fusion of the two most anterodorsal stemmata. We found it difficult to determine in our unstained material the number of stemmata with any degree of confidence. However, we are certain that larval Glossosomatidae have just six stemmata. Nielsen (1942) reported six stemmata in most species of Trichoptera that he studied, but just two or three in Wormaldia (Philopotamidae). A broader survey of taxa must therefore be made before the number of stemmata can be employed as a character in phylogenetic studies on Trichoptera. Paulus and Schmidt (1978) also put forth, as an apomorphy for Annulipalpia, reduction in the number of primary pigment cells. Examination of this ultrastructural character is beyond the scope of our study.

\section{Mouthparts}

Mandibles. The structure of the larval mandibles in Trichoptera reflects the diverse feeding habits in this order. In general, the mandibles have either an entire, scraperlike edge, or a cutting edge with one or more teeth (Wiggins, 1977). Both mandibles sometimes bear a median penicillus, and the left a dorsal penicillus (Nielsen, 1948). In many Integripalpia (e.g., Brachycentrus occidentalis) the pars incisivus is broad and has four prominent teeth arranged either in a row or in a semicircle, and the medial surface of the pars incisivus is concave. The condition in $B$. occidentalis and many other Integripalpia is probably plesiomorphic for Trichoptera because in larvae of many Lepidoptera also the pars incisivus is broad and has four cusps. Kristensen (1984b) considered this to be the groundplan condition for Lepidoptera, hence it is probably plesiomorphic for Amphiesmenoptera. Presence of a penicillus could also be plesiomorphic for Amphiesmenoptera, but various Lepidoptera and Trichoptera do not have this trait (Kristensen, 1984b).

According to Nielsen (1942) reduction of the upper edge of the median concavity of the pars incisivus has occurred in various taxa with cutting-type mandibles; in others the lower edge has been reduced, in Rhyacophilidae to the extent that a knife edge has been formed. The teeth tend to assume a subapical position, so that the mandible is tapered to a point. In species with a scraping-type mandible the lower edge is reduced, the upper edge becomes more pronounced, and the teeth tend to be lost. A difficulty with using this information for phylogenetic purposes is that mandibular structure can be very different in the early instars (e.g., in Agraylea multipunctata, Nielsen, 1948, fig. 10). Moreover, species in the same genus can have different kinds of mandibles in the final instar (cf. Dicosmoecus atripes and D. gilvipes, Wiggins and Richardson, 1982). For these reasons, we do not consider mandibular type further.

Prelabium. In larvae of most Trichoptera the prelabio-hypopharyngeal lobe is relatively short, broadly rounded, and largely membranous, except for the prementum (mentum of Nielsen, 1942, and other authors; prelabial sclerite of Fotius-Jaboulet, 1961) and a few small rodlike sclerites (Wiggins, 1977, fig. VIB; Fotius-Jaboulet, 1961, figs. 6, 9). The labial palps are prominent and have 
one segment. This description also applies to primitive Lepidoptera (Kristensen, 1984b, fig. 11), except that most Lepidoptera have two-segmented labial palps (Kristensen, 1984b).

The prelabio-hypopharyngeal lobe of larvae of most Polycentropodidae, Dipseudopsidae, Psychomyiidae, Ecnomidae, and Xiphocentronidae (Annulipalpia) is long and tapered; most or all of the venter and at least the basal portion of the dorsal surface of the lobe are heavily sclerotized; and the labial palps are closely appressed to the sides of the lobe, or are absent (Wiggins, 1977, fig. 16.2C). The genus Polycentropus (Polycentropodidae) differs only in that the prelabio-hypopharyngeal lobe is shorter and more rounded (Nielsen, 1942, fig. 55). The labial palps of Ecnomus (Ecnomidae) are unusually long and two-segmented. Shape and degree of sclerotization of the prelabio-hypopharyngeal lobe, and prominence of the labial palps, are included as characters in this study; the condition of each of these traits in most Trichoptera and in Lepidoptera is considered plesiomorphic (Appendix, characters 6-8).

Silk press. The silk press of the larva of Rhyacophila septentrionis (Rhyacophilidae) consists of a long, narrow sclerotized tube, at the posterior end of which is a pair of inconspicuous dorsolateral lobes (Fotius-Jaboulet, 1963, fig. 2). The associated musculature comprises one dorsal dilator that inserts anteriorly on the roof of the press, another that inserts on the terminal apodeme, and a ventral dilator (Fotius-Jaboulet, 1963). The silk press of larvae of Hydroptilidae is short and broad, and both the posterior dorsolateral lobes and the terminal apodeme are prominent (Figs. 7-8). The silk press of larvae of at least some other Trichoptera (e.g., Hydrobiosidae, Glossosomatidae, Hydropsychidae, Limnephilidae) differs with respect to Rhyacophilidae and Hydroptilidae, and to one another. The silk press of the larva of Agathiphaga (Lepidoptera: Agathiphagidae) is evidently a long, simple tube with one dorsal and one ventral dilator muscle (Kristensen, 1984b, fig. 12). Although the condition of the silk press in Rhyacophilidae is probably plesiomorphic for Trichoptera, we suggest that more detailed observations on a broader range of families of Trichoptera and Lepidoptera are required before further consideration of our findings.

Hypopharyngeal rods. Nielsen (1948) indicated that "an important point of similarity between the Rhyacophilidae and Hydroptilidae" is the presence of long hypopharyngeal rods on the dorsum of the hypopharynx (Nielsen, 1942, fig. 14; 1948, fig. 11B). The Hydrobiosidae also have long hypopharyngeal rods. In Integripalpia the hypopharyngeal rods are represented by only a small anterior and posterior pair of sclerites (hypopharyngeal sclerites 2 and 3 of Fotius-Jaboulet, 1961; dorsoanal and anal sclerites of Nielsen, 1948). In
Glossosomatidae and Annulipalpia hypopharyngeal sclerite 3 is not evident, while sclerite 2 may be represented in some taxa by a transverse band (e.g., Nielsen, 1942, fig. 40). Kristensen (1984b) considered the hypopharyngeal rods in Trichoptera to be homologous to similar structures in Agathiphagidae; if so, then the condition in Rhyacophilidae, Hydrobiosidae, and Hydroptilidae is probably plesiomorphic. To understand and use this character system, we believe it is neccessary to study the associated musculature, and therefore do not consider this character system further.

Maxillae. Mesad of the maxillary palps of larval Trichoptera there is a lobe which, according to Matsuda (1965), is the lacinia, galea, or galeolacinia. This "maxillary lobe" bears various sensilla, and its size and shape vary considerably. The lobe is always sclerotized laterally, but the extent to which this sclerite extends mesally around the lobe varies, and determines in part the distribution of the sensilla, which are confined to the membranous portion of the lobe. At one extreme, the lobe is barely discernible; it is almost entirely membranous, and sensilla cover most of the surface, as in Glossosomatidae, some Hydroptilinae, and Goeridae (Nielsen, 1942, figs. 26, $164 ; 1948$, fig. 46). In some other taxa the lobe is prominent, but largely membranous, as in Philopotamidae (Nielsen, 1942, fig. 41). At the other extreme, the maxillary lobe is long, cylindrical, and largely sclerotized, and the sensilla are confined to the tip, as in Rhyacophilidae, Hydrobiosidae, Polycentropodidae, Phryganeidae, and Molannidae (Wiggins, 1977, fig. 17.3B).

The variation is such that we were unable to construct a character transformation series for the maxillary lobe or to score all the taxa. Among Lepidoptera, the size, form, and degree of sclerotization of this lobe (lobarium of Kristensen, 1984b) also vary considerably, although we did not observe in Lepidoptera the extreme condition shown by the Rhyacophilidae. In Mecoptera, the maxillary lobe is prominent, as in the Philopotamidae. In view of the difficulties we do not consider the maxillary lobe further.

\section{Postlabium}

The postlabium (submentum or postmentum of various authors, e.g., Wiggins, 1977, fig. VIB) of most Trichoptera larvae bears a pair of large setae which arise from one large sclerite or a pair of smaller ones. C. R. Parker (pers. comm.) has observed that Kokiriidae and Molannidae have a large number of setae on the postlabium and interpreted this as a derived condition. We concur (Appendix, character 9) because Lepidoptera and Mecoptera have either two setae or none at all on the postlabium.

\section{Frontoclypeus}

In larvae of most Trichoptera frontoclypeal seta 1 (Wiggins, 1977, fig. IIIC) is curved mesad and is colour- 


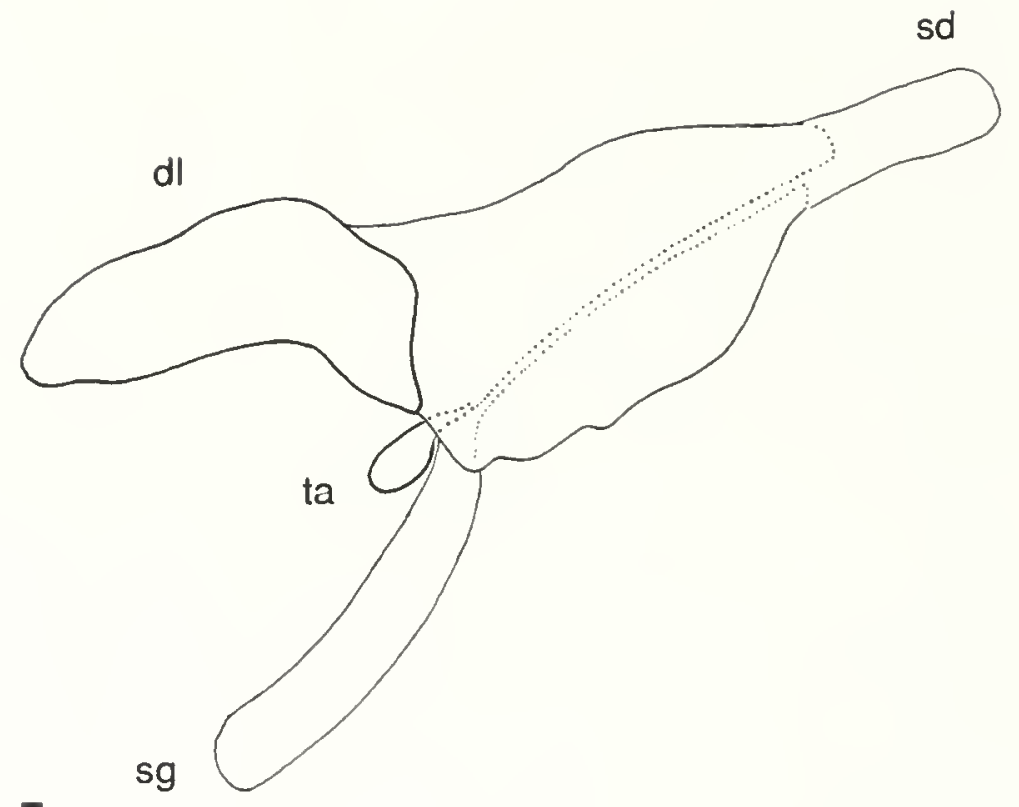

$7 a$

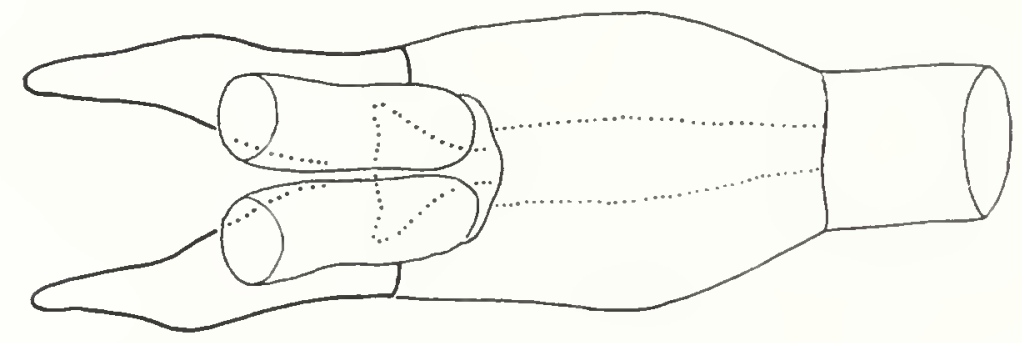

$7 b$

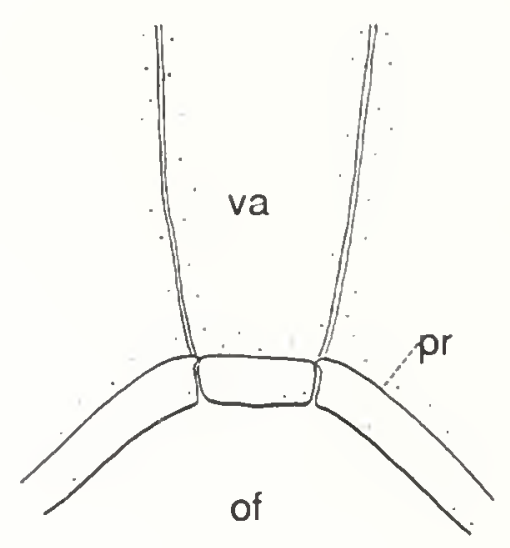

9

FIGs. 7-10. 7-8. Silk press of larva: (a) right lateral aspect, (b) ventral aspect. 7. Palaeagapetus nearcticus. 8. Leucotrichia sp. 9-10. Head capsule of larva, base of ventral apotome. 9. Arctopsyche grandis. 10. Phryganea cinerea. Abbreviations: $d l$, dorsolateral lobe; of, occipital foramen; pr, postocciptal ridge; $s d$, portion of salivary duct; $s g$, portion of silk gland duct; $t a$, terminal apodeme; $v a$, ventral apotome.

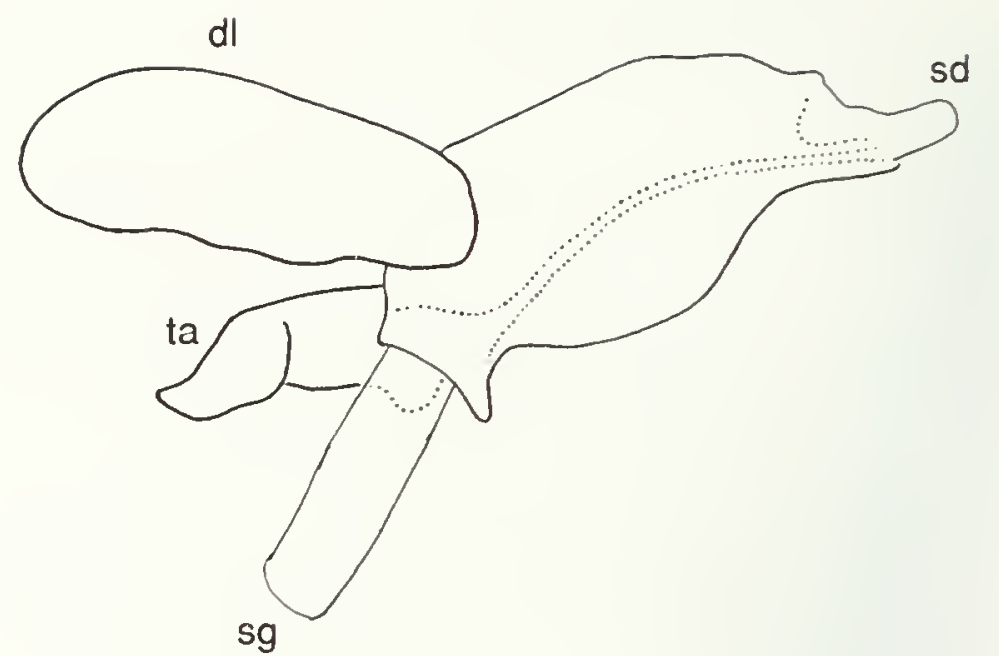

$8 a$

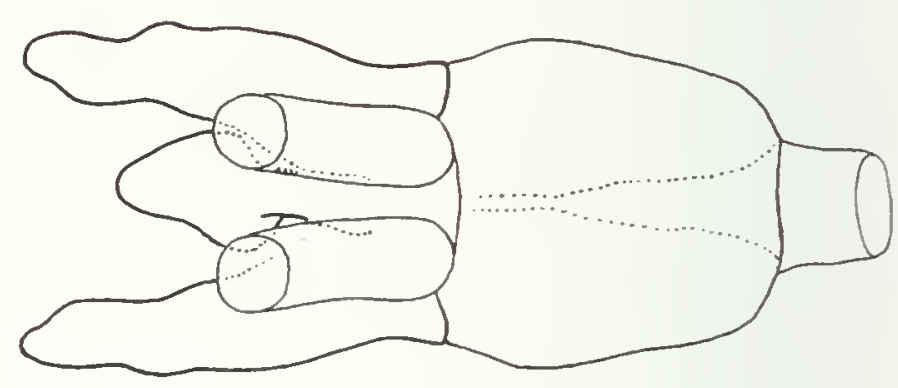

$8 b$

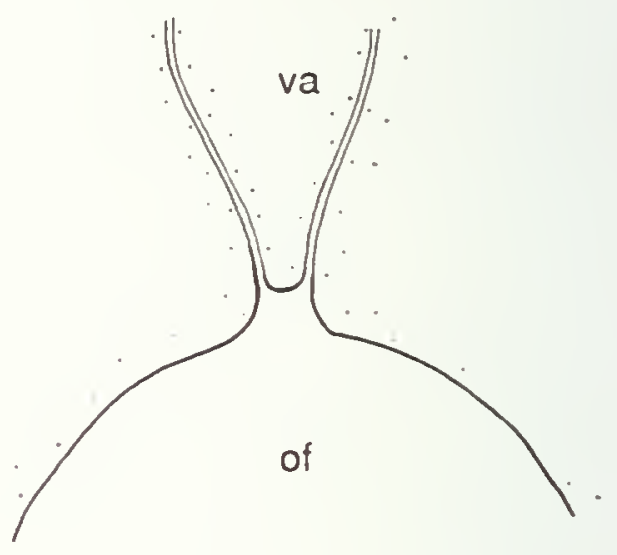

10 
less, while other setae on the frontoclypeus are relatively straight and dark in colour. C. R. Parker (pers. comm.) has indicated that in Kokiriidae and Molannidae seta 1 is also straight and dark in colour. Parker (pers. comm.) considered the latter condition of seta 1 to be derived. We agree (Appendix, character 10) but note that in Lepidoptera that we examined seta 1 is straight and colourless, as are the other setae on the frontoclypeus.

\section{Tentorium}

The tentorium is difficult to discern in larval Trichoptera, and this has led to conflicting statements in the literature about this structure (cf. Badcock, 1963; Hinton, 1963). We did not study it, except for location of the anterior tentorial pits. In most Trichoptera these pits contact the frontal arms of the dorsal ecdysial line. In Hydropsychidac (there may be exceptions, Hinton, 1958:185) the pits arise on the dorsal apotome some distance mesad of the frontal arms (Badcock, 1963). Mecoptera have the former condition; those Lepidoptera in which dorsal ecdysial lines are recognizable have the latter condition. Provisionally, we consider the condition in which the pits are in contact with the frontal arms to be plesiomorphic in Trichoptera (Appendix, character 11).

\section{Ventral Ecdysial Lines}

Larvae of Trichoptera have either one or two ventral ecdysial lines (Hinton, 1963). If there is just one, it is forked either just anteriorly, or both anteriorly and posteriorly so that there is a posterior as well as an anterior ventral apotome. If there are two ecdysial lines, these converge posteriorly or are subparallel, so that the genae are completely separated by a triangular or lozenge-shaped apotome. Larvae of various Integripalpia, Agapetus and Protoptila (Glossosomatidae), and all Annulipalpia except Hydropsychidae have only the anterior ventral apotome. Larvae of Rhyacophilidae, Hydrobiosidae, Glossosoma (Glossosomatidae), Hydroptilidae, and most Hydropsychidae also have a posterior ventral apotome. Except for some Hydropsychidae, e.g., Diplectrona modesta (Wiggins, 1977, fig. 6.4C), the posterior ventral apotome is quite small, and does not extend anteriorly beyond the postoccipital ridge. Larvae of many Integripalpia and some Hydropsychidae have two ventral ecdysial lines, e.g., Arctopsyche grandis (Hydropsychidae) and Phryganea cinerea (Phryganeidae); in the former the postoccipital ridge extends across the apotome (Fig. 9), while in the latter it does not (Fig. 10).

Krafka (1923) proposed that two subparallel ventral ecdysial lines are plesiomorphic for Trichoptera, and the two lines have fused medially or posteriorly to varying degrees to produce the other conditions. Nielsen (1942), citing Siltala (1907), and Badcock (1963) rejected this proposal because in some Trichoptera with two subparal- lel ecdysial lines in later instars, e.g., Odontocerum (Odontoceridae) and Molanna (Molannidae), the ecdysial lines in the first instar converge posteriorly and join at the occipital foramen. We concur with Nielsen (1942) that originally in Trichoptera there was a single ventral ecdysial line which was forked anteriorly.

The question remains whether the ventral ecdysial line was also forked posteriorly. Outgroup comparison was of no use in resolving this issue because few Lepidoptera have ventral ecdysial lines; the exceptions have a single median line or three parallel lines (Hinton, 1963). In Mecoptera, there is a single median line (Hinton, 1963; Kristensen, 1984b). In certain Trichoptera in which the ecdysial line is forked posteriorly as well as anteriorly, the posterior apotome is smaller in the early instars than in the later ones (e.g., Diplectrona felix, Badcock, 1963). This indicates that if a posterior ventral apotome was present in the ancestral Trichopteran, it did not extend anteriorly beyond the postoccipital ridge. Regardless, it appears that in Trichoptera the condition of two parallel ecdysial lines arose through fusion of the anterior and posterior ventral apotomes. Given the difference in extent of the postoccipital ridge in Hydropsychidae and Integripalpia, parallel ecdysial lines probably evolved independently in these two groups. On the basis of these considerations, we propose one transformation series for the ventral ecdysial line system, and tentatively consider the presence of a single ecdysial line that is forked only anteriorly to be the most plesiomorphic condition (Appendix, character 12).

\section{Tanning of the Head Capsule}

The appearance of the head capsule of most Trichoptera larvae suggests that it is uniformly tanned. In Sericostomatidae and some other Brevitentoria (Integripalpia) the venter of the posterior third of the head capsule is pale in colour, making it difficult to discern the ventral ecdysial lines in that region. This could represent a difference in degree of sclerotization, pigmentation, or both; it is undoubtedly a derived condition because in Lepidoptera and Mecoptera the head capsule is uniformly tanned. This trait is included as a character in our study (Appendix, character 13).

\section{THORAX}

\section{Pronotum}

The sides of the pronotum of larvae of most Trichoptera are not incised anteriorly. The posterior margin is invariably thickened; this thickening is usually marked externally by a ridge, which we term the posterior external ridge (Fig. 11). This ridge usually extends ventrally to the posterolateral angle and then anteriorly to the pleural condyle (Wiggins, 1977, fig. 6.2A). The pronotum is usually more or less uniformly tanned. Finally, the hind angles are gen- 
erally only slightly or not at all prominent.

Larvae of Glossosomatidae have the sides of the pronotum notched anteriorly to accommodate the propleuron (Nielsen, 1942, fig. 28b). Some Integripalpia have a slightly or strongly developed transverse internal flange laterally that more or less parallels the anterior margin of the pronotum. The flange is invariably present in taxa in which the anterolateral angle of the pronotum is prolonged into a spine (e.g., Psilotreta (Odontoceridae), Fig. 12).

The pronotum of larvae of various Integripalpia such as Phryganea (Phryganeidae) has a transverse sulcus that extends more or less parallel with the posterior margin from the midline anteroventrally to the pleural condyle a short distance anterad of the posterior external ridge (Fig. 11). This sulcus marks the position internally of the tergal ridge of Tindall (1964, fig. 4; Figs. 11-12). In some taxa such as Limnephilus (Limnephilidae) and Goera (Goeridae) the tergal ridge is present only laterally. In Goeridae the posterior external ridge extends to the anterolateral angles of the pronotum isolating the posterolateral portion of the pronotum (e.g., Nielsen, 1942, fig. 167c). Larvae of Beraeidae and Anomalopsychidac also have a posterior external ridge that extends to the anterolateral angles of the pronotum but originates dorsally about a third of the distance from the posterior margin of the pronotum (Nielsen, 1942, fig. 70) and presumably is not homologous with the posterior external ridge in Goeridae. In some taxa such as Ceraclea (Leptoceridae), the transverse sulcus is not evident because it is coincident with the posterior external ridge. In still other taxa such as Gumaga (Sericostomatidae), the posterior third of the pronotum is lightly tanned, and there is no indication of the posterior external ridge.

The hind angles of the pronotum of larvac of Ecnomidae, Psychomyiidae, Xiphocentronidae, Polycentropodidae, and Dipseudopsidae extend ventrally and come into contact on the sternum behind the procoxae (Nielsen, 1942, fig. 51). That the prolonged portion is continuous with the sides of the pronotum was verified by examination of exuviae of the last instar larva. In Philopotamidae and Stenopsychidae the sternal region of the prothorax is discernibly more sclerotized behind the procoxae. This area of sclerotization extends laterally to the hind angles of the pronotum but examination of exuviae of the last instar larva shows that the former is a separate sclerite. The Hydropsychidae have a large sclerite behind the procoxae, but this plate is separated from the pronotum by a narrow strip of membrane. The same is true for other Trichoptera with a sternal plate, c.g., Hydrobiosidae, Glossosoma (Glossosomatidae), Odontoceridae.

In larvae of Lepidoptera and Mecoptera the sides of the pronotum (dorsal shield) are entire anteriorly, the pronotum is only slightly thickened posteriorly and is more or less uniformly tanned, and the posterolateral angles are not prolonged. Thus, within Trichoptera, anterolateral notches, presence of an internal flange anteriorly, presence of the tergal ridge posteriorly and then its confinement to the sides of the pronotum, light tanning of the posterior third of the pronotum, and prolongation of the posterior angle of the pronotum are derived features. We include all of these traits in our data set (Appendix, characters 14-18). Ross (1967) considered the anterior location of the pronotal sulcus in Phryganea and various other Integripalpia (variously referred to in his paper as the preapical crease or posterior suture) to be the derived condition. However, there is intrafamilial variation for this trait (e.g., in Leptoceridae), and it is not evident which position of the sulcus is apomorphic; hence, we do not use the position of the pronotal sulcus as a character.

\section{Prosternal Horn and the Glands of Gilson}

Ross (1967) stated that in most taxa that he included in the Limnephilid branch (= Plenitentoria), including Kokiriidae, a membranous horn arises medially on the prosternum. This horn marks the position of the gland of Gilson, the opening of which is at the tip of the horn (Gilson, 1896; Henseval, 1896). Several genera of Brachycentridae and Uenoidae lack the prosternal horn (Vineyard and Wiggins, 1988), but according to R. N. Vineyard (unpublished observations) examination of sectioned and stained material shows that the gland of Gilson is still present. We have been able to verify this because the external opening and ectodermal portion of the duct leading from the gland to the surface are visible in larvae that have been cleared in $\mathrm{KOH}$ or lactic acid. However, neither the horn nor the duct is evident in cleared larvae of Kokiria mihoro (Kokiriidae).

Larvae of various Lepidoptera belonging to the Ditrysia have a midventral cervical gland located anterior to the prothoracic legs (Stehr, 1987:293); in at least some of these taxa the opening of the gland is at the tip of a fleshy prominence. There is no evidence for such a gland in primitive Lepidoptera or in Mecoptera. For this reason, we consider the gland to have independently evolved in Trichoptera and Lepidoptera. If so, then its presence in Trichoptera is probably the derived condition, as is the additional appearance of a prosternal horn (Appendix, character 19).

The situation is more complicated than this in Trichoptera because Gilson (1896) and Henseval (1896) found that Phryganea grandis has a counterpart to the prothoracic gland on both the mesothorax and metathorax; the opening of each gland is located at the anterior margin of the sternum. Gilson and Henseval also found that in $P$. grandis all three glands are bifurcate and consist of two bundles of tubules. In contrast, both authors reported that in Limnephilus flavicomis the gland of Gilson is present only on the prosternum and consists of a simple tube. 
Bicchicrai and Moretti (1986) indicated that all Phryganeidae have the condition in $P$. grandis, while Lepidostomatidae, other Limnephilidae, and Goeridae have the condition in L. flavicornis. We have observed in Pycnopsyche (Limnephilidae) what appear to be openings on all three thoracic segments. The openings on the mesothorax and metathorax are usually hidden by the folds of the intersegmental membrane and easily overlooked. Thus, the generalizations of Bicchicrai and Moretti (1986) concerning this gland in Limnephilidae require confirmation. Moreover, we have observed in some Brevitentoria, e.g., Gumaga (Sericostomatidae), Molanna (Molannidae), and Limnocentropus (Limnocentropodidae), apparent openings on the mesothorax and metathorax, in positions corresponding to the openings of the glands of Gilson in Phryganea. If Gilson's gland is present on the mesothorax and metathorax of at least some Brevitentoria, this would raise the possibility that presence of this gland on all three thoracic segments is primitive for Integripalpia, or for some part of that group. Histological studies will be required to pursue these considerations further.

\section{Mesonotum and Metanotum}

On the mesonotum of larvae of many Trichoptera there is a single, large, dark-coloured sclerite which, except in a few taxa, e.g., Zumatrichia (Hydroptilidac), Ecnomus (Ecnomidae), and Hydropsychidae, is usually interrupted medially by the dorsal ecdysial line. Otherwise there are some smaller, more or less widely separated, sclerites, or the notum is entirely membranous. Usually if the mesonotum has just a single large sclerite, the metanotum has only some smaller sclerites. Larvae of Ecnomidae, Hydropsychidac, some Hydroptilidae, and Anomalopsychidae are exceptional because there is a single large sclerite on the metanotum as well as on the mesonotum, which in some genera of Hydropsychidae is interrupted by a transverse ecdysial line.

The mesonotum and metanotum of larvae of most Lepidoptera and Mecoptera are membranous, or each bears several small, pale sclerites. In Psychidae at least, each segment has a single, large, pale notal sclerite (Davis, 1990, fig. 31). We infer that the membranous condition is plesiomorphic for Trichoptera (Appendix, characters 20, 22).

Larvae of Rhyacophilidae, Hydrobiosidae, Glossosomatidae, and Annulipalpia have on the mesonotum one seta in setal area (sa) 1, one in sa2, and two in sa3. Larvae of Hydroptilidae and Integripalpia have more than two setae in sa3, and usually there are more than two setae in sal, or sa2, or in both areas. The situation is the same on the metanotum, except that Conoesucidae, Leptoceridae, and Helicophidae that we examined have the condition in Rhyacophilidae.
Lepidopterists recognize four primary setae on the mesonotum and metanotum: setae D1, D2, SD1, and SD2 (Stehr, 1987). Williams and Wiggins (1981) homologized setae SD1 and SD2 in Lepidoptera with setae 5 and 6 in Trichoptera. Since setae 5 and 6 are in sa3, it follows that presence of two setae in sa3, and one each in sal and sa2 is plesiomorphic for Trichoptera (Appendix, characters 21, 23).

\section{Pleural Sclerites and Legs}

Larvac of Trichoptera have one or two well-developed pleural sclerites on each thoracic segment; these were designated by Tindall (1963) as the first and second pleural sclerites. Tindall (1963:447) suggested that the first prothoracic pleural selerite could be the preepisternum, but on the basis of musculature ruled out that it is the protrochantin. According to Tindall (1963), the second pleural sclerite is subdivided into an episternum and epimeron separated by a pleural ridge which articulates with the coxa.

The first and second prothoracic pleural selerites of larvae of many Trichoptera are separate (Figs. 13a, 14a). Certain Hydroptilidae (e.g., Palaeagapetus) and Hydropsychidae (e.g., Arctopsyche, Diplectrona, and Hydropsyche) have two separate sclerites on all three thoracic segments; usually the mesothorax and metathorax have only one pleural sclerite each. From the location of one large and two small setae which appear to be always present in Trichoptera (setae 10, 19, and 20 of Williams and Wiggins, 1981), it appears that the first pleural sclerite is continuous with the second pleural sclerite in Glossosomatidae and other taxa with just one apparent pleural sclerite. Nielsen (1948:28) noted this similarity in setal patterns, but expressed doubt that the oral sclerite of the mesepisternum and metepisternum is homodynamous with the protrochantin.

The shape of propleural sclerite I varies considerably in Trichoptera, but in most families the ventral or mesal portion is membranous. In Psychomyiidae it is hatchetshaped and entirely sclerotized (Wiggins, 1977, fig. 16.1).

The second prothoracic pleural sclerite of larvae of Hydroptilidae, Integripalpia, and Annulipalpia (except Hydropsychidae) articulates with the pronotum as well as the coxa. The point of articulation is a condyle located at the edge of the pronotum anterad of the hind angle. Larvae of Glossosomatidae have such a condyle, but the pleural sclerite does not articulate with the pronotum. This fact and the unusually small size of the second pleural sclerite in Glossosomatidae led Nielsen (1948) to conclude that lack of a notopleural articulation is a secondary condition in this family. Rhyacophilidae, Hydrobiosidae, Stenopsychidae, and Hydropsychidae are the only families of Trichoptera that do not have at least a trace of a notopleural articulation.

The legs of Trichoptera larvae usually have five seg- 

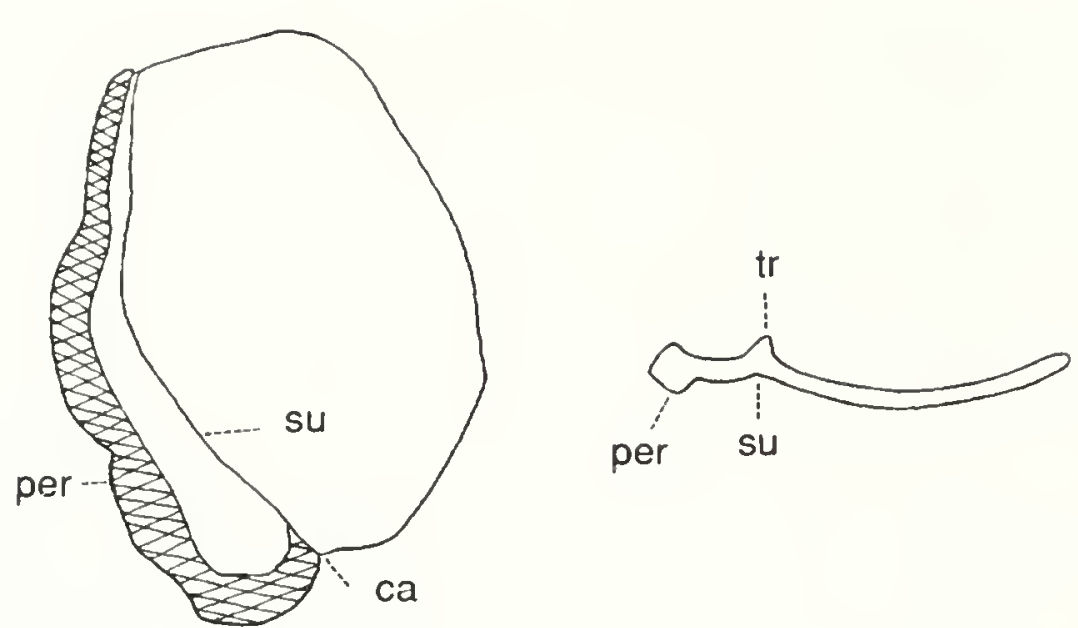

11

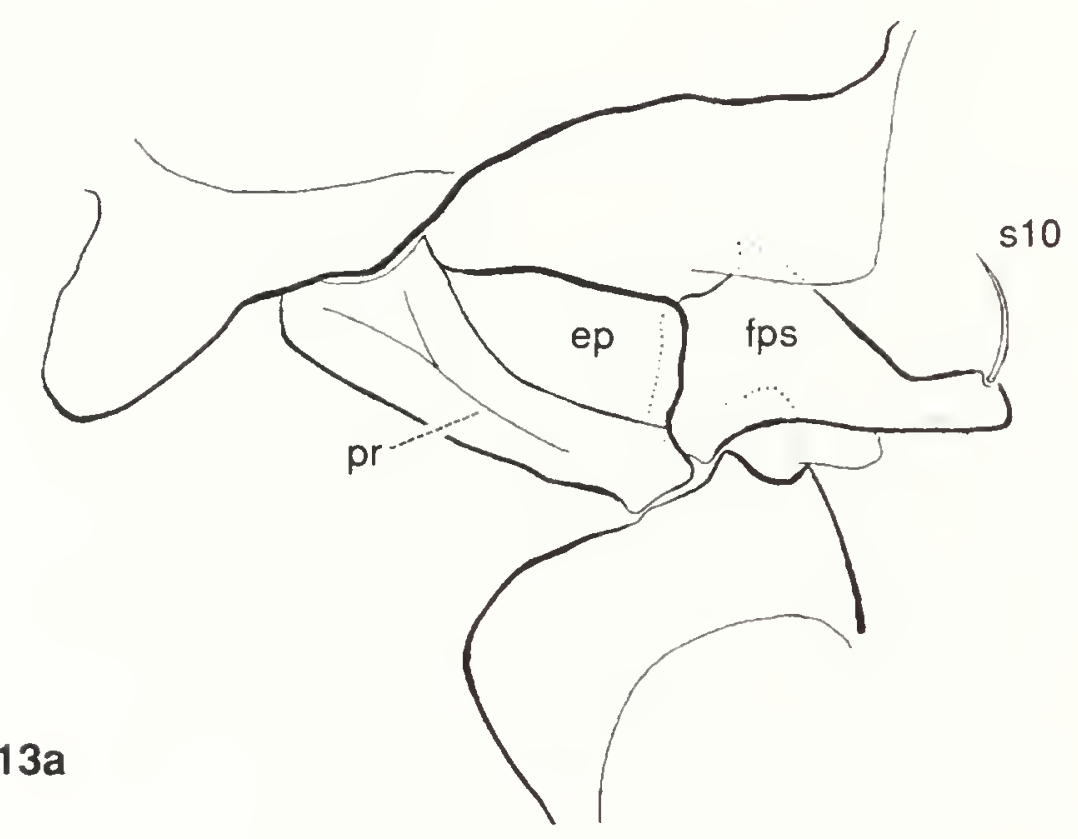

$14 a$

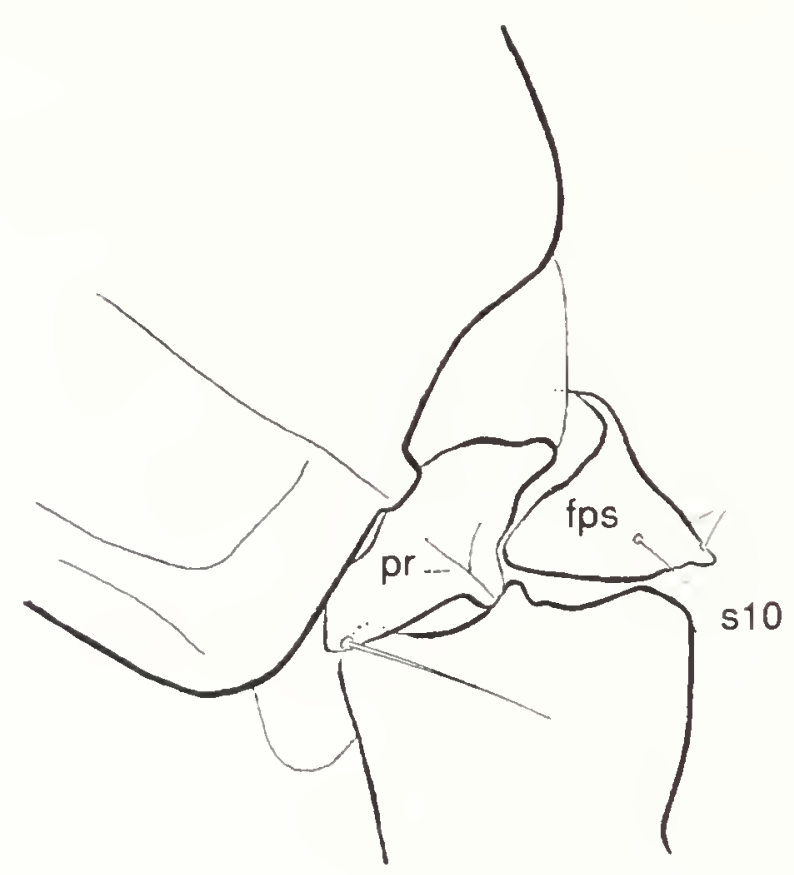

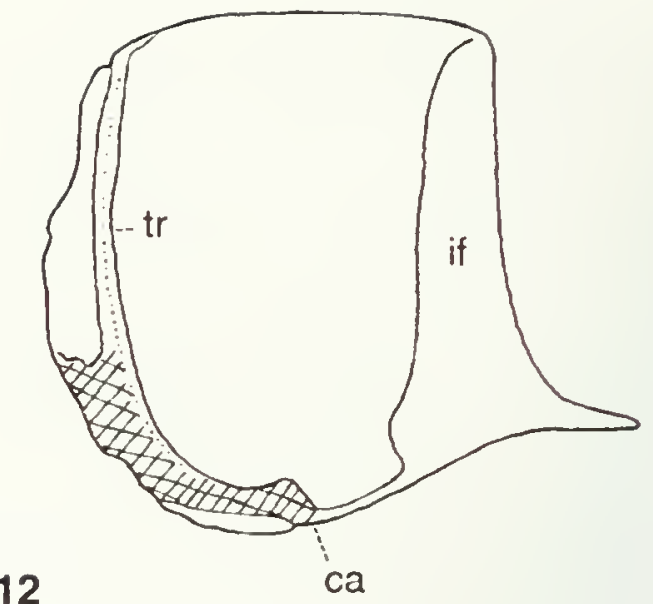

12

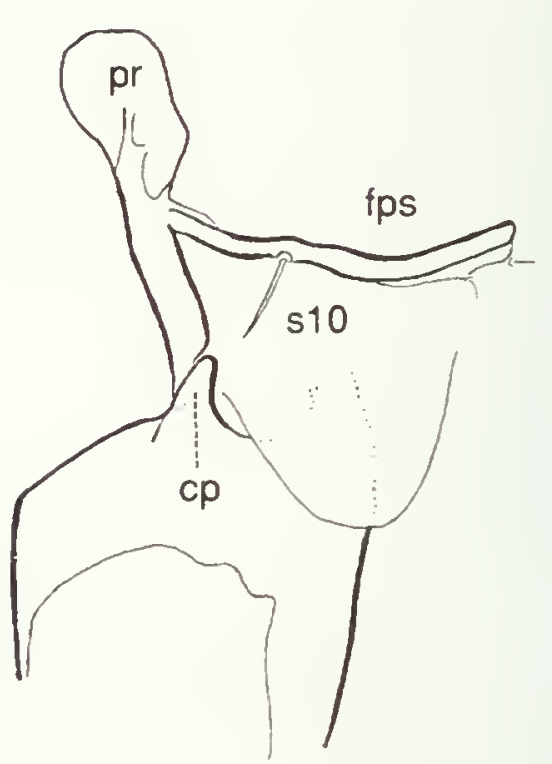

$13 b$

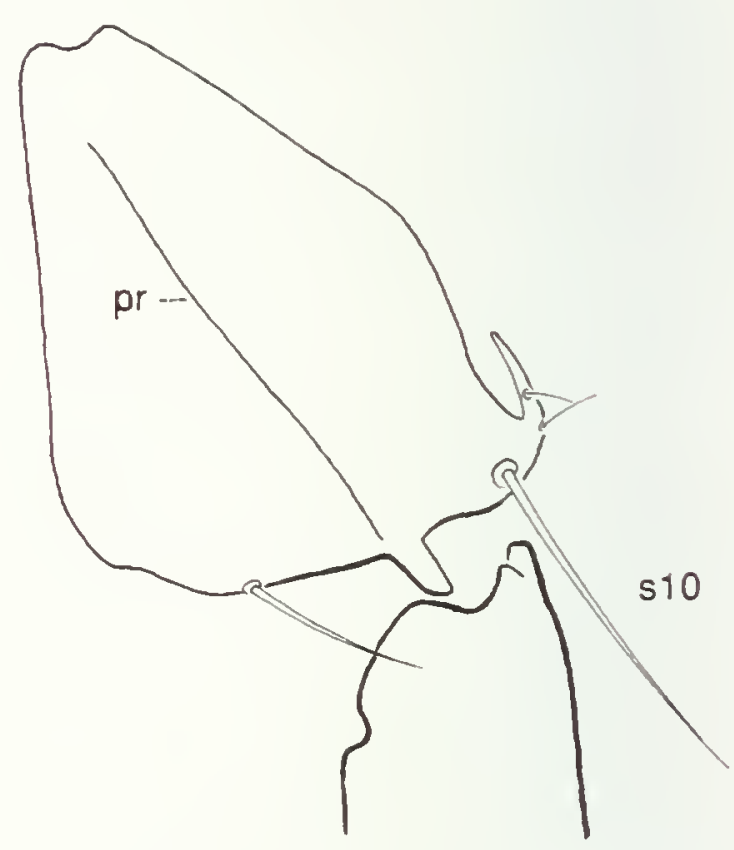

FIGs. 11-14. 11-12. Pronotum of larva. 11. Phryganea sp., external right lateral view and cross-section. 12. Psilotreta sp., internal left lateral view. $13-14$. Pleural region of larva, right lateral aspect: $(a)$ prothorax, $(b)$ mesothorax. 13. Rhyacophila sp. 14. Oligostomis sp. Abbreviations: ca, coxal articulation; $c p$, coxal process; $e p$, episternum; $f p s$, first pleural sclerite; if, internal flange; per, posterior external ridge; $p r$, pleural ridge; $s u$, sulcus; $s 10$, seta $10 ; t r$, tergal ridge. 
ments (six if the tarsal claw or pretarsus is considered a segment, N. P. Kristensen, pers. comm.), but the tibia and tarsus are fused in Xiphocentronidae. The coxac are prominent-about as long as the trochanter and femur logether, conical to subcylindrical in shape, and sclerotized on all sides. The trochanter is long, cylindrical, completely separate from the tibia, and subdivided by the annular line (Fig. 15). All leg joints are hinged: the articulation between femur and tibia is dorsal and dicondylic; those between tibia and tarsus, and tarsus and claw, are dorsal and monocondylic. The legs of larvac of some Hydroptilidae and all Integripalpia are progressively longer from front to rear, and except in some swimmers, the larva walks on the last two pairs; in larvac of other Trichoptera the legs are all about the same length (Wiggins, 1977). The walking legs are always comparatively long and slender.

Larvac of Lepidoptera have short, thick, and subconical legs. The coxae are inconspicuous and incompletely sclerotized. Generally, the legs are five-segmented, but the trochanter is small and partly fused to the femur, and some of the other segments may also be partly or entirely fused together; in Micropterigidae just three scgments are evident. Only the joints between femur and tibia, and tibia and tarsus, are hinged; both articulations are dorsal and monocondylic. The legs of Mecoptera larvae are threesegmented and similar in shape to those of Lepidoptera, but are more fleshy and the joints lack a hinge. In larvae of both Lepidoptera and Mecoptera the pleural region is limited to some small, isolated raised areas (pinacula).

To find larvae of other insects in which the pleural sclerites and legs are as highly developed as in Trichoptera, it is necessary to go outside of the Panorpoidea to the neuropteroid orders. Snodgrass (1935:194) stated that Neuroptera (s.l.) and Trichoptera larvae are unusual in having a dicondylic femoral-tibial joint; according to Snodgrass this hinge is usually monocondylic in larval insects. The larva of Corydalus (Megaloptera) has a particularly close resemblance to Trichoptera in structure of the legs and pleural sclerites, and this similarity also extends to the anal prolegs of the abdomen. For the anal prolegs, Pryor (1951) went so far as to assert that these are homologous in Trichoptera and Corydalus. Hinton (1955) rejected this proposal, in part because there is no evidence that the ancestor of either the Neuropteroidea or Panorpoidea had anal prolegs. This argument is not as compelling for the thoracic legs and pleural sclerites because the features in Corydalus could be ancestral for Neuropteroidea. If this were also true for Panorpoidea, then there have been numerous convergences for various general features of the larva in Lepidoptera and other panorpoid lineages, and more so if the Hymenoptera are the sister group of the Panorpoidea.

These considerations place severe limits on what can be deduced using outgroup comparison about the condition of the thoracic pleural sclerites and legs (and also the abdominal prolegs) in the ancestor of Trichoptera.

Another difficulty is that some traits of the pleural sclerites appear to be correlated with the case-making behaviour of the larva. In larvae of the free-living Rhyacophilidae and the retreat-making Annulipalpia the prothoracic pleural ridge has an oblique oricntation, so that the point of articulation with the coxa is well forward of the notopleural articulation-if any (Fig. 13a). The pleural sclerites of the mesothorax and metathorax of these two taxa are also similar in several respects: the pleura are small and are moderately sclerotized judging from the dark colour, and there is an anteriorly directed internal ridge anterad of the pleural ridge (Fig. 13b). Furthermore, the coxal portion of the mesothoracic and metathoracic coxopleural articulation consists of a large, heavily sclerotized prominence (Fig. 13a). Larvae of the free-living Hydrobiosidae have the second and third traits, but the prothoracic pleural sclerites and legs are located far forward compared to other Trichoptera, and the second pleural sclerite is very small, so the first character does not apply to this family.

The prothoracic pleural ridge of larvae that construct portable cases-Glossosomatidae, Hydroptilidae (in part), and Integripalpia-usually has a nearly vertical orientation, so that the coxal articulation is almost directly below the notal articulation-if present (Fig. 14a), although in the free-swimming larva of Nectopsyche (Leptoceridae) the pleural ridge has an oblique orientation. The second mesothoracic and metathoracic pleural sclerites are large (although in some Hydroptilidae the episternum is relatively small), the second pleural sclerite is usually triangular in shape and much of it is lightly sclerotized judging from the pale colour (although in Palaeagapetus [Hydroptilidae] the second pleural sclerite is more elongate, and heavily sclerotized), and the episternum lacks an anteriorly directed internal ridge (Fig. 14b). The coxal portion of the mesothoracic and metathoracic coxopleural articulations usually consists of a small emargination, although there is a small prominence in Glossosomatidae and Leucotrichia (Hydroptilidae).

Nielsen (1942:301) stated that in Trichoptera the type of coxopleural articulation differs in eruciform and campodeiform larvae, but body form is also correlated with use of a portable case. However, for all three traits of the pleural sclerites discussed above, the free-living larva of Corydalus has the condition usually exhibited by Trichoptera that construct a portable case. Despite the potential difficulty with character correlation, and the problem of making meaningful outgroup comparisons, we employ several of the above traits as characters-shape and distinctness of prothoracic pleural sclerite 1 (Appendix, character 24), whether the propleural ridge has 
an oblique orientation (25), whether the mesepisternum and mesepimeron have an anteriorly directed apodeme (26), the nature of the pleurocoxal articulation (27), and length of the legs as expressed by the length of the trochanter (28). We regard as tentative our assignment of the primitive condition for all but the last of these characters.

The only other characters of the larval leg that we employ concern the trochanter and adjoining portion of the femur, and the claw. The trochanter of Trichoptera larvae is subdivided into proximal and distal parts, separated by the annular line (Tindall, 1963; Fig. 15). The dorsum of one or both parts of the trochanter may be membranous; we term this the open condition. On all legs both parts of the trochanter are open in larvae of Rhyacophilidae, Hydrobiosidae, Glossosomatidae, Hydroptilidae, Hydropsychidae, Psychomyiidae, Xiphocentronidae, and various Integripalpia (Fig. 15a). The Philopotamidae, Stenopsychidae, and Ecnomidae differ in that the distal part of the protrochanter is completely sclerotized (closed condition, Fig. 16a); the proximal part is open, albeit in Philopotamidae the anterior side is fused to the distal part (Fig. 16a). All three families have both parts of the mesotrochanter and metatrochanter open, although the sides are approximate dorsally (Fig. 16b). The Polycentropodidae and Dipseudopsidae are unique among Trichoptera because both parts of the trochanter are closed on all legs (Fig. 17).

In various families of Integripalpia the proximal part of the trochanter on one or more legs is closed, while the distal part is open; the opposite is never true (unlike the Philopotamidae, Stenopsychidae, and Ecnomidae). Furthermore, if both parts of the protrochanter are closed in Integripalpia, then the distal part of the metatrochanter is open; conversely, if both parts of the metatrochanter are closed, then the distal part of the protrochanter is open.

The trochanter of the larva of the primitive lepidopteran Heterobathmia is relatively large and subdivided (Kristensen and Nielsen, 1983). In this, Heterobathmia resembles Trichoptera more than other Lepidoptera, but because the distal part is fused to the femur and the proximal part is very small and in contact dorsally with the distal part (Kristensen and Nielsen, 1983, fig. 14), more detailed comparison seems unwarranted. The trochanter of the larva of Corydalus (Megaloptera) is of one piece and entirely sclerotized.

Provisionally we take the open condition of the trochanter to be plesiomorphic for larvae of Trichoptera (Appendix, character 29) because this state is represented in all major lineages. From the patterns described above, it follows that in Annulipalpia closure of the distal part of the trochanter occurred first; in Integripalpia closure of the proximal part took place first. Closure of the distal part has subsequently taken place in Integripalpia, starting with either the first or the last pair of legs.
Larvae of Odontoceridae (except Atriplectides) have a different type of modification (Appendix, character 30): either the distal part or the distal and proximal parts of the trochanter are split lengthwise ventrally. Because both parts are open dorsally, the trochanter consists of three or four pieces (Pseudogoera, and other Odontoceridae, respectively, C. R. Parker, unpublished observations).

A character of the femur that involves the trochanter is exhibited by Helicopsychidae, Sericostomatidae, Calamoceratidae, and Leptoceridae. There is a break in the sclerotization of the dorsal and anterior face of the femur proximal to the trochanter so that the base of the femur is cut off from the rest of femur (pseudo-joint of Tindall, 1964, fig. 22). This is clearly a derived condition (Appendix, character 31).

A modification of the tarsal claw of the middle and hind pairs of legs is exhibited by Psilotreta and Pseudogoera (Odontoceridae) and by Heteroplectron (Calamoceratidae), the claw being divided; in most Trichoptera, including Atriplectides (Odontoceridae) and Phylloicus (Calamoceratidae), and in Lepidoptera and Mecoptera the tarsal claw is entire. The latter is undoubtedly the plesiomorphic condition (Appendix, character 32).

\section{ABDOMEN}

\section{Terga}

Abdominal segments I through VIII of most Trichoptera larvae are largely or entirely membranous. Larvae of Hydroptilidae for the first four instars and sometimes the fifth, have a single large, sclerite on the tergum of segments I-VIII (Nielsen, 1948:34). Most Annulipalpia have on tergum IX a pair of small sclerites located considerably laterad of the midline; at the posterior margin of each sclerite is at least one long seta (subequal in length to seta 7 of Williams and Wiggins, 1981), and one or more much shorter setae. In Philopotamidae and Stenopsychidae tergum IX is completely membranous, and all setae on tergum IX are inconspicuous. In Rhyacophilidae, Hydrobiosdiae, Glossosomatidae, Hydroptilidae, and most Integripalpia tergum IX bears a large sclerite posteriorly (tergal plate of Ross, 1967), and all setae on tergum IX are located along the posterior margin of this sclerite; there is a minimum of four setae, at least one pair of which is long. In Beraeidae, Sericostomatidae, Helicopsychidae, and Anomalopsychidae tergum IX is entirely membranous, while in Conoesucus (Conoesucidae) there are two small plates; in all of these taxa the associated setae are as long and arranged as in other Integripalpia.

Larvae of Lepidoptera have terga I-VIII membranous except for small sclerotized areas which are usually located around the bases of setae (Mutuura, 1980:698). Mutuura (1980) hypothesized that the prothoracic shield 


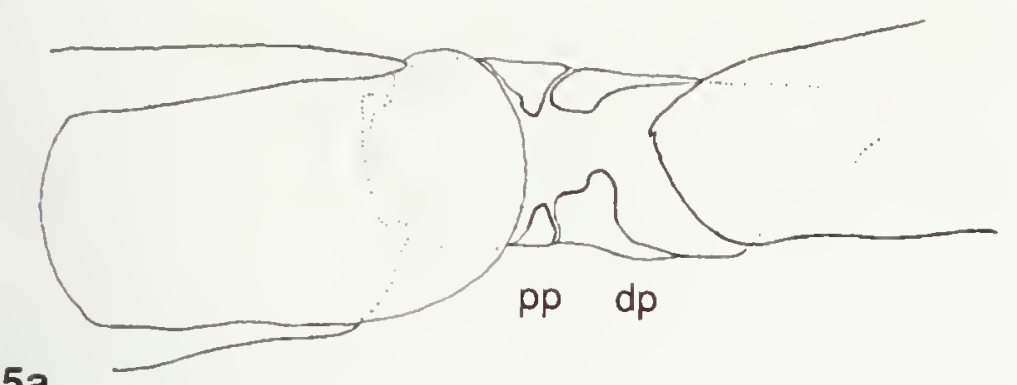

$15 a$

$15 b$

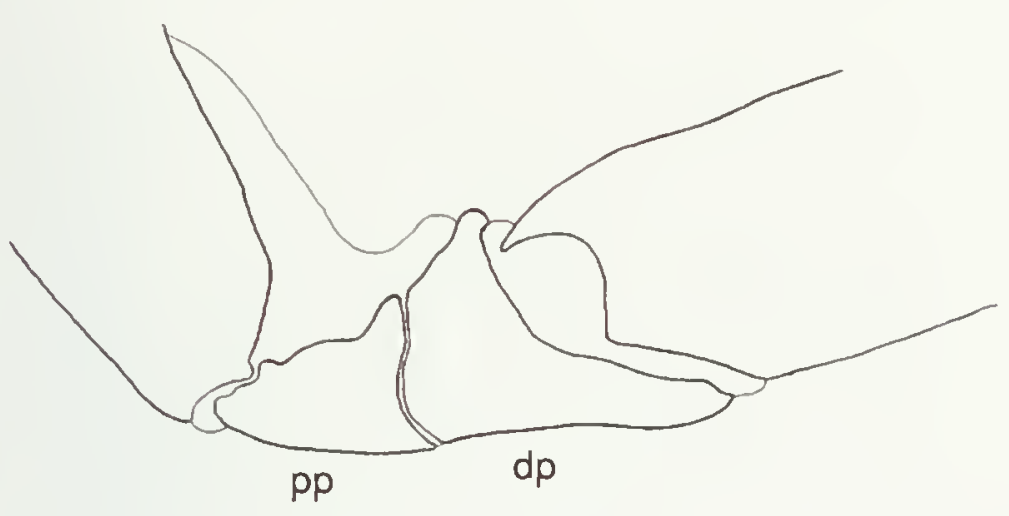

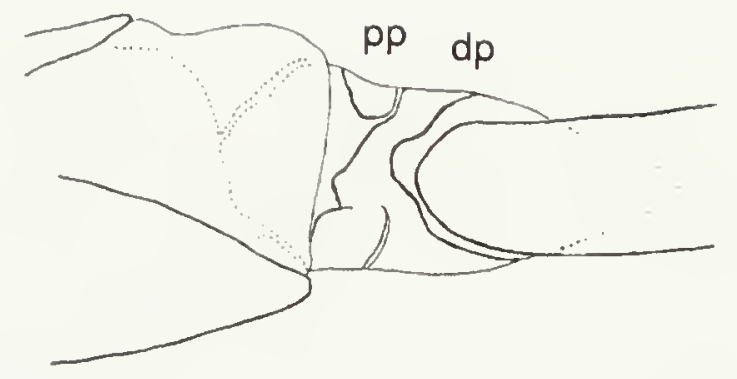

$16 a$

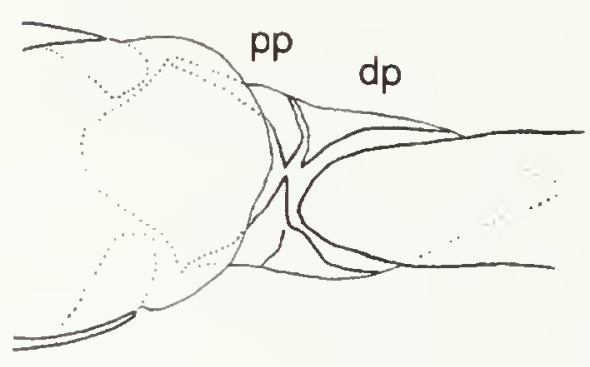

$16 b$

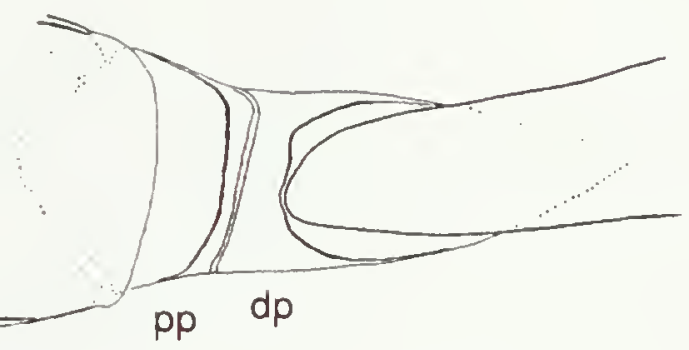

17

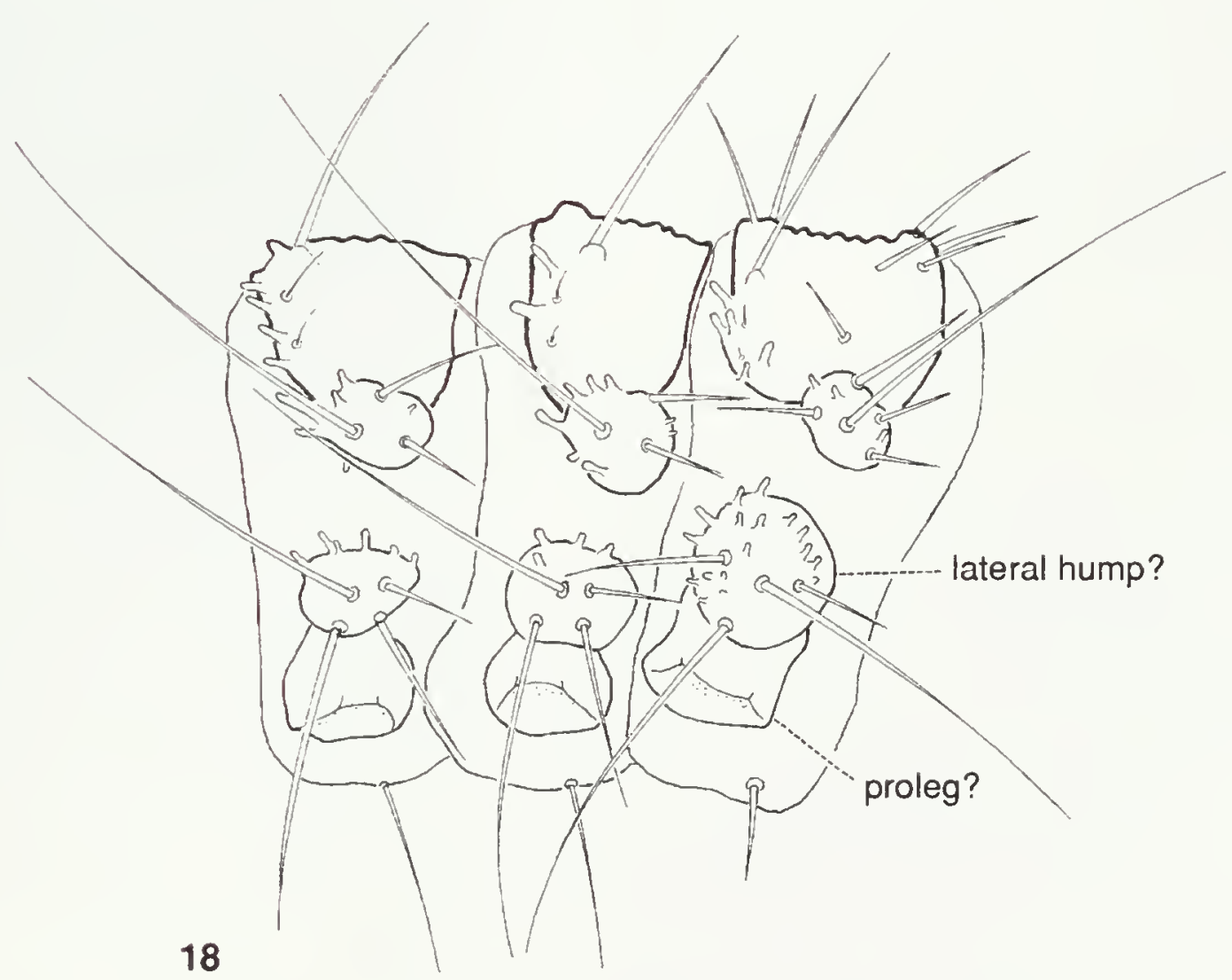

FIGs. 15-18. 15-17. Trochanter of larva. 15. Atopsyche sp., metatrochanter: (a) dorsal aspect, (b) posterior aspect. 16. Dolophilodes sp., dorsal aspect: (a) protrochanter, (b) metatrochanter. 17. Phylocentropus sp., metatrochanter, dorsal aspect. 18. Palaeagapetus nearcticus, IV instar, abdominal segments I-III, right lateral view; not all setae shown on terga. Abbreviations: $d p$, distal part; $p p$, proximal part. 
and also the anal plate of the tenth abdominal segment were "formed by union of several pinacula with the sclerotized areas that are found at the points of attachment of muscles." Certain Psychidae have on tergum IX a pair of transverse pinacula from which three of the four pairs of dorsal setae arise, but we do not know of a Lepidopteran larva that has just a single large sclerite on tergum IX. Among larvae of Mecoptera, abdominal tergum IX is membranous in Boreus and is entirely sclerotized in Panorpa. In both Lepidoptera and Mecoptera at least one of the setae on tergum IX is long.

It is evident from the preceding discussion that presence in Trichoptera of large sclerites on tergites I-VIII is a derived trait (Appendix, character 33). It is also probable that Ross (1967) was correct in suggesting that a single large tergal sclerite on segment IX is a derived condition in Trichoptera. Absence of long setae on tergum IX is also derived in Trichoptera. Among Annulipalpia tergum IX is entirely membranous only in those taxa in which all setae on this tergum are inconspicuous. In those families of Integripalpia in which tergum IX is largely or entirely membranous, e.g., Beraeidae and Conoesucidae, the chaetotaxy is the same as in other Integripalpia. In these same families the posterior third of the head and pronotum are lightly tanned (characters 10 and 11) compared to other Integripalpia. We conclude that presence of a pair of small sclerites on tergum IX with at least one large seta arising from each sclerite is plesiomorphic for Trichoptera, and the membranous condition of tergum IX in some Integripalpia represents a separate state from that in Annulipalpia. Because our conclusions about chaetotaxy and sclerotization of tergum IX are not independent of one another, we recognize one character that incorporates both traits (Appendix, character 34).

\section{Lateral and Dorsal Humps, and Abdominal "Prolegs"}

Larvae of most Integripalpia have one dorsal and two lateral humps on abdominal segment $\mathbf{l}$; the function of these humps is thought to be related to the use of a larval case. Small lateral humps are also present in some taxa on segment VII, or on segments VII and VIII. According to Nielsen (1948), certain Hydroptilidae have lateral humps on abdominal segment II. Nielsen (1948) proposed that Hydroptilidae and Integripalpia both originally had lateral humps on abdominal segments I-VIII, and that these humps have been lost on different segments in the two groups. The larva of Palaeagapetus (Ptilocolepinae) is significant in this respect because it does appear to have lateral humps on segments I-VIII (Fig. 18). The lateral humps of Palaeagapetus are found immediately above a row of fleshy tubercles which are characteristic for this genus (Wiggins, 1977). Each hump bears all the lateral setae for that segment (Fig. 18); the lateral humps on segment I of Integripalpia also bear all of the lateral setae for that segment (figures in Wiggins, 1977). We interpret these observations as evidence that the lateral humps on segment I of Palaeagapetus and Integripalpia are homologous. This interpretation, if correct, would provide support for Nielsen's proposal, but based on a study of musculature of certain Integripalpia, Fuller, Tomaszewski, and Marciniak (1991) concluded that the dorsal and lateral humps are primitively absent in Brachycentridae. Such investigations are beyond the scope of our study.

Discovery of what appear to be lateral humps in Palaeagapetus led us to examine the row of fleshy tubercles found just ventrad of the lateral humps. In preserved material the apex is always indented so that the fleshy tubercle appears truncate. The tubercle is most deeply indented at the centre (Fig. 18), and there appears to be a muscle or ligament attached to this dimple. These observations suggest that the tubercles are actually abdominal prolegs, the indented portion of the tubercle corresponding to the retractile vesicle or planta of the Lepidopteran proleg. Observation of living larvae would help to resolve this issue. Even so, it is unlikely that the abdominal "prolegs" in Palaeagapetus and Lepidoptera would turn out to be homologous because in Palaeagapetus the "prolegs" are located laterally rather than ventrally, the base of the "proleg" lacks setae, and there are no crochets. According to Matsuda (1976) and studies cited therein, embryos of some Lepidoptera have abdominal appendages which on segments III-VI and the last segment develop into larval prolegs. As far as is known, embryos of Trichoptera do not have abdominal appendages; but neither does the embryo of Neomicropteryx (figures in Kobayashi and Ando, 1981), although larvae of Micropterigidae do have abdominal prolegs. This makes it difficult to assess the significance of the embryological data in relation to abdominal prolegs in Trichoptera.

Lateral humps and abdominal "prolegs" are both present in all instars of Palaeagapetus examined; in the last instar they are most conspicuous before the abdomen attains its full size. Their presence is not a feature of the subfamily Ptilocolepinae because there is no indication of abdominal "prolegs" in the mature larva of Ptilocolepus, nor are lateral humps evident (Jacquemart and Coineau, 1962, fig. 11). We did observe in the fifth instar larva of Stactobia (Hydroptilinae) what appear to be prolegs on segments I-III, although the apical portion of each "proleg" is rounded rather than truncate. Nevertheless, the apical portion is clearly differentiated from the basal portion. It remains to be determined whether there is some difference in Stactobia that causes the apical portion of the "proleg" to be everted when the larva is preserved, or whether the apex is not retractile.

Lateral and dorsal abdominal humps are unique to some Trichoptera, and we code their presence on abdominal segment I as a derived condition (Appendix, character 

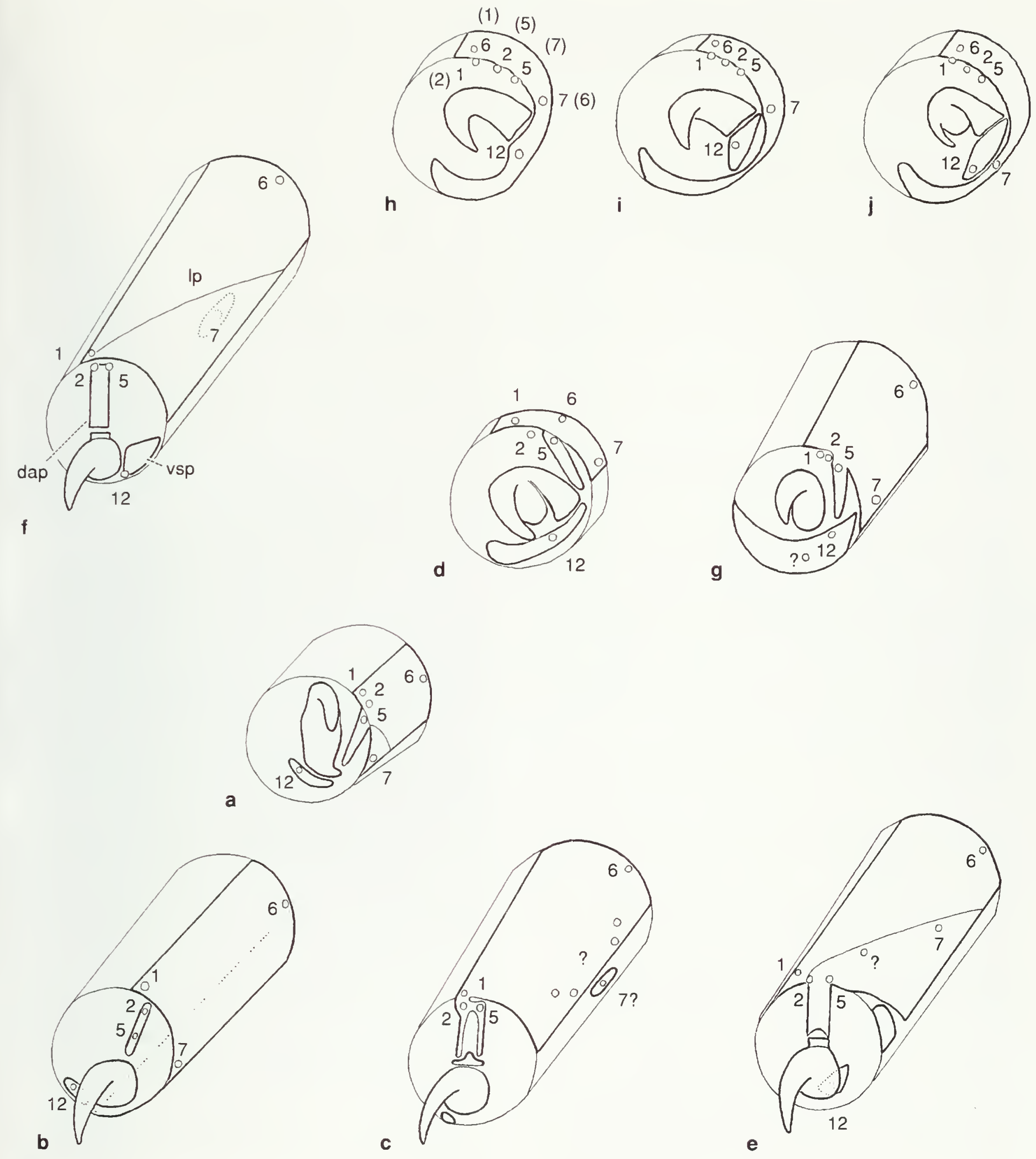

19

FIG. 19. Trichoptera larvae, schematic diagram of right anal proleg, right-dorsal oblique view; identity and location of each seta are indicated by a number and circle; numbers in parentheses are from Williams and Wiggins (1981); (a) Palaeagapetus, (b) Agraylea, IV instar, (c) Leucotrichia, (d) Agraylea, V instar, (e) Wormaldia, (f) Rhyacophila, (g) Glossosoma, (h) Mystacides, (i) Sericostoma, (j) Phryganea. Abbreviations: dap, dorsal articular plate; lp, lateral plate; $v s p$, ventral sole plate. 
35). In view of the uncertainties about homologies, we do not consider further the presence of lateral humps on other segments. Presence of abdominal "prolegs" in Palaeagapetus and some other Hydroptilidae is not taken into account either.

\section{Chaetotaxy of the Pleural Region}

Larvae of Spicipalpia and of Philopotamidae, Stenopsychidae, Psychomyiidae, and Xiphocentronidae (Annulipalpia) have on the pleural region of abdominal segments II-VIII a few widely spaced primary setac, and in some taxa a few secondary setae. Some genera of Hydropsychidae, e.g., Leptonema, have small patches of long setae in the pleural region (Wiggins, 1977, fig. 6.7). In Ecnomidae and Polycentropodidae much of the pleural region of segments II-VIII is covered by patches of long setae. The Dipseudopsidae have on segments II-VIII a lateral fringe of fine, single filaments which on most segments are short. The genus Neotrichia (Hydroptilidae) also has a lateral fringe of fine, single filaments (Wiggins, 1977, fig. 7.8).

In larvae of Integripalpia, the pleural region of at least some abdominal segments has, in addition to setae, other structures including bifid filaments (Kerr and Wiggins, 1995; twin filaments of Denis, I984b; haardornen or thorn hairs of Nielsen, 1942); forked lamellae (fork-bearing plates of Moretti, Cianficconi, and Bicchierai, 1975; doppeldornen or double thorns of Nielsen, 1942; bifid processes of Flint, 1960; lateral tubercles of Wiggins, 1977; spicules of Weaver, 1984); and serrate lamellae (featherlike organs of Denis, 1984b). Bifid filaments invariably are arranged in a lateral fringe; a few single filaments may be present along with the bifid filaments. A row of forked lamellae is often present above the lateral fringe on some segments, e.g., in Grammotaulius atomarius Fbr. (Limnephilidae), or in line with the fringe on segment VIII, e.g., in Molanna (Molannidae). Several families have serrate lamellae but no lateral fringe, e.g., Beraeidae, and the forked lamellae (if present) are confined to segment VIII, e.g., in Gumaga (Sericostomatidae). In some taxa there are only forked lamellae, e.g., Caenota (Calocidae) and Alloecella (Helicophidae). No larvae are known to have both a lateral fringe and serrate lamellae.

Bifid filaments are usually hollow and united at the base, but divided for most of their length (cf. Denis, 1984b, fig. 6a). Forked lamellae are also divided for most of their length, and at least in Grammotaulius atomarius each blade is hollow medially (Moretti, Cianficconi, and Bicchierai, 1975, fig. 3). Moretti, Cianficconi, and Bicchierai (1975) showed that in G. atomarius each forked lamella has associated with it one tormogenous and two trichogenous cells, and is supplied with a nerve fibre; also a nerve trunk extends parallel to the lateral line under the forked lamellae. Based upon these observations they inferred that each forked lamella consists of two modified setae arising from a sclerotized base. The filaments of the lateral fringe probably have a different origin than lamellae because it does not appear from the figures in Moretti, Cianficconi, and Bicchierai (1975) that they are associated with trichogen and tormogen cells.

Larvae of primitive Lepidoptera and Mecoptera have only a few primary setae in the pleural region of abdominal segments II-VIII. Accordingly, presence in the pleural region of patches of setae, a lateral fringe, forked lamellae, or serrate lamellae is apomorphic for Trichoptera. Since the filaments of the lateral fringe are probably not homologous with setae (see above), we consider the large patches of setae present in some Annulipalpia to have evolved independently of the lateral fringe. In contrast, we have been unable to establish a priori whether the lateral fringe evolved independently in Dipseudopsidae, Neotrichia (Hydroptilidae) and Integripalpia because both single and bifid filaments are present in the lateral fringe of some Integripalpia, although only larvae that live in close-fitting tubes (a derived condition for Trichoptera, see below) have a lateral fringe.

We also have not been able to ascertain from available data whether presence of both a lateral fringe and forked lamellac, or just one of these features, is plesiomorphic for Integripalpia. Nielsen (1942) reported that a lateral fringe of bifid filaments is present in all instars of Phryganeidae, but not in the first instar of other Integripalpia. Denis (1984b) stated that as far as is known forked lamellae first appear in the third instar of Plenitentoria, but in the second instar of Brevitentoria. Indications that the lateral fringe appeared first are presence of the lateral fringe in the first instar of Phryganeidae, absence of lamellae in larvae of this family, and presence of filaments in all pupae of Integripalpia (Kerr and Wiggins, 1995). Alternatively, presence of both a lateral fringe and forked lamellae is plesiomorphic for larvae of Integripalpia since the first instars of most Plenitentoria lack a lateral fringe, while a lateral fringe and forked lamellae are both present in the second instar of those Brevitentoria that have a fringe. Serrate lamellae probably developed from forked lamellae because no larvae are known to have both a lateral fringe and serrate lamellae, while some have both serrate and forked lamellae.

In view of the many uncertainties for chaetotaxy of the pleural region of abdominal segments II-VIII, we recognize just one transformation series with four states (Appendix, character 36).

Chloride Epithelia, Anal Papillae, and Tracheal Gills Certain differentiated regions of epidermis in Limnephilidae (s.l., including Goerinae) are osmoregulatory structures termed chloride epithelia (Wichard and Komnick, 
1973; Wichard and Schmitz, 1980). Wichard (1976) suggested that some modified areas of epidermis in Molannidae and Hydroptilinae (Hydroptilidae) are also chloride epithelia. The chloride epithelia of Limnephilidae are seen as "ovoid areas of cuticle bordered by a thin sclerotized line" and may be found ventrally, at the sides above the lateral fringe, and dorsally (Wiggins, 1977:32; Wichard and Schmitz, 1980). In Anabolia nenvosa Curtis (Limnephilidae) each chloride epithelium actually comprises a number of highly modified cells, and the cuticle is also altered (Wichard and Komnick, 1973; Wichard, 1976, fig. 2).

We were able to identify chloride epithelia in Molanna tryphena Betten (Molannidae), but not in $M$. flavicornis Banks. In $M$. tryphena the chloride epithelia are located laterally, and extend beneath adjoining areas of unmodified epidermis so that the lateral fringe crosses the chloride epithelium slightly below the centre (Betten, 1902, fig. 2, dermal glands). Superficially, this gives the chloride epithelium in $M$. tryphena a unique appearance, but the central portion resembles the chloride epithelia in Limnephilidae. In the subfamily Hydroptilinae the chloride epithelia are located dorsally, and are in pairs, or there is a single eliptical structure (Nielsen, 1948, fig. 7; Marshall, 1979). Wichard (1991) has proposed that presence of chloride epithelia is a derived condition in Trichoptera. We agree and consider the presence of chloride epithelia in Limnephilidae, Molanna tryphena, and Hydroptilinae to represent a single derived condition (Appendix, character 37). A more detailed analysis of this character within the Plentitentoria is being done by Gall and Wiggins (in press).

Another type of osmoregulatory structure in larvae of Trichoptera is the anal papillae (Nüske and Wichard, 1971). These are present in all Annulipalpia, Rhyacophilidae, Hydrobiosidae, Glossosomatidae, and certain Hydroptilidae (e.g., Ithytrichia). Structures resembling anal papillae have been observed in Beraea (Integripalpia: Brevitentoria) by Nielsen (1942) and Wiggins (1954), and possibly some sericostomatids (Nielsen, 1942), but not by Wichard (pers. comm.), who indicates that it is neccessary to demonstrate an osmoregulatory function before calling such features anal papillae. Wichard (1991) suggested that presence of anal papillae is a derived condition in Trichoptera. However, the papillae are difficult to detect in preserved material, and they could be present in certain Integripalpia, as noted above. For these reasons, we do not use this trait in our analyses.

The tracheal gills have a respiratory function (Wichard, 1976), unlike the chloride epithelia and anal papillae. Tracheal gills are found in almost all Integripalpia and sporadically among other Trichoptera, e.g., Hydropsychidae (Annulipalpia). Where they do occur in other Trichoptera, the gills are different in gross structure and location from Integripalpia, but this does not rule out the possibility that presence of gills is plesiomorphic for Trichoptera. Moreover, there is variation in many families of Trichoptera for their presence. For these reasons, we do not consider this trait further.

\section{Anal Prolegs}

The sclerotized portions of the anal prolegs of Trichoptera larvae consist of an anal claw and three sclerites (Ross, 1956)-the dorsal articular plate, lateral plate, and ventral sole plate (Fig. 19f). Six primary setae are usually located on or near the three sclerites (Williams, 1983), and eight are present on the anal claw (Nielsen, 1942). The former were numbered by Williams (1983). However, we propose that what Williams identified as seta 6 in Integripalpia is actually seta 7 (Fig. 19i). This is more consistent with the assertions of Williams (1983:84) about the relative sizes of the setae on the anal proleg, and is the homology suggested by Nielsen (1942:308). We also consider what Williams (1983) identified as setae 1, 2, 5, and 7 in Integripalpia to be setae 6, 1, 2, and 5, respectively (Fig. 19i). We recognize six types of anal prolegs in Trichoptera.

Ptilocolepine type. In all instars the claw-bearing portion of the anal proleg projects posteriorly to a slight extent, forming a distinct shaft (the free condition of various authors); in the first four instars and the early final instar the anal claw points downward, while in the mature final instar larva the claw points slightly outward (Fig. 19a). The lateral plate is confined to the outer (lateral) side of the anal proleg. The ventral sole plate is in contact only with the base of the anal claw, and seta 6 is located at the anterior margin of the lateral plate. The dorsal plate is rodshaped and extends laterally to the base of the anal claw. Hydroptilidae: Ptilcolepinae (Fig. 19a).

Hydroptiline type. In the first four instars the anal proleg (Fig. 19b) is of the Rhyacophilid type and in the last instar (Fig. 19c-d) it is of the Limnephilid type (see below), except in all instars the dorsal plate is rod-shaped. Most Hydroptilinae (Hydroptilidae).

Glossosomatid type. This type differs from the Ptilocolepine type mainly in that the ventral sole plate extends onto the mesal part of the proleg, and in the vicinity of the anal claw this plate bears a field of stout spines. Glossosomatidae (Fig. 19g).

Rhyacophilid type. This type is similar to the Ptilocolepine type except that the proleg projects considerably farther posteriorly. Also, the dorsal plate is in the shape of an $\mathrm{H}$, a $Y$, an inverted $U$, or a rectangle, and articulates with but does not extend below the dorsal margin of the anal claw. All instars of Leucotrichia (Hydroptilidae) (Fig. 19c), most Annulipalpia (Fig. 19e), Rhyacophilidae (Fig. 19f), and Hydrobiosidae. Neotrichia (Hydroptilidae) also has this type of proleg except that the dorsal plate is rod-shaped and in the last instar extends laterally to the base of the anal claw. 
Polycentropodid type. This is like the Rhyacophilid type except that the proleg is even more prominent and incorporates part of abdominal segment IX (Pryor, 1951:367). Philopotamidae, Dipseudopsidae, Polycentropodidae, and Ecnomidae.

Limnephilid type. In all instars only the claw of the anal proleg projects posteriorly and the claw points outward. The lateral plate extends ventrad and mesad of the anal claw. The ventral sole plate articulates with or is partly or completely fused to the lateral plate, and seta 6 is located at the posterior margin of the lateral plate near seta 1 (Fig. 19h-j). The dorsal plate is absent or vestigial, but the setae associated with this plate are arranged as in taxa with a rod-shaped dorsal plate. Integripalpia.

Lack of prominence of the anal proleg and outward orientation of the anal claw in most final instar Hydroptilinae is associated with hypertrophy of the abdomen. Leucotrichia and Neotrichia are exceptions because the prolegs are comparatively prominent, even in the last instar. The prolegs of the last instar larva of Palaeagapetus are not as prominent as in Leucotrichia and Neotrichia; as the larva of Palaeagapetus matures, and the abdomen attains its full size, the prolegs become even less prominent and the anal claws become oriented slightly outward, even though the degree of hypertrophy of the abdomen is less in this genus than in other Hydroptilidae. In genera that exhibit marked hypertrophy, such as Agraylea, a difference in prominence of the anal proleg was also observed between mature and early fifth-instar larvae, but the claw was consistently oriented outward. Thus, the similarities of the anal prolegs between the last instar of most Hydroptilinae and larvae of Limnephiloidea may be convergences, the degree of similarity of a species of Hydroptilidae being partly dependent upon the degree of hypertrophy of the abdomen, provided that the anal proleg is not very prominent initially.

Larvae of Lepidoptera generally have anal prolegs, but these occupy only a small part of segment $X$, are fleshy, and have an eversible planta ringed with crochets, rather than a claw. Pryor (1951) proposed that the anal prolegs of Corydalus (Megaloptera) are homologous with those of Rlyacophila, but did not come to a decision on the question of the homologies of the anal prolegs in Lepidoptera; Matsuda (1976) considered them all to be homologous. Hinton (1955) concluded that the anal prolegs of Cordydalus, Lepidoptera, and Trichoptera were derived independently of one another, or, if they share a common origin, the original structure from which the pro- legs arose in the three orders was very generalized (most likely homodynamous with the lateral abdominal filaments in Corydalus), and all subsequent changes took place independently. Williams (1983) proposed homologies between some setae present on segment $X$ in Lepidoptera, either on or lateral to the anal shield, with setae present in Trichoptera on or near the lateral plate, the dorsal articular plate, and the ventral sole plate. The implication is that the anal shield in Lepidoptera has been incorporated into the anal prolegs in Trichoptera. Williams (1983) refrained from proposing homologies for the setae of the anal claw. However, there are about the same number of primary setae on segment $\mathrm{X}$ in Lepidoptera and Trichoptera, if the setae on the anal claws are included. This concordance indicates that in principle it is possible to homologize all the primary setae on segment $\mathrm{X}$ in the two orders.

We propose one multistate character transformation series which encompasses degree of prominence of the anal prolegs and orientation of the anal claws (Appendix, character 38). This adequately expresses variation in Trichoptera for positioning of the lateral plate, the dorsal plate, the ventral sole plate, and seta 6 , and for shape of the dorsal plate. Nielsen (1948) took the free condition of the anal prolegs in early instar Hydroptilidae and in Rhyacophilidae to be primitive for Trichoptera, as did Ross (1967). Weaver $(1983,1984)$ inferred it to be a synapomorphy for Annulipalpia, including Spicipalpia. Krafka (1924) considered the fused condition in Leptoceridae to be ancestral. It is evident that the issue cannot be decided at present using outgroup comparison. Provisionally, we designate the Ptilocolepine type as representing the primitive condition.

We consider the presence of a field of stout spines on the ventral sole plate of Glossosomatidae to be a separate character (Appendix, character 39).

Finally, in larvae of most Trichoptera, seta 7 of the anal prolegs is located in a relatively dorsal position on or near the ventral margin of the lateral plate, about in line with the junction of the claw and the ventral sole plate (e.g., Fig. 19h-i). In larvae of some families of Integripalpia, including all of those which Ross (1967) placed in the Limnephilid branch (= Plenitentoria), seta 7 is located near the ventral articulation of the ventral sole plate with the lateral plate (Fig. 19j). Position of seta 7 is treated separately from the other anal proleg characters. the more ventral position being derived (Appendix, character 40). 


\section{Morphology of Adults}

\section{HEAD}

\section{Labrum}

Ross (1967) considered adults of the Limnephilid branch of Integripalpia (= Plenitentoria) to differ from adults of other Trichoptera including the Leptocerid branch (= Brevitentoria), in having the labrum more clongate and set off by a basal piece (Crichton, 1957, figs. 1, 33). We have been unable to make this distinction with any confidence. For example, in Helicopsychidac, a member of Brevitentoria, the labrum is short but does appear to be set off by a basal piece, while in Mystacides (Leptoceridae), which also belongs to Brevitentoria, the labrum is comparatively long and is set off by a basal piece. Moreover, at least one member of Plenitentoria, Apatania (Limnephilidae), has the condition in Helicopsychidae. For this reason, we do not consider this character further.

\section{Mouthparts}

Mandibles. Adults of many Trichoptera have relatively large mandibles, which are only partly hidden under the labrum in repose (Crichton, 1957, figs. 48-49). In Integripalpia, with the exception of a few members of the Brevitentoria, the mandibles are reduced in size and largely or entirely concealed in repose (Crichton, 1957, fig. 1); or the mandibles are vestigial (Crichton, 1957, fig. 33). Primitive Lepidoptera and Mecoptera have well-developed mandibles, and this is certainly the plesiomorphic condition (Appendix, character 41).

Labial palps. In adults of most Trichoptera the sensilla on the terminal segment of the labial palps are generally distributed, or if some are localized, these do not form a pad. Females of many Integripalpia have a large pad of sensilla which covers a large portion of the inner surface of the palp (Denis and Le Lannic, 1991, pl. X, figs. 1-3). The female of Stenopsyche (Stenopsychidae: Annulipalpia) also has a pad of sensilla mesally, but this is confined to the base of the palp. Lepidoptera have a sensory pit apically on the inner face of the palp (Davis, 1978, figs. 215-216, organ of von Rath). In Mecoptera the sensilla are generally distributed on the palp. The latter is presumably the plesiomorphic condition in Trichoptera (Appendix, character 42), assuming the organ of von Rath is not homologous to the pad of sensilla present in most female Integripalpia.

Maxillary palps. Adults of many Trichoptera have five-segmented maxillary palps, but some members of Brevitentoria and most Plenitentoria (Integripalpia) have fewer segments. Both sexes of Anisocentropus (Calamoceratidae: Brevitentoria) have six-segmented palps (J. C. Morse, pers. comm.). Males of all species of
Paduniella (Psychomyiidae: Annulipalpia) and females of some have six-segmented maxillary palps (Bowles and Allen, 1988). Lepidoptera and Mecoptera have five-segmented maxillary palps; this is clearly the plesiomorphic condition. We interpret change in number of segments of the maxillary palps as a linear transformation series (Appendix, character 43).

In adults of Rhyacophilidae, some Hydrobiosidae, some Glossosomatidae, Ptilocolepinae (Hydroptilidae), Stenopsychidae, and some Philopotamidae, the apex of the terminal segment of the maxillary palps is drawn out to a point and is glabrous, except for one or more coniform sensilla visible only at high magnifications (Denis and Le Lannic, 1991, pl. VI, figs. 5-6; pl. XIII, figs. 9-10). The shape of the palp and the distribution of sensilla in Ptilocolepinae are similar in Micropterigidae (e.g., Chauvin and Faucheux, 1981, fig. 4A); in Rhyacophilidae and the other taxa listed above, the palp is similar to that in some Eriocraniidae (e.g., Davis, 1978, fig. 184). In other Trichoptera, including several Spicipalpia, e.g., Agapetus (Glossosomatidae), Atopsyche (Hydrobiosidae), and Hydroptilinae, the apex of the terminal segment is not attenuate but is rounded and covered with setae and setiform and coniform sensilla. Weaver $(1983,1984)$ inferred that in all Spicipalpia there is a prominent spicule at the apex of the palps, referring presumably to the attenuate portion of the palp in taxa such as Rhyacophila. Weaver suggested that presence of a spicule is a derived condition in Trichoptera. However, reference to the figures cited above demonstrates that in various primitive Lepidoptera, including Micropterigidae, and in some Mecoptera (e.g., Bittacus) the tip of the palp is also attenuate and glabrous, although in other Lepidoptera and Mecoptera it is rounded and setose. We consider, as did Denis and Le Lannic (1991), that the attenuate glabrous condition is plesiomorphic for Trichoptera (Appendix, character 44).

Segment 2 of the maxillary palps of many adult Trichoptera, including Hydrobiosidae, is cylindrical and longer than segment 1 (Crichton, 1957, figs. 1, 33). In Rhyacophilidae, Glossosomatidae, Hydroptilidae, and some Annulipalpia (e.g., Macrostemum (Hydropsychidae), Nyctiophylax (Polycentropodidae)) segment 2 is ovoid and about as long as segment 1 (Crichton, 1957, figs. 48-49). Lepidoptera exhibit the first condition; in Mecoptera segment 2 is cylindrical, but not necessarily long (e.g., Hepburn, 1969, fig. 43). Nonetheless, the first condition is undoubtedly plesiomorphic (Appendix, character 45).

The terminal segment of the maxillary palps of most adult Trichoptera, and of Mecoptera and Lepidoptera, is more or less smooth and inflexible. In most Annulipalpia 
the terminal segment is annulate and flexible, with raised, sclerotized, setose areas narrowly separated by an irregular network of membranous cuticle (Fig. 20; Denis and Le Lannic, 1991, pl. IX, fig. 1). We are not certain whether the terminal segment of the palps of Phylocentropus (Dipseudopsidae) is annulate, but it is flexible, and the surface is modified with respect to other Trichoptera. The palps of Paduniella (Psychomyiidae) are most certainly not annulate, nor do they appear to be flexible. The terminal segment and sometimes also the subterminal segment of Leptoceridae (Integripalpia) is flexible (Morse and Holzenthal, 1987), and the surface appears to be slightly pinched in at irregular intervals (Fig. 21), but the modifications characteristic of the annulate palps of Annulipalpia are not evident. Thus, the annulate condition in Annulipalpia is clearly derived and not comparable to that in Leptoceridae (Appendix, character 46).

Haustellum. Adult Integripalpia have a system of parallel channels on the upper surface of the haustellum that extends from the sitophore nearly to the apex of the haustellum. Crichton (1957), using light microscopy, observed that the walls of these channels are lined with pectinate microtrichia (= hairs), and noted that the microtrichia arising along the apical portion of the channels have a symmetrical shape, while most of those located more basally are asymmetrical. Crichton (1957) also noted that around the apex of the haustellum there is an area of scattered tubercles, each of which is drawn into a symmetrical pectinate microtrichium, and he suggested that towards the base of the haustellum these isolated pectinate microtrichia "are joined by their bases in longitudinal ridges, thus forming channels between them."

Crichton (1957) indicated that a system of channels is also found in Polycentropodidae, but not in Hydropsychidae, Ecnomidae, Psychomyiidae, and Philopotamidae, or in Rhyacophilidae, Hydroptilidae, or Glossosomatidae. Among those taxa without channels, Crichton (1957) observed that the surface of the haustellum is covered with tubercles, which on some areas are drawn into either unbranched microtrichia or symmetrical pectinate microtrichia (Hydropsychidae, Ecnomidae, Rhyacophilidae) or just unbranched microtrichia (Philopotamidae, Psychomyiidae, Glossosomatidae, Rhyacophilidae). We note that Phylocentropus (Dipseudopsidae) has only unbranched microtrichia.

Denis and Le Lannic (1991), using scanning electron microscopy, concluded that Annulipalpia (s.s.) have a system of channels at least on the basal half of the haustellum, as do Rhyacophilidae, but not Glossosomatidae or Hydroptilidae. We suggest (based on observations of adults preserved in lactic acid) that in Protoptila sp. (Glossosomatidae) and Hydroptila sp. (Hydroptilidae), as in Rhyacophilidae, Hydrobiosidae, and most Annulipalpia, the microtrichia-bearing tubercles are arranged in short rows that become longer and run parallel to the long axis of the haustellum only near the sitophore. In Polycentropodidae the channels do run parallel for most of their length to the long axis of the haustellum, but are lined only with symmetrical pectinate hairs. In Psychomyia (Psychomyiidae), the microtrichia appear to be uniformly distributed on the haustellum, so there are no channels, as in some Hydroptilidae (e.g., Ochrotrichia sp.) and various Glossosomatidae (e.g., Glossosoma).

Weaver $(1983,1984)$ considered the presence of parallel channels to be plesiomorphic for Trichoptera, based on their occurrence in Polycentropodidae (Annulipalpia) as well as in Integripalpia, and speculated that they are the prototype of the median food channel in Lepidoptera. In Micropterigidae and Heterobathmiidae the upper hypopharyngeal surface bears a triangular field of unbranched microtrichia and the basal portion is modified into a triturating basket (Kristensen and Nielsen, 1979). Thus, a food channel is not necessarily part of the Lepidopteran groundplan. Based upon the condition found in primitive Lepidoptera, we consider a system of parallel channels partly lined with asymmetrical pectinate microtrichia, as found in Integripalpia, to be the most derived condition in Trichoptera, while a uniform cover of unbranched microtrichia represents the most primitive state in Trichoptera. The condition in Polycentropodidae is possibly intermediate between that in Integripalpia and that in Rhyacophilidae, some Glossosomatidae and Hydroptilidae, and most Annulipalpia, but we do not distinguish this or any other intermediate state from the plesiomorphic condition (Appendix, character 47) because, as shown above, the distinctions among families of Annulipalpia and Spicipalpia indicated by Denis and Le Lannic (1991) do not appear to apply in all instances. Further observations using a variety of techniques are necessary to clarify the issue.

\section{Ocelli}

Rhyacophilidae, Glossosomatidae, and many Hydroptilidae have ocelli, as do some Annulipalpia, and, among Integripalpia, most Plenitentoria and a few Brevitentoria. Some Mecoptera and Lepidoptera have ocelli, others do not. We consider presence of ocelli to be plesiomorphic, based upon the premise that loss of a character is more likely than reaquisition of a lost trait (Appendix, character 48).

In Hydroptilidae that have ocelli, and in Stenopsychidae, the lateral ocelli are located near (within half their diameter) to the inner margin of the eye. Other Trichoptera, and Lepidoptera and Mecoptera, have the lateral ocelli located further from the eye. The latter is clearly the plesiomorphic condition (Appendix, character 49). 
Sutures and Warts

Lepidoptera and Trichoptera are unique among insects in having on the head a large number of sutures, and also setose warts (= Eltringham's organs or chaetosemata, Kristensen and Nielsen, 1979). However, both orders are so diverse regarding the presence and configuration of the various sutures and warts (figures in Ivanov, 1990; Kristensen and Nielsen, 1979, fig. 18; Issiki, 1931, fig. 35 ), that these traits have only limited value as characters at higher taxonomic levels (e.g., Ivanov, 1990). One trait of the head sutures which could be informative concerns the temporal suture. In Rhyacophilidae, Hydrobiosidae, and most Glossosomatidae and Annulipalpia the temporal suture appears to be divided for most or all of its length by a strip of membrane; this is the open condition (Fig. 22a-b). In Hydroptilidae and Integripalpia the temporal suture is intact-the closed condition (Fig. 22c). The temporal suture is also closed in Protoptila (Glossosomatidae), Macrostemum (Hydropsychidae), Phylocentropus (Dipseudopsidae), and Xiphocentron (Xiphocentronidae), and also in Mecoptera and Lepidoptera. Hence, the closed condition is plesiomorphic for Trichoptera (Appendix, character 50).

\section{Tentorium}

The tentorium of adult Trichoptera consists of anterior and posterior arms, and a tentorial bridge (corporotentorium). Dorsal arms (supratentorium) may or not be present, but if so, they arise from the anterior arms. The dorsal arms are intact among Trichoptera only in the Plenitentoria (Weaver, 1984; Neboiss, 1991), with some notable exceptions, including Phryganopsychidae and Lepania (Goeridae). A portion of the anterior arms is sometimes expanded, forming a lobe; in Rhyacophila the tentoriocardinal and stipital muscles and adductors of the scape originate on this lobe (Klemm, 1966, fig. 5). In Rhyacophilidae, Hydrobiosidae, and various Plenitentoria and Brevitentoria, the tentorial bridge has an anteromedian prominence (Neboiss, 1991, fig. 1), which in Atriplectides and most other Odontoceridae (Neboiss, 1991, figs. 44, 52) is paired (single in Pseudogoera). This prominence perhaps serves as the origin of a ventral cibarial dilator (N. P. Kristensen, pers. comm.). In many caddisflies the tentorium has the shape of an $\mathrm{H}$, with the posterior arms and tentorial bridge forming an arch, and the posterior arms relatively long (Neboiss, 1991, fig. 1); more rarely it has an $X$ shape (Neboiss, 1991, fig. 19). 1n some taxa the tentorium is $U$-shaped, the posterior arms being absent, and the anterior arms and tentorial bridge joining at the head capsule, e.g., in a few Hydropsychidae (Neboiss, 1991, fig. 15), Phylocentropus (Dipseudopsidae), most Plenitentoria (Integripalpia), and some Brevitentoria (e.g., Neboiss, 1991, fig. 32). Most Trichoptera have the anterior arms separate, but in some the arms are contiguous, and in a few the arms are united basally, e.g., in Philopotamidae (Neboiss, 1991, fig. 24) and in at least some Protoptilinae (Glossosomatidae).

In adults of most Lepidoptera the anterior arms are subparallel, while the posterior arms are short and in line with the tentorial bridge; thus, the tentorium has more or less the form of the inverted Greek letter phi $(\pi)$. We consider this to approximate the $\mathrm{H}$-shaped tentorium in Trichoptera. The tentorium of Mecoptera is $U$-shaped. Some Lepidoptera have the anterior arms united basally, but this is considered to be a derived condition (Kristensen and Nielsen, 1979). In Lepidoptera that we examined the anterior arms lack lobes, but a lobe (serving as the origin of the stipital muscle) is distinct in at least the Aglossata (i.c., Agathiphaga) and some homoneurous Glossata (N. P. Kristensen, pers. comm.). The anterior arms of adult Mecoptera have medial lobes (Hepburn, 1969). The dorsal arms are short in the three non-glossatan suborders of Lepidoptera, but are well developed in most lineages of the homoneurous grade within the Glossosata (N. P. Kristensen, pers. comm.). According to N. P. Kristensen (pers. comm.) their absence in Heteroneura is secondary, short arms being part of the groundplan of the order. The dorsal arms are incomplete or lacking in many Mecoptera. According to Hepburn (1969), reduction or loss of the dorsal arms in Mecoptera is accompanied by loss of a muscle, the rotator of the scape. In neither Lepidoptera nor Mecoptera does the tentorial bridge have an anteromedian prominence, but in Lepidoptera there is a posteromedial prominence, which serves as the insertion of the ventral neck muscles, and is considered to be autapomorphic for the order (Kristensen and Nielsen, 1979).

We infer that an $\mathrm{H}$-shaped tentorium is plesiomorphic for Trichoptera. Whether the lobate condition of the anterior arms is plesiomorphic is not clear. Provisionally, we consider presence of one or a pair of anteromedian processes on the tentorial bridge to be plesiomorphic in Trichoptera. Ross (1967) and Weaver $(1983,1984)$ considered fully developed dorsal arms to be plesiomorphic for Trichoptera, presumably on the basis that losses are more likely than gains. This seems justified because a tiny rudiment of the dorsal arms is present in many taxa. Weaver $(1983,1984)$ suggested that reduction of the dorsal arms has taken place differently in the Integripalpia as compared to the Spicipalpia and Annulipalpia. According to Weaver, reduction of the dorsal arms in the Integripalpia was a matter of simple atrophy, starting at the base of the antenna; in Spicipalpia and Annulipalpia the anterior arms were displaced anteriorly to become fused with the frons. It is clear from the position of the vestige of the dorsal arms which is evident in many Spicipalpia and Annulipalpia (Klemm, 1966, fig. 5; Neboiss, 1991, figs. $1-7)$, that there has not been any displacement of the dorsal arms; hence, reduction has taken place by atrophy in all 
Trichoptera. In Spicipalpia the frontogenal suture tends to be strongly inflexed (Klemm, 1966, fig. 5; Neboiss, 1991, fig. 1) and this could have misled Weaver.

Traits of the tentorium included as characters in our study are overall shape (Appendix, character 51), degree to which the anterior arms are united (52), degree of development of the dorsal arms (53), and absence of any anteromedian processes on the tentorial bridge (54).

\section{THORAX}

\section{Prothorax}

Prosternum. Adult Trichoptera have the anterior and posterior borders of the furcasternum inflected inwards. Anteriorly the inflected sides of the furcasternum converge and are fused to form a median carina internally. This carina may be continuous with a pair of lateral carinae which extend from the furcae. Posteriorly the inflected sides of the furcasternum also converge, but in Spicipalpia and most if not all Integripalpia they come into contact only dorsomedially or not at all (Ross, 1967, fig. 2). In Annulipalpia exclusive of Stenopsychidae the sides of the furcasternum are entirely fused posteriorly, forming a narrow mesal point. The latter condition is approached if not attained in Leptoceridae and Odontoceridae (Integripalpia). Ross (1967, fig. 3) described the condition in Spicipalpia and most Integripalpia differently: posterior border of prosternum lightly sclerotized medially, dividing the sides of the mesal point into an almost membranous central area.

Most Lepidoptera and all Mecoptera that we examined have the condition in Spicipalpia and Integripalpia; Hepialus and Solenobia appear to exhibit the condition in most Annulipalpia, but interpretation of this trait is not straightforward because in Lepidoptera the spina is connected to the furcasternum posteriorly; in Trichoptera it is not. Ross (1967) designated the condition in most Annulipalpia as plesiomorphic, but the distribution of the two character states in Lepidoptera and Mecoptera does not provide support for this inference. We consider the condition exhibited by most Annulipalpia to be the derived state (Appendix, character 55).

\section{Mesothorax and Metathorax}

Wing venation. Two characters of the forewing that have been used at high taxonomic levels in Trichoptera are absence of crossvein $\mathrm{m}$ and absence of vein M4 (Ross, 1967). Most Annulipalpia have crossvein $m$, as does Heteroplectron (Integripalpia: Calamoceratidae) (Schmid, 1980, fig. 730). Other Trichoptera, including many Xiphocentronidae, do not (figures in Schmid 1982a, 1982b). Crossvein m occurs in Heterobathmia (Kristensen and Nielsen, 1979, figs. 28-29), but not in various micropterigids (Issiki, 1931, fig. 1) or in many other
Lepidoptera. Kristensen (1984a) did not include crossvein $\mathrm{m}$ in an illustration of a hypothetical ancestral moth (fig. 14), nor did Kukalová-Peck (1991) in an illustration of a fossil Mecopteran forewing (fig. 6.27A). Extant Mecoptera have one or more crossveins $m$ (Borror, Triplehorn, and Johnson, 1989, fig. 30-3).

At least the male of most Integripalpia lacks forewing vein M4; exceptions are Beraea and Heteroplectron (Schmid, 1980, figs. 649, 730). This vein is absent from various micropterigids (Issiki, 1931, fig. 1), Heterobathmia (Kristensen and Nielsen, 1979, figs. 28-29), eriocraniids (Davis, 1978), Yponomeuta (Incuvariidae), Adela (Adelidae), and psychid moths. Kristensen (1984a) considered presence of vein M4 to be primitive for Lepidoptera. Designation of the presence of both crossvein $\mathrm{m}$ and vein $\mathrm{M} 4$ as plesiomorphic for Trichoptera (Appendix, characters 56-57) is justifiable on the grounds that losses or fusions are more likely than gains.

Another character of the forewing that has been analysed at the familial level concerns the position of the thyridial cell (e.g., Weaver, 1983). In most Trichoptera, and in Lepidoptera and Mecoptera, the thyridial cell is large and is in contact or nearly so with the medial cell. In most Psychomyiidae and in Xiphocentronidae the thyridial cell is relatively small and is separated from the medial cell by at least one-quarter the length of the thyridial cell. An exception occurs in Paduniella (Psychomyiidae) (Ulmer, 1951, fig. 210; Flint, 1967, fig. 1). The former condition is obviously plesiomorphic (Appendix, character 58).

Wing base. We examined the wing bases, using the studies of Ivanov and coworkers on Trichoptera (e.g., Ivanov, 1985; Kozlov, Ivanov, and Grodnitsky, 1986) and those of Sharplin (1963) on Lepidoptera as a starting point, but we were unable to refine characters sufficiently to use them in our phylogenetic analyses. We do not rule out the possibility that the wing bases will ultimately prove useful in caddisfly phylogeny.

Mesoscutellum. The mesoscutellum of most Trichoptera and of Lepidoptera and Mecoptera is evenly convex (Ross, 1944, figs. 80, 83). In Hydroptilinae (Hydroptilidae) and in Psychomyiidae, Xiphocentronidae, Ecnomidae, Polycentropodidae, and Dipseudopsidae the posterior portion of the mesoscutellum is a flat triangular area with steep sides (Ross, 1944, figs. 438-446). The former is plesiomorphic for Trichoptera (Appendix, character 59).

Mesopleuron. Ross (1967) noted that in most Trichoptera there is a short ridge on the mesopleuron, mesopleural suture $Y$, which extends downward in front of the pleurocoxal articulation onto the katepisternum. Tindall (1965) termed this pleural ridge r4. Annulipalpia do not have this ridge, except for Philopotamidae and Stenopsychidae; neither do Limnocentropodidae. some Hydroptilinae, and some Phryganeidae. Lepidoptera and 
Mecoptera have it; hence, we infer that the presence of pleural ridge $\mathrm{r} 4$ is plesiomorphic for Trichoptera (Appendix, character 60).

Mesofurca. Ross (1967) noted that in most Trichoptera the anteromedial tendon of the mesofurca is membranous, while in others the anteromedial tendon is sclerotized, forming a beak (Ross, 1967, fig. 1). If present, the beak is usually short, but it is long in some Brevitentoria (e.g., Molanna, Fig. 23a) and in Macrostemum (Hydropsychidae). Mecoptera exhibit the first condition, as does Epimartyria (Micropterigidac). Yponomeuta (Incuvariidae) has a short beak, Adela (Adelidae) a long one. Bagworm moths (Psychidae) exhibit a condition not readily comparable to that in other Lepidoptera. The membranous condition is probably plesiomorphic, and the long beak the most derived condition (Appendix, character 61).

Many Trichoptera have the ventrolateral arms of the mesofurca tapered to a point. A few such as Leucotrichia (Hydroptilidae) do not have ventrolateral arms. In most Integripalpia these arms are forked (Fig. 23a). Lepidoptera have the first condition, or lack ventrolateral arms. We consider the forked condition to be derived in Trichoptera (Appendix, character 62).

Metafurca. In all Trichoptera, Lepidoptera, and Mecoptera the metafurca is forked, but in Molannidae and Atriplectides (Odontoceridae) the metafurca also has a median process (Fig. 23b). Presence of the process is clearly a derived condition (Appendix, character 63).

Middle leg. The mesotibia of many Trichoptera bears two preapical spurs. In Hydroptilinae and many Integripalpia there is one or none. Presence of two preapical spurs is plesiomorphic for Lepidoptera (Kristensen, 1984a, fig. 14) and undoubtedly also for Trichoptera (Appendix, character 64).

Weaver $(1983,1984)$ stated that, unlike other Trichoptera, in females of Spicipalpia and Annulipalpia the tibia and tarsus of the middle leg are dilated; this is reputed to facilitate their habit of swimming underwater to reach an oviposition site. However, the middle leg is slender in Atopsyche (Hydrobiosidae), Hydroptilidae, and Diplectrona (Hydropsychidae), and only slightly expanded, if at all, in Dolophilodes (Philopotamidae). With respect to those taxa with dilated middle legs, in Rhyacophilidae the tibia is swollen apically, while the rest of the leg, including the tarsus, is slender. In Glossosomatidae and Annulipalpia, rather than being swollen, the tibia and tarsus are both flattened laterally. In Lepidoptera and Mecoptera the middle leg is slender. The latter is obviously the plesiomorphic condition in Trichoptera. We consider the condition in Rhyacophilidae and that in most Annulipalpia and Glossosomatidae both to be independently evolved from the plesiomorphic condition (Appendix, character 65).

\section{ABDOMEN}

\section{Adult Female}

There is a general consensus in the literature that an oviscapt bearing rodlike apodemes and a cloaca is part of the groundplan of the Amphiesmenoptera (Ross, 1967:173; Matsuda, 1976:418; Kristensen and Nielsen, 1979:115; Nielsen, 1980:197; Schmid, 1989, fig. 32). Partly on this basis, a number of female genitalic characters have been used in previous studies on the higher relationships of Trichoptera. However, there are numerous difficulties concerning the morphology of the female genitalic segments.

Shape of the apex of the abdomen. Adult females of some Trichoptera have a slender, tapered, extensile oviscapt, large sections of which are membranous, e.g., Rhyacophila (Rhyacophilidae) and Glossosoma (Glossosomatidae). In others there is a non-extensile but flexible oviscapt, e.g., Dolophilodes (Philopotamidae). In still others the apex of the abdomen is blunt, comprising sclerotized lobes and plates which are non-extensile and have little flexibility, e.g., Hydropsyche (Hydropsychidae) and Phryganea (Phryganeidae).

There is considerable intrafamilial variation in Trichoptera for this trait. For example, among the Philopotamidae, Wormaldia has a well-developed retractile oviscapt (Schmid, 1980, fig. 156); in Dolophilodes the oviscapt is shorter (Schmid, 1980, fig. 136), and flexible, but not retractile; in Chimarra the apex of the abdomen is blunt and largely sclerotized (Schmid, 1980, fig. 175). Among the Psychomyiidae, Tinodes has an oviscapt, but the segments are largely sclerotized dorsally, so that it is not retractile; in Psychomyia the terminal segments are so short (Nielsen, 1980, fig. 17) that it is a matter of definition whether an oviscapt is present. Some Hydrobiosidae such as Atopsyche do not have an oviscapt (Dugdale, 1974, fig. 8), while certain others apparently do, although it is probably not retractile (e.g., Tiphobiosis montana, Neboiss, 1986). Among the Integripalpia, Kokiria has a non-retractile oviscapt, but in some other Kokiriidac the apex of the abdomen is blunt (e.g., Kokiria miharo and Mecynostomella fusca, Neboiss, 1986). As for which condition is primitive, contrary to expectation in many primitive Lepidoptera such as Micropterigidae and Heterobathmiidae, among others, the apex of the abdomen is blunt (Mutuura, 1972, figs. 1-2, 22; Kristensen and Nielsen, 1979, figs. 57-59). Hence, it is not obvious which condition is plesiomorphic for Amphiesmenoptera.

Number of abdominal segments. According to Schmid (1970:32, fig. 1; 1989, fig. 32), taxa with a long, flexible retractile oviscapt such as the Rhyacophilidae have 11 recognizable segments; but of those taxa in which the apex of the abdomen is blunt, segments $\mathrm{X}$ and $\mathrm{XI}$ are fused in the Integripalpia, IX is reduced or absent in Annulipalpia (Schmid, 1980, fig. 136), and in Protoptila 

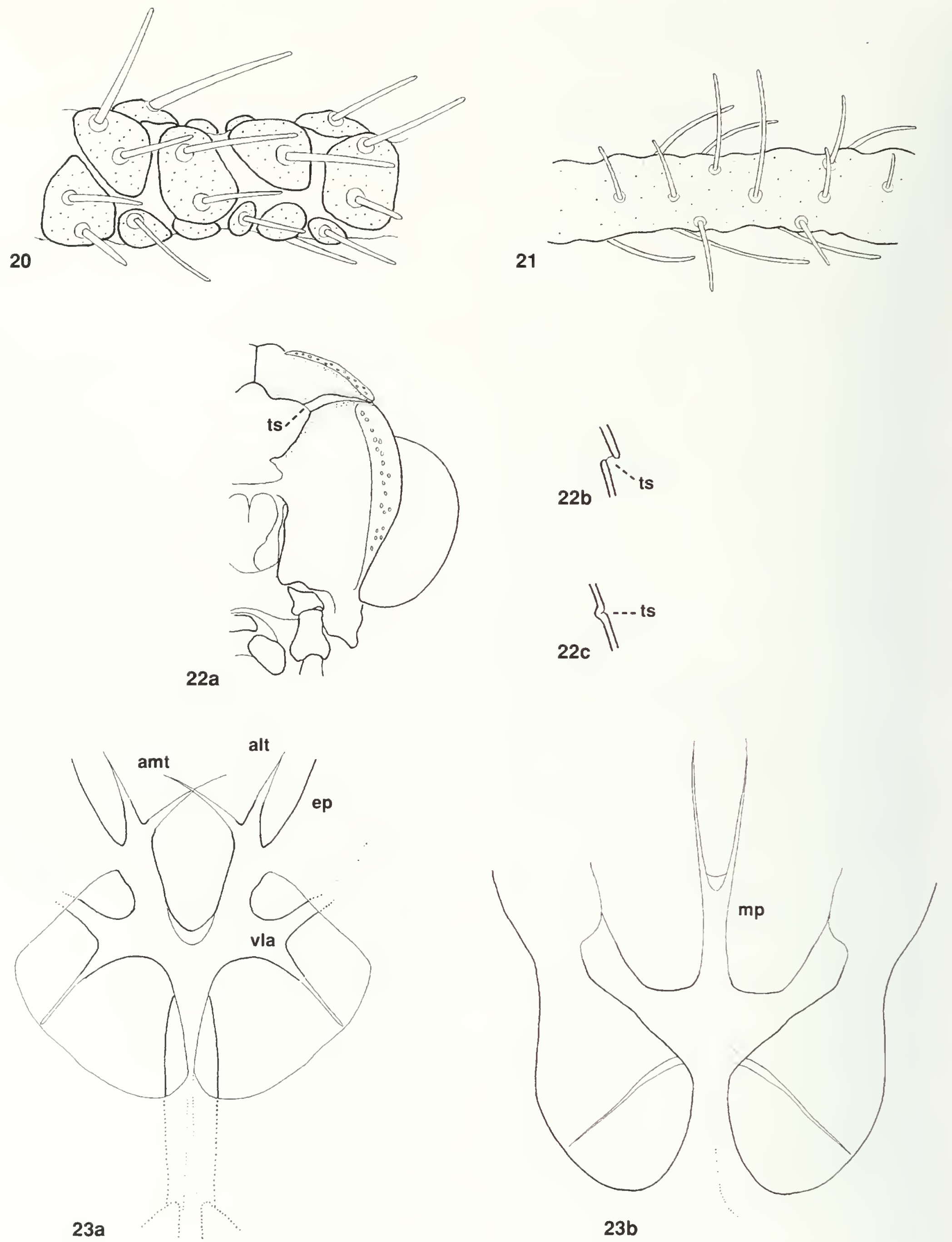

FIGS. 20-23. 20-21. Maxillary palp, middle section, right lateral aspect, areas with spiculate microsculpture indicated by stippling. 20. Arctopsyche grandis. 21. Mystacides interjecta. 22. (a) Atopsyche sperryi, head of adult, posterior aspect: $(b-c)$ schematic diagram of cross-section through temporal suture: (b) open condition, (c) closed condition. 23. Molanna sp., adult: (a) mesofurca, (b) metafurca, dorsal aspect. Abbreviations: alt, anterolateral tendon; amt. anteromedial tendon; $e p$, mesepimeron; $m p$, median process; $t s$, temporal suture; $v l a$, ventrolateral arm. 
(Glossosomatidae) X and XI are fused and IX is absent (Schmid 1980, fig. 116). Matsuda (1976:402) accepted Schmid's interpretation. In contrast, Nielsen (1980:15) stated that in female Trichoptera, segment XI is fused to X and "cannol be recognized as a separate entity," while any division between $\mathrm{X}$ and IX is secondary; accordingly in Rhyacophila there are 10 segments (Nielsen, 1980, fig. 8). Mecoptera have 11 abdominal scgments, and Lepidoptera usually have 10 or fewer (Mutuura, 1972, fig. 22). Niclsen suggested that his interpretation is consistent with musculature. Schmid's is based upon the presence of certain sclerites, but the sclerites indicating the position of segment IX in females of some species of Rhyacophila and Himalopsyche (Schmid, 1970, fig. 1; Schmid and Botoşăneanu, 1966, fig. 12) are absent in other species of these genera (Schmid, 1970, fig. 6; Schmid and Botoşăneanu, 1966, fig. 16), although they all undoubtedly have the same number of abdominal segments. It is evident that the question of the number of abdominal segments in Trichoptera requires further study for this trait to be useful in phylogenetic analysis.

Rod-shaped apodernes of segments VIII and IX. Various Trichoptera have two pairs of long rod-shaped apodemes extending cephalad from the anterior margin of segments VIII and IX, c.g., in Rhyacophila (Schmid, 1970, fig. 1), most Glossosomatidae, all Hydroptilidae examined, Wormaldia (Philopotamidae), Xiphocentronidae, and probably also in Stenopsychodes (Stenopsychidae) (based on Schmid, 1969, figs. 7-9). Apodemes are entirely lacking or vestigial in Hydrobiosidae (Dugdale, 1974, fig. 8), Protoptila (Glossosomatidae) (Schmid, 1980, figs. 116-120), Hydropsychidae, Polycentropodidae, Psychomyiidae, and Integripalpia. Intermediate states are exhibited by Himalopsyche (Rhyacophilidae) (Schmid and Botoşăneanu, 1966, figs. 12, 16, 18), Dolophilodes (Schmid, 1980, fig. 136) and Chimarra (Philopotamidae) (Schmid, 1980, fig. 175), and Stenopsyche (Stenopsychidae) (Schmid, 1969, figs. 5-6). In some caddisflies that do not have apodemes, e.g., Tinodes (Psychomyiidae, Schmid, 1980, figs. 208-209), the lateral wall of segment $X$ is provided with chitinous bands, which are not apophyseal (Matsuda, 1976:325). In many Trichoptera that have apodemes, these extend posteriorly as chitinous bands in the lateral wall, implying that Tinodes, among others, once had rodlike apodemes.

According to Kristensen and Nielsen (1979), among Lepidoptera, rod-shaped apodemes are entirely lacking in Micropterigidae (Mutuura, 1972, figs. 1-2), Heterobathmiidae (Kristensen and Nielsen, 1979, figs. 57-58), and Exoporia, while the anterior pair is lacking in some Neopseustoidea (Mutuura, 1972, fig. 22). Mecoptera also lack these apodemes. Ross (1967) invoked the likelihood of losses over independent derivation of the rod-shaped apodemes to justify designating their presence as the ple- siomorphic condition in Trichoptera. Kristensen (1984a) considered this condition to be a probable synapomorphy for Amphiesmenoptera, but notes (pers. comm.) that the segmental assignment of these rods in both Lepidoptera and Trichoptera is problematic. We adopt the position of both authors that presence of both pairs of rods is plesiomorphic.

Presence of a cloaca. Schmid (1970:28) stated that in the Spicipalpia and Annulipalpia the anus always opens into the vaginal cavity, forming a cloaca (Schmid, 1969, figs. 5-6; 1989, fig. 32). However, Nielsen (1980:44) stated that in Tinodes (Psychomyiidae) "the anus is situated on the dorsal wall of the genital chamber ... immediately in front of the dorsal side of segment X. Since this part of the genital chamber morphologically is open on the ventral side it perhaps is not correct to speak of a cloaca." Furthermore, in Hydropsyche (Hydropsychidae), which along with Holocentropus and Polycentropus (Polycentropodidac) has an atrium into which the reproductive and digestive tracts open, "the intestine and the genital tract have not a common opening ... unless the 'mouth' of the atrium is considered as the common opening" (Nielsen, 1980:85). In Hydropsyche the colleterial duct opens into the posteriormost part of the genital chamber (Nielsen, 1980:87). However, in Holocentropus (= Polycentropus s.l.) the colleterial duct opens on the inside of the upper lip of the atrium, outside the genital chamber (Nielsen, 1980:16); by the criteria of Dugdale (1974) this genus has a genital pouch.

Dugdale (1974:130, fig. 8) reported that the rectal and genital systems are unassociated in the Hydrobiosidae, and the colleterial duct opens beyond the genital chamber, so that there is a genital pouch. Schmid (1989:13) found Dugdale's observations on the Hydrobiosidae to be étonnante, but we find that Dugdale's description applies to Atopsyche. Moreover, the condition of the female genitalia in Protoptila (Glossosomatidae) does not seem to us to be much different from that in Atopsyche, although we have not been able to observe the duct of the colleterial gland. It is reasonable to conclude that a cloaca is present in all Trichoptera with a long, retractile oviscapt. Some with a non-retractile oviscapt such as Stenopsyche also have a cloaca, but it seems that the shorter the terminal segments the more likely it is that the anal and genital openings are separate; then it is still necessary to determine whether the openings are contiguous as appears to be the case in Hydropsyche and in various Integripalpia such as Molannidae (Nielsen, 1980, fig. 63) and Limnocentropodidae, or widely separated as in many other Integripalpia such as Phryganeidae (Nielsen, 1980, fig. 78).

Matsuda (1976:418) referred to the presence of a cloaca in Amphiesmenoptera as an "archaic specialization," presumably because the rectal and genital systems are unassociated in most other insects, including 
Mecoptera. Kristensen and Nielsen agreed (1979:126), but noted that the rectal and genital systems are not associated in Heterobathmia (Kristensen and Nielsen, 1979, figs. 59, 61) or Neopseustidae. Whatever the merits of this argument, we do not consider this trait in our phylogenetic analyses because of the difficulty in ascertaining the condition in many Trichoptera.

Location of the gonopore. Schmid, cited in Matsuda (1976:406), stated that in Rhyacophila the gonopore is located on the apical part of segment $X$, while in the Dicosmoecinae (Limnephilidae) the opening is at the apex of segment IX, and in the Limnephilinae between segments VIII and IX. According to Nielsen (1980:16), in some Spicipalpia such as Hydroptilidae and in some Integripalpia such as Sericostoma (Sericostomatidae) "the genital opening is surrounded by four lips" (e.g., Nielsen, 1980, figs. 41, 50), the anterior and posterior gonopods (=valvulae = gonapophyses, Tuxen 1970:272). The basal pair have fused to form a false segment IX; the true venter of IX and even part of X form the dorsal wall of the genital chamber so that primitively in Trichoptera the common oviduct opens caudally between segments VIII and IX, as in most other insects, and the posterior opening in Rhyacophilidae is secondary and due to fusion of the posterior gonapophyses (Nielsen, 1980:15-16, 196-197). Lepidoptera with a cloaca have the anal-genital opening located at the apex of segment X (Mutuura, 1972, fig. 1). In Heterobathmia and Mecoptera the gonopore is located between segments VIII and IX.

Kristensen and Nielsen (1979:126), citing Nielsen (1980:15), asserted that the morphologically primitive condition for Trichoptera is for the genital chamber to open in a longitudinal depression behind venter VIII. Nielsen (1980) indicated that Ecnomus (Ecnomidae) and Psychomyia (Psychomyiidae) have this condition, albeit in Psychomyia the gonopore has shifted posteriorly. According to Kristensen and Nielsen (1979:126, figs. 59, 61), the same condition also occurs in Heterobathmia (Lepidoptera), so that "the superficial similarity [of the female postabdomen] between Heterobathmia and ... Psychomyia is particularly striking." The condition in Limnocentropus (Limnocentropodidae) also fits this description (Wiggins, 1969, figs. 17-21); and possibly that in Molannidae, where according to Nielsen (1980:125) the genital opening is located in a vertical cleft. That the anal and genital openings are contiguous in Limnocentropodidae and Molannidae suggests to us that the cleft condition is primitive for Integripalpia. We are reluctant to use this as a character because some of the derived conditions are difficult to relate to one another-for example, it is doubtful that the atrium in Hydropsychidae is comparable to the broad depression in most Integripalpia.

Nature of the subgenital plate. According to Nielsen (1980), in Integripalpia external gonopods VIII and IX have fused, forming the subgenital plate (= apical lobes, ventral plate), which originally was separate from sternum VIII (Nielsen, 1980, fig. 50). The subgenital plate then fused to sternum VIII (Nielsen, 1980, fig. 80). However, Nielsen (1980:16) suggested that in those limnephiloids with a separate subgenital plate, the division between this plate and sternum VIII is secondary. A difficulty with this hypothesis pointed out to us by N. P. Kristensen (pers. comm.) is that "a genuine female sternum VIII plate probably was not present in the insect groundplan; in some non-endopterygote insects the apparent sternum VIII is seen to develop from what is morphologically venter VII (Bitsch, 1979)." We continue to refer to sternum VIII for convenience only.

Fusion of terga and sterna of segments VIII and IX. In many Trichoptera sternum VIII is separated from tergum VIII by a membranous band, as in segments II-VII. In other Trichoptera segment VIII is synscleritous. However, this trait varies within some families (e.g., Rhyacophilidac — cf. Schmid, 1970, fig. 1; Schmid and Botoşăneanu, 1966, fig. 16; Schmid, 1980, figs. 136, 175). The same difficulty applies to segment IX.

Divison of sternum VIII. In Ecnomidae, Polycentropodidae, and most Hydropsychidae, sternum VIII is divided mesally into a pair of ventrolateral lobes. In some Hydropsychidae (e.g., Arctopsyche and Hydropsyche) sternum VIII is merely incised, and not more so than in Phylocentropus placidus (Dipseudopsidae), Stenopsyche (Stenopsychidae), or Rhyacophilidae, Hydrobiosidae, and Hydroptilidae (see also Nielsen, 1980:74). Sternum VIII is entire in Lepidoptera and Mecoptera.

Eversibility of the vagina. Females of certain Trichoptera have an eversible vaginal apparatus, so that the processus spermathecae protrudes outside of the body during copulation (e.g., Schmid and Botoşăneanu, 1966, fig. 18). In other Trichoptera the vagina is not eversible. Weaver (1983:31; 1984:417), citing Schmid (1970, 1980) for the observations, proposed that an eversible vagina is a synapomorphy for Spicipalpia. However, according to Schmid (1980:33), the Hydroptilidae do not have an eversible vagina; Weaver (1983) suggested without supporting data that some hydroptilids do have this condition. Other exceptions are Protoptila (Glossosomatidae) (Schmid 1980:34) and Hydrobiosidae (Schmid, 1989).

Cerci and lateral papillae. Female Trichoptera. except for Integripalpia, have one- or two-segmented papillate cerci which arise on the terminal abdominal segment (Schmid, 1970, fig. 1). In caddisflies, these structures have no muscle attachments; hence, according to Nielsen (1980:14-15), it can only be assumed that they are cerci. In Hydropsychidae and Polycentropodidae, and in Dolophilodes (Fumonta) major Banks (Philopotamidae), there is a pair of lateral papillae next to the cerci (Weaver, 1983, 1984). Mecoptera have cerci; Lepidoptera lack 
them; neither have lateral papillae. Presence of lateral papillac is clearly a derived condition. We consider presence of cerci to be plesiomorphic for Trichoptera, but only on the grounds that losses are more likely than gains.

Appendages of segment $X$. According to Weaver (1984:418), a synapomorphy for Integripalpia is presence in the female of a pair of appendages on segment $X$. If these are the processes sometimes labelled as such by Schmid (1980, fig. 428), then many taxa that are supposed to have them, do not, e.g., Limnocentropus (Limnocentropodidae), many Phryganeidae, Brachycentridae, Limnephilidae, and Gocridae.

Conclusions about female genitalic characters. Nielsen (1980) stated that Trichoptera show considerable variation both between and within families for structure of the female genitalia, and that the structural diversity of the female genital chamber is unrivalled among insects. Nonetheless, the morphological diversity of the postabdomen in female Lepidoptera does approach that in the Trichoptera; moreover, few of the primitive Lepidoptera conform to the generally accepted groundplan for the Amphiesmenoptera. These considerations, plus the difficulty in establishing homologies for some of the traits, undermine the use of female genitalic characters for phylogenetic purposes in caddisflies. We include in our data set three of the more readily defined traits: the condition of the rodlike apodemes of segments VIII and IX, and occurrence of lateral papillae and cerci (Appendix, characters $66-68)$.

\section{Adult Male}

Relatively few characters of the male in comparison to the female genitalia have been employed in studies of the higher classification of Trichoptera. We have not been able to find any new characters for consideration. Two traits that have been used previously are included in the data set.

Inferior appendages. Various Trichoptera, and Lepidoptera and Mecoptera, have two-segmented inferior appendages that consist of the coxopodite and harpago (Nielsen, 1957a). In some Trichoptera they are one-segmented, while Protoptila (Glossosomatidae) does not appear to have them (Schmid, 1980). The presence of inferior appendages of two segments is generally held to be the plesiomorphic condition for Trichoptera. However, according to Nielsen (1957b:8), among Trichoptera the derived condition has arisen in several different ways. Verification of Nielsen's hypothesis is beyond the scope of our study; we simply consider the number of segments (Appendix, character 69).
Parameres. Many Trichoptera have paired parameres. Others have a single paramere, or none at all. According to N. P. Kristensen (pers. comm.), "such formations are unknown from the lowermost (non-myoglossatan) Lepidoptera," while "the phallic apparatus of Mecoptera is difficult to homologize with that of Trichoptera." Nielsen (1957b:13) could only assume that the parameres in different families of Trichoptera are homologous. Provisionally, we consider having fewer than two parameres to be a derived condition in Trichoptera (Appendix, character 70).

Nielsen (1957b) proposed that Rhyacophilidae are more primitive than other Trichoptera in having fused distinct paraprocts and epiparaprocts in the male. Consideration of this issue and others raised by Nielsen (1957b) are beyond the scope of this study. Schmid (1989) used reduction of the aedeagus as a character in his phylogenetic analyses. We did not examine this trait because of the difficulties involved in making adequate observations, but we do consider below Schmid's conclusions based on this character.

\section{Spermatozoa}

The spermatozoa of the Integripalpian families Phryganeidae, Limnephilidae, Leptoceridae, and Odontoceridae each have an axoneme with a nine + two arrangement of groups of microtubules typical of most animals, including Lepidoptera (Friedländer, 1983). Families of Annulipalpia studied to date have aberrant spermatozoa. The axoneme of Polycentropodidae contains three centrally located microtubules (Friedländer, 1983). The axoneme of Hydropsychidae is highly modified and contains trailing microtubular doublets radiating out from the basal body (Friedländer and Morse, 1982). Philopotamidae do not have a discernible axoneme, although their spermatozoa develop from spermatids with zero to four centrally located axoneme microtubules (Friedländer, 1983; Friedländer and Jeger, 1990). The axonemes of the Spicipalpian families Rhyacophilidae and Glossosomatidae also are aberrant, each lacking the central pair of microtubules (Friedländer, 1993). Based on these data, Friedländer (1993) suggested that having aberrant spermatozoa is a synapomorphy linking Annulipalpia with Spicipalpia.

There are two difficulties with Friedländer's (1993) hypothesis. The fine structure of the spermatozoa of Hydroptilidae (Spicipalpia) is unknown. Also, it has not been shown that all of the above modifications of the axoneme can be included in a single character transformation series from the original nine + two condition. For these reasons, we do not consider this trait further. 


\section{Results of Numerical Phylogenetic Analyses of the Morphological Data}

When we did a parsimony analysis using the larval data alone, without weighting the characters, we obtained 100 equally parsimonious trees (the maximum possible number using HENNIG86) having a consistency index of 0.41 . We also obtained 100 trees using the adult data alone, each with a consistency index of 0.25 . When we combined the two sets of data, we obtained three trees having a consistency index of 0.29 (Fig. 24); upon rearranging the order in which the taxa appeared in the data set, we obtained another two trees with the same length as the first three (Fig. 25).

When we did a compatibility analysis of the larval data alone, we obtained five cliques (sets) of 34 compatible (uniquely derived) characters; for the adult data alone we obtained two cliques of 10 compatible characters. For the combined larval + adult data, we obtained 20 cliques of 37 characters (Figs. 26-27).

Families traditionally assigned to the Annulipalpia (s.s. excluding Spicipalpia) were always grouped together in our parsimony analyses; so also were all families assigned to the Integripalpia (s.s.), and the Limnocentropodidae were always positioned as the sister group of all other Integripalpia (Figs. 24-25). Arrangements based upon the larval data alone showed certain other congruencies with the combined larval + adult data: the Hydroptilidae and Integripalpia were treated as sister groups; the Rhyacophilidae and Hydrobiosidae were separated together or sequentially as the sister group of the Annulipalpia; the Ecnomidae, Psychomyiidae, Xiphocentronidae, Dipseudopsidae, and Polycentropodidae were grouped together; so also were the Sericostomatidae, Anomalopsychidae, Helicopsychidae, Helicophidae, Beraeidae, and Calocidae. In contrast, arrangements obtained using data from adults alone showed little congruence with those based upon the larval data alone or the combined larval + adult data.

This result was carried further when compatibility analyses were done because arrangements based upon the combined larval + adult data (Figs. 26-27) and the larval data alone were entirely consistent with one another, but hardly at all with arrangements based on the adult data alone. Thus, when the larval and adult data were analysed together, the larval characters had more influence on the outcome than the adult characters. Presumably this is because the larval characters show more congruence with one another than do the adult characters, the minimumlength trees obtained using the larval data alone having higher consistency indices compared to arrangements based on the adult data alone ( 0.41 versus 0.25$)$. The larval data also conflict with most of the adult data as evidenced by the comparatively low consistency index for trees based upon the combined data (0.29). In parsimony analysis, arrangements obtained when two independent sets of data are combined should be a more reliable indicator of phylogenetic relationships than arrangements based on any one data set (Miyamoto, 1985). The same consideration should apply to compatibility analysis. Accordingly, we do not consider further those arrangements based solely upon the adult or larval data.

Arrangements based upon compatibility and parsimony analyses of the combined larval + adult data with the characters equally weighted (cf. Figs. 24-27) agreed in the same ways as those based upon parsimony analyses of the larval data alone and the combined larval + adult data (see above), or at least were consistent with those results. Also, the families of Plenitentoria were grouped together; so were the Kokiriidae and Molannidae. The principal differences were in the placement of the Glossosomatidae and Hydrobiosidae, the arrangement of taxa within the Hydropsychoidea and Sericostomatoidea, and the position of some families of Plenitentoria.

When we changed the polarity of all characters for which we had some doubt about the ancestral condition (i.e., characters $11-12,24-27,29,38,54$ ), the only substantial difference in parsimony analyses of the combined data set compared to the original results (Figs. 24-25) was that the Rhyacophilidae and Hydrobiosidae were separated one after the other at the very base of the tree, so that the former was treated as the sister group of all other Trichoptera. Provided that Paduniella was coded as having annulate maxillary palps, as do all other genera of Psychomyiidae, the arrangements obtained using compatibility analysis were identical to those obtained using the original character codings (as in Figs. 26-27).

Compatibility analysis showed that the maximum possible number of uniquely derived traits for the combined larval + adult data under any arrangement of the taxa is 37. Fewer traits were found to be uniquely derived under the most parsimonious arrangements ( 25 and 27 for those in Figs. 24 and 25, respectively). Since we did not attempt to fully resolve the arrangements obtained using compatiblity analysis, their lengths could not be compared with those of the shortest trees obtained using parsimony analysis, but one must expect that if fully resolved, they would be longer. Coinparing the arrangements that we obtained with those of Ross (1967) and Weaver (1983, 1984), and leaving out Kokiriidae, Tasimiidae, Atriplectides (Odontoceridae), and Anomalopsychidae because either Ross or Weaver did not consider one or another of these taxa, we found the cladogram based on Ross's hypothesis of phylogeny to be 42 steps longer than our minimum-length trees, and the one based on Weaver's hypothesis to be 51 steps longer; and under their hypothe- 


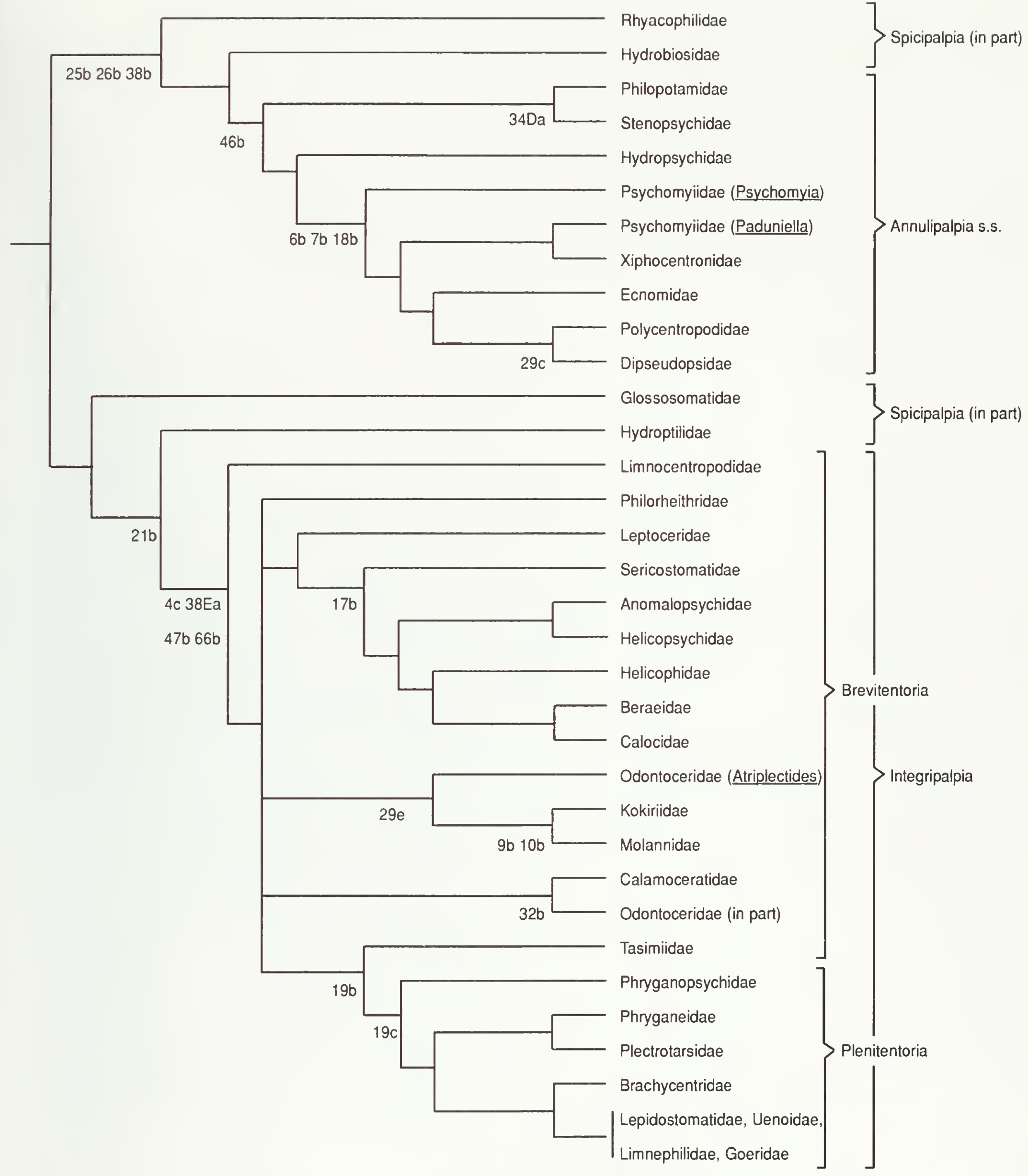

FIG. 24. Strict consensus tree for three minimum-length trees obtained using the HENNIG86 computer program on a data set of larval and adult characters for selected genera of 'Trichoptera, showing all character states that are uniquely derived for groupings above the family level. 
ses, there are nine and eight (respectively) fewer uniquely derived characters than under the arrangements that we obtained using compatibility analysis. Thus our results are preferable in terms both of the total number of character changes, and of the number of uniquely derived characters.

Nonetheless, it is evident that the results of our numerical analyses do not provide a single, decisive answer to the questions raised in the introduction to this study. Indeed, in regard to our parsimony analyses, other islands of trees of mimimum length (Maddison, 1991) probably remain to be discovered since we did not exhaus- tively change the order in which the taxa appeared in the data set. It can still be asked whether, on a character-bycharacter basis, hypotheses of relationship previously proposed are better supported than those that we obtained in our numerical analyses of the combined larval + adult morphological data. We also investigate whether a hypothesis of phylogeny based on behavioural data provides a plausible alternative to arrangements based on our analyses of the morphological data.

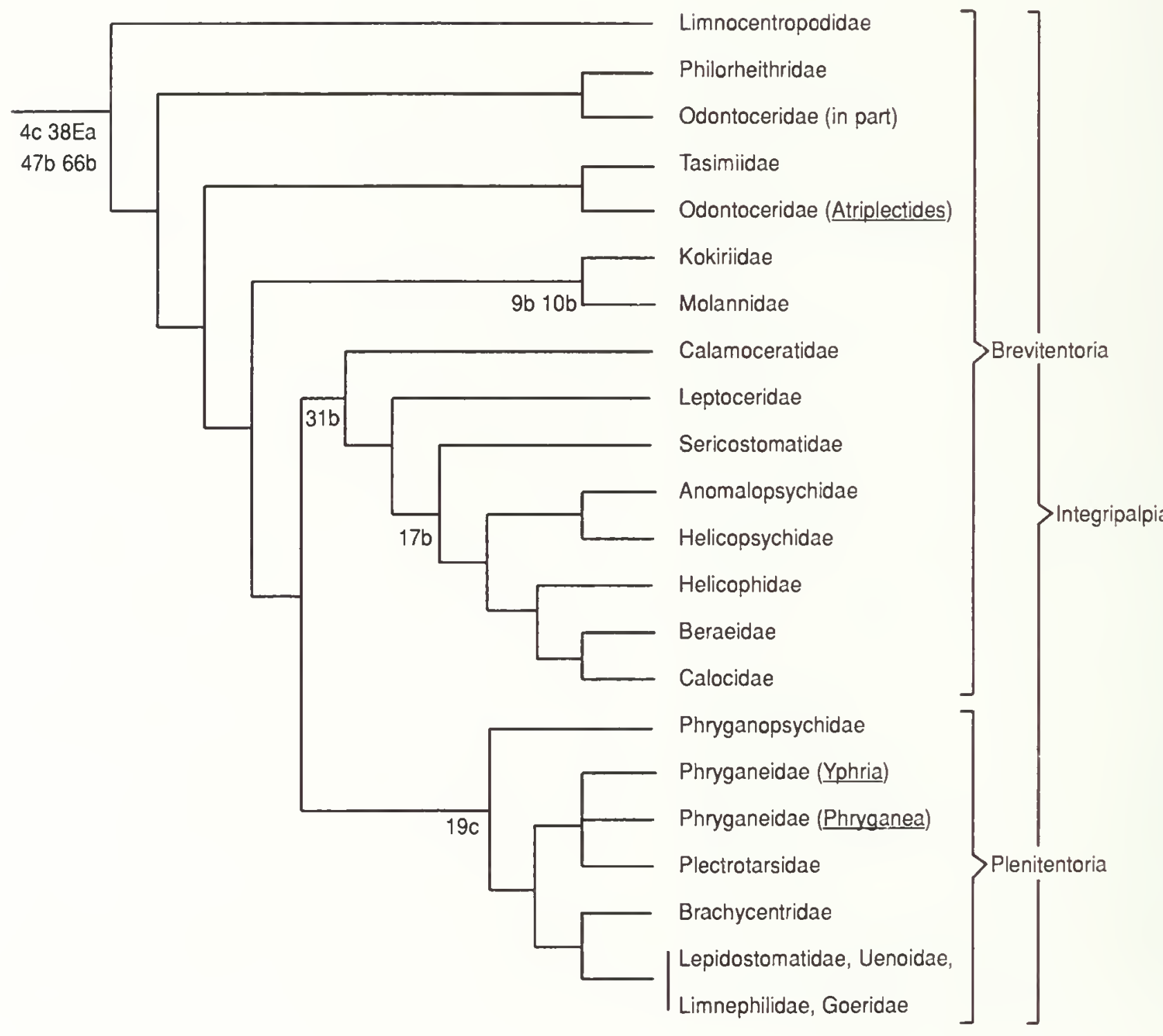

FIG. 25. Portion of strict consensus tree for two minimum-length trees obtained using the HENNIG86 computer program on a data set of larval and adult characters for selected genera of Trichoptera, when the order in which the taxa appear in the data set was changed. Shown is only that portion of the tree that differs from the one in Fig. 24. All character states shown are uniquely derived for groupings above the family level. 


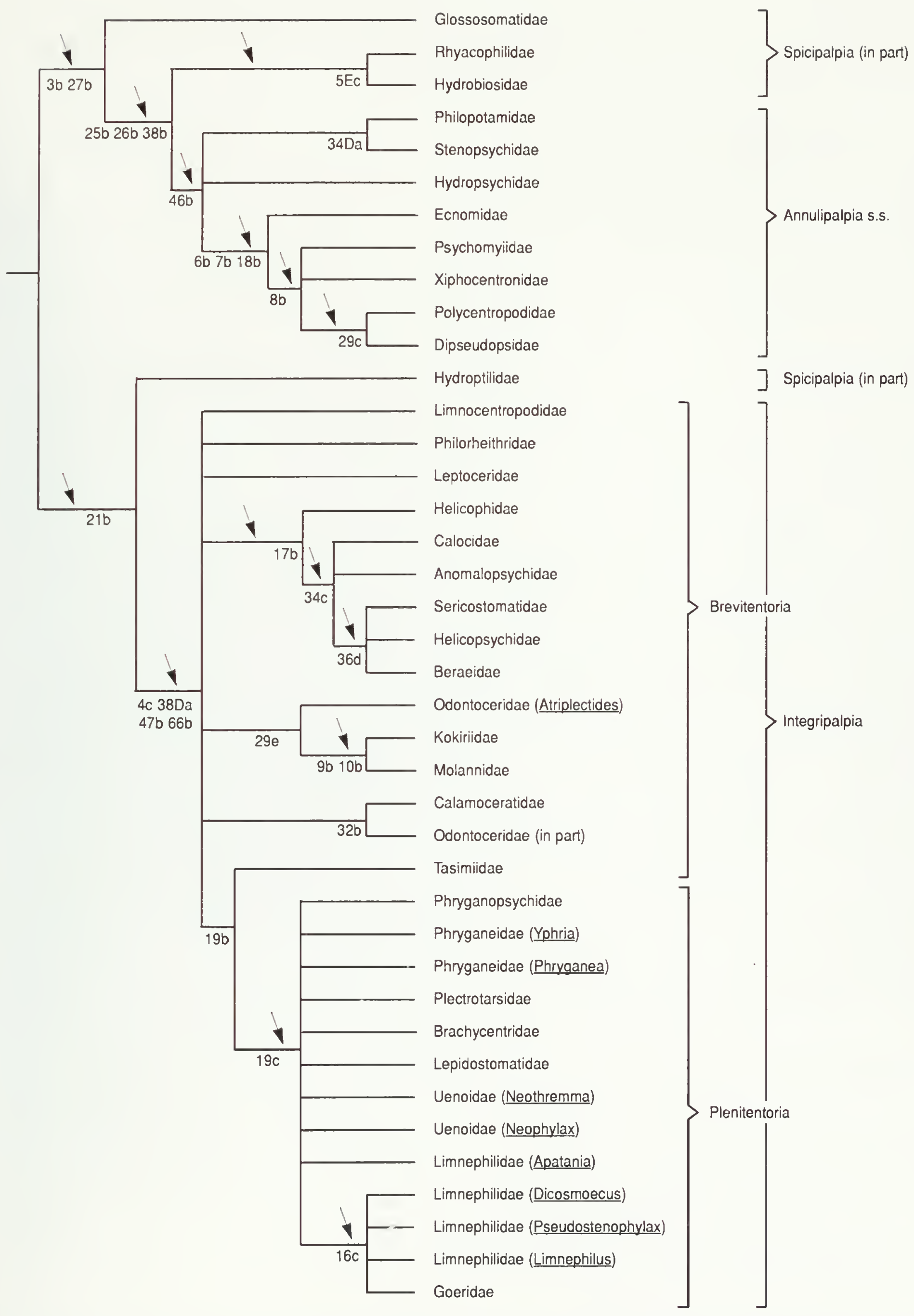

FIG. 26. Arrangeinent based on one of the 20 sets of compatible characters obtained using the CLINCH computer program on a data set of larval and adult characters for selected genera of Trichoptera, showing all character states that are uniquely derived for groupings above the family level. The arrows indicate groupings common to all 20 arrangements. 


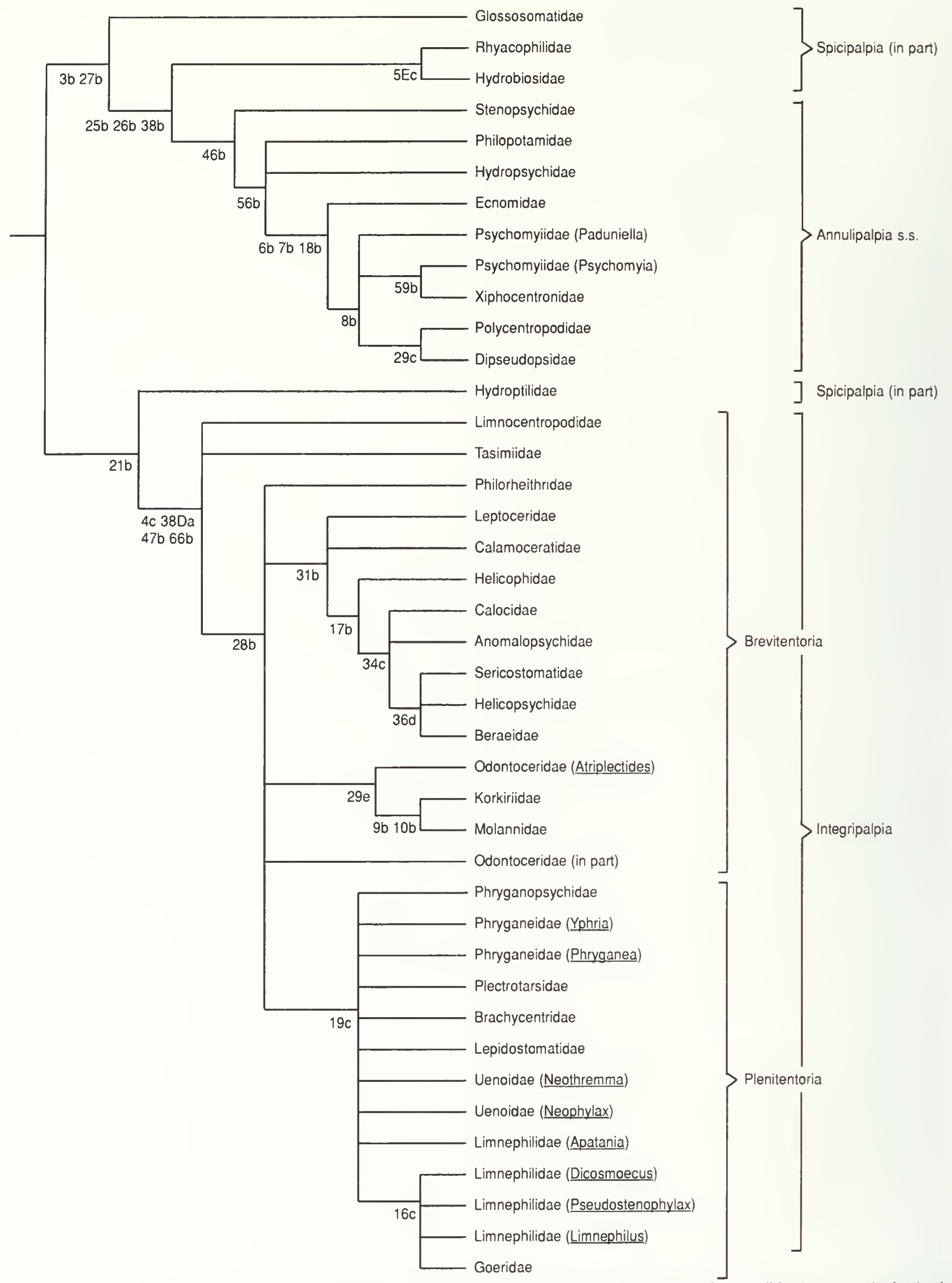

FIG. 27. Arrangement that differs the most from the one in Fig. 26, and that is also based on one of the 20 sets of compatible characters obtained using the CLINCH computer progsam on a data set of larval and adult characters for selected genera of Trichoptera. All character states shown are uniquely derived for groupings above the family level. 


\section{Evaluation of Alternative Hypotheses of Relationships for Trichoptera Based on Morphology}

\section{ISSUES ABOUT SPICIPALPIA}

Evaluation of the Ross Hypothesis of Phylogeny for Trichoptera As It Pertains to the Spicipalpia

Ross (1967, fig. 1; Fig. 2) followed Martynov (1924, 1930) in considering the Trichoptera to comprise two groups, Annulipalpia and Integripalpia, but in the former Ross included only the Philopotamoidea and Hydropsychoidea. In the latter Ross placed the Rhyacophiloidea (Rhyacophilidac including Hydrobiosidac, Glossosomatidae, and Hydroptilidae) and Limnephiloidea (= Plenitentoria + Brevitentoria), which were inferred to have evolved in that sequence. Ross (1967) listed three characters as evidence that the Rhyacophilidac, Glossosomatidae, Hydroptilidae, and Limncphiloidea constitute a monophyletic group: in adults, the weakly sclerotized posterior border of the prosternum (character 55 in our study) and the loss of crossvein $\mathrm{m}$ in the forewing (character 56); in larvae, the presence of a sclerous shield on tergum IX (character 34). We consider the condition of the posterior border of the prosternum in adult Rhyacophilidae to be primitive for Trichoptera; furthermore, Stenopsyche griseipennis (Stenopsychidae) also exhibits this condition. Crossvein $\mathrm{m}$ is present in Heteroplectron (Integripalpia: Calamoceratidae), and within Hydropsychoidea it does not occur in Xiphocentronidae; thus, this character is homoplasious. We do concur with Ross that presence of a sclerous shield on tergum IX of the larva is a derived trait, but we note that this character conflicts with some others that indicate affinity of Rhyacophilidae, Hydrobiosidae, and Glossosomatidae with Annulipalpia (see below), and that a similar condition is found in larvae of some Mecoptera (see section on morphology).

As evidence for monophyly of Glossosomatidae + Hydroptilidae + Limnephiloidea, Ross (1967) cited the highly modified anal prolegs, in particular, presence in the last instar of accessory teeth on the anal claws. Designation of the primitive condition for the anal prolegs in Trichoptera is problematic. Moreover, accessory teeth are lacking in most Hydroptilidae, including Ptilocolepinae. Despite this, in our parsimony analyses of the combined larval + adult data (Figs. 24-25), the Glossosomatidae were separated with the Hydroptilidae + Limnephiloidea (sensu Ross), but on the basis of characters that exhibit considerable homoplasy, in some instances even within this group of taxa: in larvae, antennae located cephalad (Appendix, character $2 b$ ) but far cephalad ( $2 a$ ) in Hydroptilinae, and sal or sa 3 sclerotized (20b), but membranous (20a) in Glossosoma (Glossosomatidae); in adults, apex of maxillary palps rounded (44b), but attenuate (44a) in Glossosoma and Ptilocolepinae, paramere single (69b), but paired (69a) in Protoptila (Glossosomatidae), inferior appendage one-segmented (70b), but twosegmented (70a) in Hydroptilinae.

In support of a sister-group relationship between Hydroptilidac and Limnephiloidea, Ross (1967) noted that the anal prolegs are shorter than in larvae of other Trichoptera and the anal claws are directed laterally, and cited his proposal that the larval antennae have been reduced to a single rod. However, the slight prominence of the anal prolegs in the last instar of most Hydroptilinae and all instars of Ptilocolepinae could be the plesiomorphic condition for Trichoptera. Furthermore, the lateral orientation of the anal claws in Hydroptilidae is possibly a consequence of hypertrophy of the abdomen and therefore convergent with the condition in Integripalpia. Finally, we consider presence of an antennal segment ( $=$ rod) to be plesiomorphic for Trichoptera. Nonetheless, the Hydroptilidae and Integripalpia were grouped together in all of our numerical analyses because these two groups share two other derived characters in the larval stage: mesonotum with more than two large setae in sa3 (Appendix, character 14b), and antennae with one trichoid sensilla, this located laterally (5Ca). However, the first character is suspect because it is difficult to delimit sa3 in Hydroptilidae. As for the second character, larvae of Rhyacophilidae and Hydrobiosidae also have only one antennal trichoid sensillum, and it is located medially, a more derived condition (5Ec).

We conclude that the only well-founded morphological evidence for Ross's (1967) placement of the Rhyacophilidae, Glossosomatidae, and Hydroptilidae in Integripalpia is presence in all of these taxa of a sclerous shield on tergum IX of the larva.

\section{Evaluation of the Martynov-Schmid-Weaver Hypothesis of Phylogeny for Trichoptera As It Pertains to the Spicipalpia}

According to Weaver $(1983,1984)$ and Weaver and Morse (1986), and in keeping with Martynov (1930) and Schmid (1980), the Annulipalpia (s.l.) comprise the Curvipalpia + Spicipalpia (Fig. 1). The former comprise Philopotamoidea and Hydropsychoidea, the latter Rhyacophilidae + Hydrobiosidac and Glossosomatidae + Hydroptilidae.

Weaver $(1983,1984)$ cited two morphological characters of adults as evidence for monophyly of the Annulipalpia (s.l.): dorsal arms of tentorium more cephalad and greatly shortened or completely fused with frons; 
tibia and tarsus of middle leg are dilated, extremely so in female, less so in male. It is evident that loss of the dorsal arms of the tentorium in Trichoptera (Appendix, character 53 ) has occurred several times by simple atrophy in both the Lepidoptera and the Trichoptera, including Annulipalpia (see section on morphology). The second trait (65) is also flawed because the middle leg is not dilated in Hydrobiosidae, Hydroptilidae, and some Hydropsychoidea. Furthermore, the middle leg is dilated in a different way in Rhyacophilidae compared to Glossosomatidae, Philopotamoidea, and Hydropsychoidea. To our knowledge, no taxa exhibit a condition intermediate between those found in Rhyacophilidae and Glossosomatidae; thus, the two states are probably not homologous. At the very least, if Weaver's concept of Annulipalpia is correct, then there have been several reversions to a slender middle leg in this suborder.

Another synapomorphy for Annulipalpia (s.l.) proposed by Weaver $(1983,1984)$ is the behaviour of swimming to the bottom to lay eggs. Among Spicipalpia, Rhyacophila kiyosumiensis (Rhyacophilidae) (Kuranishi, 1993) and Ptilocolepus granulatus (Hydroptilidae) (Ito and Higler, 1993) only dip their abdomens into the water to oviposit. Females of the Annulipalpia (s.s.) do actually swim to the bottom to lay eggs. Since the latter is undoubtedly the derived condition, the few species of Spicipalpia for which oviposition behaviour is known exhibit the primitive behaviour. Although most Integripalpia deposit their egg masses near the water surface (Weaver, 1984), females in some families (e.g., Phryganeidae) crawl well beneath the surface to deposit eggs (Silfvenius, 1906).

Two morphological traits of larvae that Weaver (1983, 1984) proposed as synapomorphies for Annulipalpia (s.l.) are larva campodeiform with prognathous head, and anal proleg elongated. However, it is unclear what the plesiomorphic condition of either trait is for Trichoptera; moreover, the Glossosomatidae exhibit an intermediate condition for both traits. A behavioural trait proposed by Weaver $(1983,1984)$ as a synapomorphy for Annulipalpia (s.l.) is that larvae are rheophilic. We infer from evidence from pupation behaviour (see below) that the ancestral larval Trichopteran lived in running water; consequently, restriction of larvae to flowing water is part of the groundplan for Trichoptera. We conclude that none of the evidence previously proposed for monophyly of Annulipalpia (s.l.) is convincing.

Weaver $(1983,1984)$ proposed three synapomorphies for Spicipalpia: adult with terminal segment of maxillary and labial palps bearing apical spicule; second segment of maxillary palps ovoid; and vaginal apparatus eversible. As shown in the section on morphology, the first trait is poorly defined (we consider the trait to be "terminal segment attenuate, apex glabrous"), and the attentuate condition is probably plesiomorphic for Amphiesmenoptera; further- more, in Hydrobiosidae and in many Glossosomatidae and Hydroptilidae the apex of the palps is rounded (Table 1, character 44). The second trait also presents difficulties because contrary to expectation the second segment of the maxillary palps in Hydrobiosidae is cylindrical rather than ovoid; moreover, in some Hydropsychoidea the second segment is ovoid (Table 1, character 45). Finally, the third trait is not exhibited by Glossosomatidae, Hydrobiosidae, or Hydroptilidae. Thus, all of the morphological evidence for monophyly of Spicipalpia is equivocal.

Three synapomorphies were advanced by Weaver $(1983,1984)$ as evidence for a sister-group relationship between Hydroptilidae and Glossosomatidae: larva with mesonotum and metanotum sclerotized; anal proleg and claw partially reduced; and, in adult males, inferior appendages one-segmented. However, the mesonotum and metanotum in Glossosomatidae are only partially sclerotized (e.g., Protoptila) or not at all (e.g., Glossosoma); conversely, the mesonotum and metanotum also are completely sclerotized in Ecnomidae, Hydropsychidae, and Hydroptilidae. Moreover, it is not clear to us in what manner the anal proleg and claw have been reduced in Glossosomatidae and Hydroptilidae, nor is it evident what the condition of the anal prolegs was in the ancestral Trichopteran. Finally, in Trichoptera the number of segments of the male inferior appendages has undoubtedly been reduced several times from two to one, so this evidence for relationship is not compelling.

Weaver (1983, 1984), following Ross (1967), proposed that the Rhyacophilidae have a sister-group relationship with the Hydrobiosidae, based on presence of a basoventral hook on the larval anal proleg (e.g., Flint, 1962, fig. 1b). However, in Rhyacophilidae the basoventral hook is an extension of the lateral plate. In contrast, the basoventral angle of the lateral plate is not extended in Atopsyche (Hydrobiosidae); instead, seta 7 forms the hook. Thus, the basoventral hook in these two families is not homologous. Furthermore, not all Rhyacophilidae and Hydrobiosidae have this feature. Nonetheless, there is good morphological evidence from larvae that these two families have a sister-group relationship (see below).

Unlike Ross (1967) and Weaver (1983, 1984), Schmid (1989) suggested that the Hydrobiosidae belong to the Annulipalpia (s.s.), because in the adult female the genitalic segments are short and stout, segment IX has disappeared, rod-shaped apodemes of segments VIII and IX are lacking, the anal-vaginal orifice is open for the entire length of segment $X$ and is protected by a vulvar scale, and the cerci are tiny. Furthermore, according to Schmid (1989), male Hydrobiosidae show the beginning of the replacement of the aedeagus by the phallotheca and endotheca, a trend completed in the Hydropsychoidea (sensu Schmid). In contrast, females of Rhyacophilidae have an oviscapt with well-developed rod-shaped 
apodemes and large cerci, and segment $\mathrm{IX}$ is present, while in males the phallotheca is well developed.

Although the differences between females of Hydrobiosidae and Rhyacophilidae are considerable, differences of this magnitude are also apparent between females of Protoptilinae and the other subfamilies of Glossosomatidac. The Protoptilinae have short, stout genital segments with segment IX absent, they lack rodshaped apodemes, and the rectal and genital systems are unassociated; the other subfamilies have a long retractile oviscapt, prominent rod-shaped apodemes, and a cloaca. Moreover, females of Philopotamidae are more primitive than females of Hydrobiosidae in that they have a welldeveloped oviscapt, hence Schmid's difficulty about where to place Hydrobiosidae within Annulipalpia (Schmid, 1989, fig. 33).

Considering male genitalic morphology, various stages in reduction of the aedeagus are indeed evident in the Annulipalpia, as stated by Schmid (1989), culminating in complete replacement by the phallotheca and endotheca in the Hydropsychidae; but similar tendencies are evident in the Integripalpia where the phallotheca and endotheca have also replaced the aedeagus in various families of Integripalpia, including Phryganeidae, Brachycentridae, Sericostomatidae, and Helicopsychidae (Schmid, 1980, figs. 564, 596, 633, 643). This considerably weakens the basis for Schmid's interpretation of phallic structure as supporting affinity of the Hydrobiosidae with the Annulipalpia.

Nonetheless, in our parsimony analyses of the combined larval + adult data, the Hydrobiosidac emerged as the sister group of the Annulipalpia (Figs. 24-25) based on the following synapomorphies: in adults, apex of maxillary palps rounded, not drawn out to a point (Appendix, character 44b); in females, anterior pair of rodlike apodemes at apex of abdomen vestigial, posterior pair short (68d); and in males, parameres absent (70c). All of this evidence is equivocal because in Stenopsyche (Stenopyschidae) and Dolophilodes (Philopotamidae) the maxillary palp is attenuate, as in Rhyacophilidae (44a); species of Paduniella (Psychomyiidae) have one paramere (70b), while some Hydrobiosidae have two (Schmid, 1989); and, as noted by Schmid (1989), in females of many Annulipalpia the rodlike apodemes at the apex of the abdomen are more developed than in the Hydrobiosidae (Table 1, character 68).

In our compatiblity analyses of the combined larval + adult data the Rhyacophilidae and Hydrobiosidae were grouped together based upon a larval trait-the medial position of the single antennal trichoid sensillum (Appendix, character 3Ec), a condition unique to these two families (Figs. 26-27). This is the only unequivocal morphological evidence we found for relationship of Hydrobiosidae to any other group of Trichoptera. The array of characters advanced by Schmid (1989) linking the Hydrobiosidae with the Annulipalpia does demonstrate that this family has diverged markedly from the Rhyacophilidae and other families of Spicipalpia; we interpret the similarities between Hydrobiosidae and Annulipalpia as convergent developments for the reasons presented above.

To conclude, there is no unequivocal morphological evidence for monophyly of the Spicipalpia, or for closer relationship of all the Spicipalpian families to Annulipalpia than to Integripalpia. The structure of the larval antenna provides clear support for a sister-group relationship between Hydrobiosidae and Rhyacophilidae.

\section{Evaluation of Other Arrangements of the Families in Spicipalpia Based upon Larval and Adult Morphology}

In our compatibility analyses of the combined larval + adult data the Glossosomatidae emerged as the sister group of the ((Rhyacophilidae + Hydrobiosidae) + Annulipalpia) (Figs. 26-27). Monophyly of this group as a whole is supported by two larval traits: loss of the antennal segment present in Hydroptilidae and Integripalpia so that only some sensilla remain (Appendix, character $1 \mathrm{~b}$ ), and presence of a large mesocoxal and metacoxal prominence with which the pleural condyle articulates (26b). Interpretation of the first character is straightforward, and we do not know of another instance in insects where the antennae have been reduced to this extent. We have less confidence in the second character because of the difficulty in making meaningful outgroup comparsions for traits of the larval pleura and legs (see section on morphology). An adult character that provides limited support for this grouping is the open condition of the temporal suture of the head $(50 \mathrm{~b})$. However, the temporal suture is closed in some Hydropsychidae and Glossosomatidae; moreover, expression of this trait could be related to body size; exclusion of Hydroptilidae from this group based upon the closed condition of the temporal suture is therefore unwarranted.

Three larval traits suggest that the Rhyacophilidae and Hydrobiosidae are more closely related to the Annulipalpia than are the Glossosomatidae (Figs. 24-27): the oblique orientation of the propleural suture (Appendix, character $25 \mathrm{~b}$ ), presence of an anteriorly directed apodeme on the mesepisternum and metepisternum (26b), and the prominent anal prolegs with the claw directed downward (38b). This evidence is not convincing because there is some question about the polarity of each of these characters. It is also uncertain whether the condition of the mesepisternum and metepisternum (26) in the Rhyacophilidae and Hydrobiosidae really differs from the condition in Integripalpia and Hydroptilidae.

Thus, one character of the larval antenna provides 
unequivocal evidence that the Glossosomatidae, Rhyacophilidae + Hydrobiosidae, and Annulipalpia (s.s.) constitute a monophyletic group.

\section{Limits of the Hydroptilidae}

Monophyly of the Hydroptilidae has never been seriously questioned, although Kristensen (1990), among others, has drawn attention to the many plesiomorphic traits of the subfamily Ptilocolepinae. Although this subfamily differs in a number of characters from the Hydroptilinae, a sistergroup relationship between them is supported by several larval characters. One is hypermetamorphosis in the last larval instar (Appendix, character 1b); another is presence of a large sclerite on abdominal terga I-VIII in at least the first four instars (33b). The shape of the larval silk press could also be a synapomorphy for Hydroptilidae (see section on morphology). According to Weaver $(1983,1984)$ another feature unique to Hydroptilidae is that in adults the lateral ocelli are very close to the compound eyes (49). However, Stenopsyche (Stenopsychidae) also has this condition, and many Hydroptilidae do not have ocelli (e.g., Hydroptila). Weaver (1983, 1984), following Schmid (1980), also proposed as a synapomorphy for Hydroptilidae the modification of the parameres into a single coiled rod resembling a cork-screw, but Ptilocolepinae and at least some genera of Hydroptilinae (c.g., Leucotrichia) do not have this condition.

In summary, one character of the larval antennae provides unequivocal morphological evidence that the Hydrobiosidae and Rhyacophilidae are sister groups, and another character of the larval antennae is equally strong evidence that these two families plus the Glossosomatidae and the Annulipalpia form a monophyletic group. Other arrangements of these families and of the Hydroptilidae, which have been proposed previously or which emerged in some of our numerical analyses, are based on traits that are homoplasious or poorly defined, or for which the polarity is uncertain. A possible exception is presence of a sclerous shield on tergum IX of the larva, which indicates that the Spicipalpian families are most closely related to the Integripalpia.

\section{ISSUES ABOUT ANNULIPALPIA}

Our results confirm the monophyly of the Annulipalpia (s.s.), and are consistent with monophyly of Hydropsychoidea (Figs. 24, 26-27). The most significant issues are monophyly of the Philopotamoidea and placement of the Hydropsychidae. A synapomorphy of long standing for adults of Annulipalpia (s.s.) is the annulate condition of the last segment of the labial and maxillary palps (Appendix, character 46b). Although the last segment of the palps is not annulate in Paduniella (Psychomyiidae), this is undoubtedly a reversal which could be related to the fact that the maxillary palps are six-segmented in males of all species of Paduniella and females of some; no other Trichoptera (other than Anisocentropus (Calamocertidae)) have more than five segments. It would be of interest to determine whether females of species of Paduniella with five-segmented maxillary palps have the annulate condition. We examined females of only P. nearctica, which has six-segmented palps (Bowles and Allen, 1988).

A synapomorphy for larvae of Annulipalpia is an increase in the number of antennal trichoid sensilla from two to three (Appendix, character 3b); however, larvae of Xiphocentronidae have just two trichoid sensilla, which presumably is a reversal.

According to Weaver $(1983,1984)$ presence in the adult female of lateral papillae on segment $X$ is another synapomorphy for Annulipalpia (s.s.) because these are found not only in Polycentropodidae and Hydropsychidae, but also in Dolophilodes (Fumonta) major Banks (Philopotamidae), although they are not found in other Philopotamoidea. Weaver $(1983,1984)$ concluded that the papillae have been lost numerous times in Annulipalpia (s.s.). We have confirmed their presence in $D$. major. Presumably Weaver is correct, or this trait is an underlying synapomorphy (sensu Saether, 1979) for the suborder. Weaver also proposed as synapomorphies reduction in larvae of the sclerotized plate on abdominal tergum IX and loss in the adult male of the parameres. We consider the presence of a small pair of sclerites on abdominal tergite IX in most Annulipalpia to be plesiomorphic for Trichoptera (see section on morphology). As for parameres, various taxa throughout the order lack them, so this evidence for monophyly of Annulipalpia is not compelling.

The Stenopsychidae + Philopotamidae (Philopotamoidea) are generally regarded as the sister group of all other Annulipalpia, i.e., the Hydropsychoidea, and some of our results are in agreement. Unequivocal evidence in larvae for monophyly of Philopotamoidea is that tergum IX is membranous and does not have any long setae (Appendix, character 34Da). A larval trait that Ross (1967) advanced as evidence for monophyly of this group is the elongate head, but the head is as elongate in some Integripalpia (e.g., Pseudogoera (Odontoceridae), Wiggins, 1977, fig. 12.5B). Weaver (1983) cited as synapomorphies the flexible, bilobed antennae (which we interpret as presence of two large basiconic sensilla) and presence on the procoxa of a mesal process which bears an apical seta. The antennal character is invalid because presence of two large basiconic sensilla is plesiomorphic for Trichoptera. Furthermore, it is difficult to ascertain whether Dolophilodes (Philopotamidae) has the procoxal mesal process, and a condition similar to that in Dolophilodes is shown by Polycentropus (Polycentropodidae). In our compatibility analyses the Philopotamidae were sometimes grouped with the Hydropsychoidea 
(Fig. 27) because in adults the posterior margin of the prosternum terminates in a sclerous point $(55 \mathrm{~b})$, but we found this to be a difficult character to score.

We were unable to discover a uniquely derived synapomorphy for Hydropsychoidea. In adults of all Hydropsychoidea the posterior margin of the prosternum terminates in a sclerous point (Appendix, character 55b), but as noted above, the Philopotamidae also exhibit this condition. Evidence from adults presented by Ross (1967) for monophyly of Hydropsychoidea is absence of the ocelli (48) and absence of suture Y of the mesopleuron (60), but Weaver (1983) noted that many taxa throughout the order and even some Stenopsychidae lack ocelli (Ross, 1967). Similarly, absence of suture Y of the mesopleuron is evident in several groups of Trichoptera; moreover, this suture is present in Paduniella (Psychomyiidae). Weaver (1983) proposed yet another synapomorphy for Hydropsychoidea: male with articulation between tergum and sternum IX resembling open mouth, but indicated that most Hydropsychidae do not exhibit this trait, and that the character does not apply to Polycentropodidae because of reduction of tergum IX. We are unable to interpret this character from the information provided.

\section{Position of the Hydropsychidae and Other Issues}

Ross (1967) considered the Psychomyiidae + Xiphocentronidae to be the sister group of the Hydropsychidae + (Polycentropodidae + Dipseudopsidae). Synapomorphies proposed by Ross (1967) for monophyly of the latter group were mesoprescutum in adults replaced by a pair of small round warts, and in females rodlike apodemes of segments VIII-IX shortened, and segment $X$ with lateral papillae. Weaver (1983) proposed another synapomorphy: segment IX of female "not ovoid, more stout." We interpret the condition of the mesoprescutum in Psychomyiidae to be identical to that in Hydropsychidae, Polycentropodidae, and Dipseudopsidae, and note that Ross (1967) acknowledged this difficulty. Furthermore, many other Trichoptera, including Dolophilodes (Philopotamidae), lack mesoprescutal sutures. As indicated above, we were unable to interpret the character for the shape of segment IX in females proposed by Weaver. Finally, the rodlike apodemes of segments VIII and IX (Appendix, character 67) are as short in females of Stenopsychidae and Psychomyiidae as in Ecnomidae, and are also as short or absent in Trichoptera other than Annulipalpia.

Ross (1967) considered the Polycentropodidae (including Ecnomidae) and Dipseudopsidae to be sister groups because the inferior appendages are one-segmented; in Hydropsychidae these are two-segmented. Weaver (1983) proposed that the Dipseudopsidae are the sister group of the Ecnomidae + (Hydropsychidae + Polycentropodidae), and considered the latter group to be monophyletic because female sternum VIII is divided mesally, forming a pair of ventrolateral lobes. However, in some Hydropsychidae (e.g., Hydropsyche) segment VIII is not more incised than in certain Rhyacophilidae, Hydrobiosidae, and Hydroptilidac, so there is at least some homoplasy for this trait within Trichoptera. Moreover, there is stronger evidence that the Hydropsychidae are the sister group of the rest of the Hydropsychoidea (see below). Weaver (1983) considered Hydropsychidae and Polycentropodidae to be sister groups because in adults the second segment of the maxillary palp has a setose mesal lobe, but most Hydropsychidae do not have such a lobe, while Phylocentropus (Dipseudopsidae) has a trace of one.

In contrast to Ross (1967) and Weaver $(1983,1984)$, Schmid (1989) considered the Hydropsychidae to be the sister group of all the other Hydropsychoidea. Our results for the combined larval + adult data are consistent with Schmid's placement of this family. Unequivocal evidence for monophyly of a group composed of the Psychomyiidae, Xiphocentronidae, Ecnomidae, Dipseudopsidae, and Polycentropodidae is the approximate hind angles of the pronotum (Appendix, character 18b), and dorsal sclerotization of the prelabio-hypopharyngeal lobe (7b). Moreover, except for Ecnomidae the labial palps are appressed to the lobe (8b), and except for some Polycentropodidae (e.g., Polycentropus) the lobe is tapered to a point (6b).

Relationships within the group comprising the Psychomyiidae, Xiphocentronidae, Ecnomidae, Dipseudopsidae, and Polycentropodidae are unclear. In our parsimony analyses of the larval + adult data, the Ecnomidae, Dipseudopsidae, and Polycentropodidae were grouped together, and the Xiphocentronidae and Psychomyiidae were variously arranged outside of this group. Schmid (1989, fig. 33) presented a very different arrangement of these families. The Ecnomidae, Dipseudo-psidae, and Polycentropodidae were always grouped together in our parsimony analyses because in larvae segment $\mathrm{IX}$ is partly divided and incorporated into the anal prolegs (Appendix, character 38c), in adults the mesoscutellum is elevated (59b), in the adult female segment $X$ has lateral papillae (68b), and as noted above the male inferior appendages are one-segmented (70b). All of these characters present difficulties. Abdominal segment IX is divided to about the same extent in larvae of Stenopsychidae and Dolophilodes (Philopotamidae); the mesoscutellum is also elevated in adults of Hydroptilinae; females of Dolophilodes major (Philopotamidae) have lateral papillae; and reduction in the number of segments of the male inferior appendages has occurred many times in Trichoptera.

Another consistent result in our analyses was that the Dipseudopsidae and Polycentropodidae were always treated as sister groups because the apical and basal piece of the trochanter is closed on all legs (Appendix, character 
29c). However, in larvae of Ecnomidae and Polycentropodidae the abdominal segments each have a large patch of setae laterally (36b); in Dipseudopsidae there is a fringe of simple lateral filaments in this location. This is evidence that the Ecnomidae are more closely related to Polycentropodidae than to Dipseudopsidae. Clearly, better data are needed to establish the relationships between these families.

To summarize, our analyses of the morphological data provide unqualified support for monophyly of AnnulipaIpia (s.s.) and Philopotamoidea, and more limited support for monophyly of Hydropsychoidea. Our results also clearly indicate that the Hydropsychidae are the sister group of the rest of the Hydropsychoidea.

\section{ISSUES ABOUT INTEGRIPALPIA}

Our results provide strong support for monophyly of the Integripalpia and Plenitentoria, but lead us to question whether the Brevitentoria and Leptoceroidea are monophyletic groups. Evidence in larvae for monophyly of Integripalpia is absence of a large basiconic sensillum at the apex of the antenna (Appendix, character 4c), and presence of a lateral fringe and/or forked lamellae along the sides of one or more abdominal segments (36Ca). A synapomorphy in adults is the structure and orientation of the pectinate microtrichia that form the walls of the channels on the haustellum (47b). In females there is the absence of the abdominal cerci (66b), and absence of the rodlike apodemes of abdominal segments VIII and IX (67e). However, according to Ross (1967) some genera have vestiges of these apodemes; moreover, they are also more or less completely absent in Hydrobiosidae, Protoptila (Glossosomatidae), and several families of Annulipalpia.

Weaver (1983, 1984) proposed some additional synapomorphies for Integripalpia from the females: abdominal segment $\mathrm{X}$ with pair of dorsolateral appendages; apex of abdomen blunt; segments X and XI reduced; vulva and rectum with separate openings. We found reason to question Weaver's interpretation of each of these characters (see section on morphology).

\section{Evaluation of the Basal Dichotomy in Integripalpia}

Ross (1967) considered the Integripalpia to be composed of two groups: the limnephilid and leptocerid branches. Weaver $(1983,1984)$ referred to them as the Plenitentoria and Brevitentoria, respectively.

Ross (1967) proposed the following synapomorphies in support of monophyly of the Plenitentoria: in larvae, presence of a prosternal horn, and pronotum with a preapical crease (= sulcus); and in adults, labrum elongate and set off basally by a narrower piece, mandibles reduced, and front wing of male with vein M4 lost. All of these characters present problems. A minor difficulty is that some genera of Brachycentridae and Uenoidae do not have a prosternal horn (see section on morphology); undoubtedly the horn has been lost in these taxa. A more serious difficulty is that the position and form of the pronotal preapical sulcus in some taxa that Ross placed in Plenitentoria, e.g., Neophylax and Neothremma (Uenoidae), is identical with some that he placed in the Brevitentoria, e.g., Molannidae, Kokiriidae, Philorheithridae, and Triaenodes (Leptoceridae). The Limnocentropodidae, Phryganeidae, Phryganopsychidae, and Brachycentridae, all placed by Ross in Plenitentoria, are much like Mystacides (Leptoceridae) for this character. We conclude, as did Flint (1981) and Scott (1993), that the position of the preapical sulcus of the pronotum does not always distinguish members of the Brevitentoria and Plenitentoria. Similarly, the form of the adult labrum does not appear to separate all taxa placed by Ross (1967) in the Plenitentoria from those included in Brevitentoria; moreover, we were unable to score the character with consistency. The adult mandibles are reduced to the same extent in some taxa that Ross placed in the Brevitentoria, i.e., Molanna, Heteroplectron, and Alloecella, as in taxa belonging to the Plenitentoria. Finally, males of most families in both groups lack forewing vein M4.

Presence of Gilson's gland in larvae (Appendix, character $68 \mathrm{c}$ ) is another synapomorphy for Plenitentoria; but this could be the plesiomorphic condition of the character. Moreover, this gland is also found in the Tasimiidae, which may or may not belong to Plenitentoria (see below). The lateral position of seta 7 of the larval anal prolegs (40b) also distinguishes all families that both Ross and Weaver included in the Plenitentoria. However, the Tasimiidae and Kokiriidae also have this condition, and the latter family was never included in the Plenitentoria in our analyses of the morphological data (see below), although Ross (1967) and Neboiss (1987) did place it there, unlike Weaver $(1983,1984)$ who placed it in Brevitentoria as a synonym of Plectrotarsidae. Based on the presence of Gilson's gland and the prosternal horn, and the position of seta 7 of the anal prolegs, the Plectrotarsidae were always placed in our analyses in the Plenitentoria; in this respect our results agree with those of Ross (1967) and Neboiss (1987), but not of Weaver (1983, 1984).

Ross (1967) listed two characters of adults as evidence for monophyly of the Brevitentoria: ocelli absent and supratentorium incompletely formed. Weaver (1983. 1984) added one larval character: spicules (= forked lamellae) absent on all larval abdominal segments except VIII. Weaver $(1983,1984)$ also tentatively proposed a behavioural character for the adult female: ability to carry the egg mass in flight. All of this evidence for monophyly is equivocal. The ocelli are absent in adults of various Trichoptera, including some undoubted members of the 
Plenitentoria; the same is true for the incomplete condition of the dorsal arms of the tentorium. Thus, neither piece of evidence is compelling. Forked lamellae are found on sev-

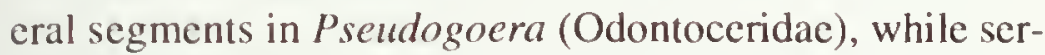
rate lamellae are present on several segments in Beraea (Beracidae), Gumaga (Sericostomatidae), and Helicopsyche (Helicopyschidae). If the presence of forked lamellae on several segments is plesiomorphic, and serrate lamellac are derived from forked lamellae, then confinement of these lamellae to segment VIII has occurred several times in Brevitentoria. However, it cannot be ruled out a priori that confinement of the lamellae to segment VIII is the plesiomorphic condition. Finally, to our knowledge, oviposition behaviour is known for too few families to support retention of the egg mass in flight as a synapomorphy for the Brevitentoria.

Lack of a unique synapomorphy for the Brevitentoria is reflected in the results of our analyses. The families that Ross (1967) and Weaver $(1983,1984)$ both placed in this group were separated as several separate lineages along with the Plenitentoria in a more or less unresolved polytomy (Figs. 24-27). The largest group belonging to the Brevitentoria that consistently emerged in our analyses comprises Helicophidae, Anomalopsychidae, Beraeidae, Calocidae, Sericostomatidae, and Helicopsychidae. These families were grouped together because in larvae the pronotum is lightly tanned posteriorly (Appendix, character 17b), and in all except Helicophidae tergum IX is membranous and has one pair of long setae (34c). The order in which these taxa were separated differed markedly in parsimony and compatibility analyses (cf. Figs. 24-27). The Beraeidae, Sericostomatidae, and Helicopsychidae were grouped together in compatibility analyses because the larvae have serrate lamellae laterally on the abdomen (36d). Weaver $(1983,1984)$ placed all six families (plus Chathamiidae and Conoesucidae, which we did not examine) in the Sericostomatoidea, noting that adults of these families are characterized by absence on the middle leg of preapical spurs, so that the tarsal formula is 2, 2, 4 .

The remaining families of Brevitentoria (i.e., Limnocentropodidae, Kokiriidae, Philorheithridae, Odontoceridae, Calamoceratidae, Molannidae, and Leptoceridae) were placed by Weaver $(1983,1984)$ in the Leptoceroidea, based upon two putative synapomorphies: predatory larvae, and adults with long narrow forewings. However, larvae of Calamoceratidae are phytophagous (Weaver, 1984), while the majority of South African Leptoceridae are phytophagous or polyphagous (Scott, 1993). As for the forewings being narrow, they are as broad in Limnocentropodidae (Kimmins, 1950, fig. 1) and Calamoceratidae (Schmid, 1980, fig. 730) as in various Sericostomatoidea (e.g., Helicopsychidae, Schmid, 1980, fig. 642).

The Kokiriidae and Molannidae were always grouped together in our numerical analyses because in larvae there are numerous setae on the postlabium (Appendix, character $9 \mathrm{~b}$ ), and on the frontoclypeus seta 1 is straight and dark in colour (10b). Together they were often grouped with Atriplectides (Odontoceridae) because the distal as well as the proximal part of the metatrochanter is closed on all legs (29e); but they were sometimes grouped with the Leptoceridae and Sericostomatoidea because the venter of the head is lightly tanned posteriorly (13b). The Limnocentropodidae, Philorheithridae, Calamoceratidae, Psilotreta + Pseudogoera (Odontoceridae), and Leptoceridae were each variously placed in our analyses (Figs. 24-27).

The position of the Limnocentropodidae is especially problematic. Ross (1967) placed this family at the base of the limnephilid branch (= Plenitentoria) but noted that except for absence of forewing vein M4, it does not have any of the derived traits that characterize the limnephilid branch. Weaver $(1983,1984)$ positioned this family at the base of the Leptoceroidea (Brevitentoria). In our parsimony analyses the Limnocentropodidae were treated as the sister group of all other Integripalpia, the evidence being that in larvae of most Integripalpia the trochanter of at least the middle and hind legs is long (Appendix, character 28b), and there is a dorsal hump as well as lateral humps on abdominal segment I (35c), while in adults ocelli are absent (48b) and the tentorium is $\mathrm{U}$-shaped (5lb). However, this evidence is equivocal because while the Limnocentropodidae have the primitive condition of each of these characters, so do some other families of Integripalpia, i.e., Tasimiidae, Kokiriidae, Atriplectides (Odontoceridae), Molannidae (28a); Phryganopyschidae, Lepidostomatidae, Anomalopyschidae (38b), and Brachycentridae (38a); Anomalopsychidae and most Plenitentoria (48a); various Brevitentoria (5la). Other possible evidence is that larvae of all Integripalpia other than Limnocentropodidae have the posterior apodeme of the pronotum; otherwise this apodeme is only present in Hydropsychidae. Finally, the terminalia in females of Limnocentropodidae are among the least modified of all Integripalpia. For example, sternum VIII is entirely separated from sternum IX, while tergum IX is partly separated from tergum $X$; this condition is otherwise found in Integripalpia only in Phryganopsychidae (Wiggins and Gall, 1993). Location of the gonopore is also primitive for Limnocentropodidae relative to all other Integripalpia except perhaps Molannidae.

Another family that is difficult to place is the Tasimiidae. Weaver $(1983,1984)$ included this family in the Brevitentoria, but could not determine whether it has closer affinities to the Leptoceroidea or to the Sericostomatoidea. In some of our analyses this family was grouped with the Plenitentoria (Figs. 24, 26) because of the presence of Gilson's gland in larvae (character 19b), 
but this could be the plesiomorphic condition of the character. Another derived trait that the Tasimiidae and all families of Plenitentoria share is the position of seta 7 of the anal prolegs (Appendix, character 40b), but the Kokiriidae also exhibit this condition. In other analyses the Tasimiidae were grouped with the Limnocentropodidae and the rest of the Integripalpia in an unresolved trichotomy (Fig. 27) because, among families of Integripalpia, only in larvae of the Tasimiidae and Limnocentropodidae is the trochanter short on all three pairs of legs (28a). In still other analyses, the Tasimiidae and Atriplectides (Odontoceridae) were grouped (Fig. 25), but only on the basis of homoplasious characters.

\section{Relationships among Families of Plenitentoria}

A consistent result in parsimony analyses for the Plenitentoria was that the Phryganopsychidae were separated first, followed by a group composed of the Phryganeidae and Plectrotarsidae. None of these groupings are supported by a character that is uniquely derived, hence this arrangement did not emerge in compatibility analyses. A detailed investigation of relationships among families of the Plenitentoria is under way (Gall and Wiggins, in press), and so we do not discuss further our results for this group.

To summarize, monophyly of both the Integripalpia and the Plenitentoria is well supported, but convincing morphological evidence for monophyly of the Brevitentoria is lacking. The Sericostomatoidea emerge as a monophyletic group; but relationships of the other families of Brevitentoria are uncertain. There are indications that the Phryganopsychidae, Plectrotarsidae, and Phryganeidae are the most primitive families of Plenitentoria.

\section{Conclusions about Phylogeny of Trichoptera Based upon Morphology}

Based on analyses of characters of larvae and adults and evaluation of previously proposed arrangements of Trichoptera, the Annulpalpia (s.s.) and Integripalpia (s.s.) emerge as robust groups at the subordinal level. All morphological evidence for arrangements previously proposed for the Hydroptilidae, Glossosomatidae, Rhyacophilidae, and Hydrobiosidae is equivocal, except for possible relationship of these families to Integripalpia based upon presence in larvae of a sclerous shield on tergum IX (Ross, 1967). In contrast, one larval antennal character provides unequivocal evidence for monophyly of a group composed of the Glossosomatidae, Rhyacophilidae, Hydrobiosidae, and Annulipalpia, and another for monophyly of Rhyacophilidae + Hydrobiosidae. The Hydroptilidae consistently emerge as the sister group of the Integripalpia in our analyses, but the morphological traits linking the two groups are not convincing. Within Annulipalpia, there is morphological evidence for monophyly of the Philopotamoidea and Hydropsychoidea, and evidence that the Hydropsychidae are the sister group of the rest of the Hydropsychoidea. Within Integripalpia, the Plenitentoria emerge as a robust group; otherwise only the Sericostomatoidea do so. Remarkably few groupings above the family level in Trichoptera are supported by even one uniquely derived morphological character. Moreover, many morphological characters in Trichoptera are poorly understood. Given this situation, the plethora of alternative classifications for Trichoptera is not surprising. In the next section we examine larval construction behaviour to try to gain further insight into the higher classification of Trichoptera.

\section{Evolution of Larval Construction Behaviour and the Phylogeny of Trichoptera}

The evolutionary diversification of Trichoptera has proceeded through exploitation by the larvae of resources of space, food, and dissolved oxygen in aquatic habitats. These resources have been subdivided by Trichoptera mainly through changes in larval behaviour involving the use of silk for construction of retreats, filter nets, and portable cases, allowing larvae to exploit similar resources in different ways (Mackay and Wiggins, 1979). In contrast, subdivision of resources by the largely terrestrial sister order Lepidoptera has taken place to a far greater extent by specialization on different food plants, mediated by plant chemistry with much less emphasis on different ways of using silk.
Two themes of construction behaviour by larvae of Trichoptera are evident (Fig. 28): behaviour of growing larvae and activities of larvae in preparation for pupation. Pupation behaviour has two aspects: spinning of the pupal cocoon and construction of the pupal shelter.

\section{Behaviour during Larval Growth}

Among Trichoptera, larvae of Rhyacophilidae, Hydrobiosidae, and the first four instars of Hydroptilidae are freeliving and construct neither cases nor retreats. Larvae of Hydroptilidae construct either a portable case or a fixed retreat at the beginning of the last instar. Larvae of Annulipalpia, beginning with the first instar, construct a 
fixed retreat; Glossosomatidae and Integripalpia construct a portable case.

Larvae of Rhyacophilidae lay down a silken guy-line as they move about (Ross, 1964), as do larvae of Lepidoptera. According to Nielsen (1948:143-144, 163), in Hydroptilidae only the last instar spins a guy-line. Larvac of Micrasema wataga (Integripalpia: Brachycentridae) are reported to use a guy-line (Chapin, 1978:14); whether other Integripalpia, Hydrobiosidac, Glossosomatidac, or Annulipalpia do so is not known.

Larvae of Micropterigidae, the most primitive family of Lepidoptera (Kristensen, 1984a; Nielsen, 1989), are "secretive, preferring to burrow through thick mats of mosses and lichens or leaf litter" (Davis, 1987a). As far as is known, other non-glossatan Lepidoptera are seed or leaf miners, and the most primitive Glossata are also leaf miners, "while exoporian larvac are . . litter feeding soil animals [the larger forms often root or stem borers, or external feeders, in later instars]" (Kristensen, 1990). Among Nearctic Mecoptera, larvac of Panorpidae and Bittacidae range freely in the leaf-litter layer and on the soil surface, Panorpodidae live in soil closely associated with roots of herbaceous plants, and Borcidae are found mostly in earthen cells among rhizoids of terrestrial mosses (Bycrs, 1987). Larvac of the family Nannochoristidae from New Zcaland live in silt at the bottom of pools and slow-moving sections of streams (Pilgrim, 1972).

The evidence from larvae of Micropterigidae and most Mecoptera indicates that although the ancestral Amphiesmenopteran larva would have lived in litter, it moved about freely; similar behaviour can thus be attributed to the ancestral Trichopteran larva. Use of silk (if any) by the growing larva would have been restricted to laying down a silken guy-line. According to Kristensen (1990), the "habits of the hygropetric larvae of the Hydroptilidae-Ptilocolepinae are strikingly similar to those inferred to be ancestral of the Amphiesmenoptera."

Ross (1967) suggested that caddisfly larvae were originally retreat makers, constructing a tube net of silk as do extant Philopotamidac, on the basis of an earlier comparison (Ross, 1964) of cocoon-making behaviour in the silk-worm caterpillars of Saturniidae and the Philopotamidae. However, because the Saturniidae are a relatively derived family of Lepidoptera, that comparison reveals lit-

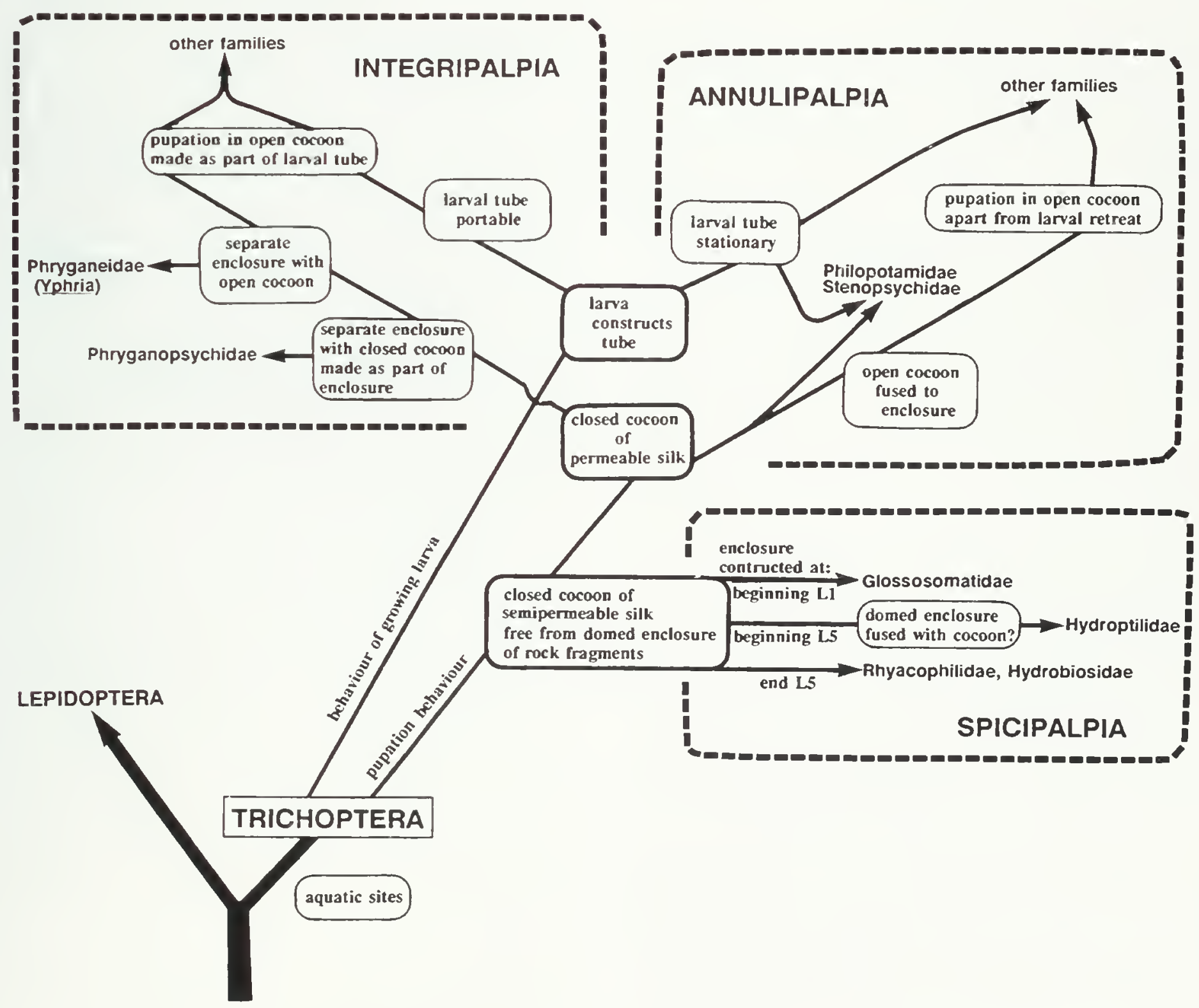

Fig. 28. Diagram showing evolution of some aspects of larval construction behaviour in Trichoptera. 
tle about shared ancestral behaviour of Lepidoptera and Trichoptera.

Weaver $(1983,1984)$ and Weaver and Morse (1986) proposed that larvae of the ancestral Trichopteran lived in sili-lined burrows in water-saturated detritus at the edge of cool slow-moving streams. However, there is no evidence that larvae of the most primitive extant family of Lepidoptera, the Micropterigidae, actually construct or continually use a burrow or any other kind of retreat, or that they can move through litter or soil sufficiently compact that anything more is required than pushing obstructions aside; and larvae of at least some species of Micropterigidae range freely to reach the above-ground parts of the liverworts and mosses upon which they feed. Nor is there evidence that larvae of Micropterigidae or other primitive Lepidoptera use silk except for pupation. Growing larvae of Mecoptera are not known to use silk (Kaltenbach, 1978, cited in Russell, 1982).

Bohle and Fischer (1983) presented evidence that the portable domed larval case of Glossosomatidae can be derived from the domed pupal shelter of Rhyacophilidae. We infer that among Hydroptilidae, the portable domed case of some Ochrotrichia (Wiggins, 1977, fig. 7.9C; also cover illustration), and the stationary domed retreat of the Leucotrichiini (e.g., Wiggins, 1977, fig. 7.6B) represent one valve of the bivalved case constructed by larvae of most gencra. The portable tubular case made by Mayatrichia (Wiggins, 1977, fig. 7.7B) can also be derived from the bivalved case. We conclude that for all families of the Spicipalpia, larval construction is solely pupation behaviour (Fig. 28), either at the close of the final instar (Rhyacophilidae, Hydrobiosidae), which is the plesiomorphic condition, or precociously through an advance in the time of onset to the beginning of the final instar (Hydroptilidae) or the beginning of the first instar (Glossosomatidae). Moreover, the underlying behaviour is not the construction of a tube, but rather of a dome.

Construction of a silken tube at the beginning of the first instar, reinforced with various gathered materials, appears to be the fundamental behaviour common to Annulpalpia where the tube is stationary, and to Integripalpia where the tube is portable (Fig. 28). Because construction of a tube at the beginning of the first instar is not known to occur in the most primitive Lepidoptera, and because larvae of Spicipalpia build domes but not tubes, we interpret tube-making by Trichoptera as apomorphic behaviour and as a trait shared by the Annulipalpia and Integripalpia. Moreover, we consider construction of a fixed tube by larvae of Annulipalpia to be plesiomorphic as opposed to construction of a portable tube by Integripalpia because the former construct a domed pupal shelter, another plesiomorphic behaviour (see below).

\section{Cocoon Construction}

Larvae of Rhyacophilidae, Hydrobiosidae, and Glossosomatidae, and of Leucotrichiini and Alisotrichia (Hydroptilidae), construct a closed cocoon of parchmentlike silk for pupation, entirely or largely free from the pupal shelter (Fig. 28). The cocoon of most genera of Hydroptilidae, including Palaeagapetus, appears to be incorporated with the silken lining of the larval case, and the larval case with the openings entirely sealed functions as a pupal cocoon.

Among Annulipalpia (Fig. 28), closed cocoons separate from the rock-fragment pupal shelter are constructed by some Philopotamidae (Dolophilodes), but they are flimsy and the spaces between the rock fragments of the enclosure are restricted with silken meshes (Wiggins and Wichard, 1989, figs. 13, 15). A closed cocoon is also constructed by Parecnomina (Ecnomidae) (Wiggins and Wichard, 1989). In other Annulipalpia, the walls of the cocoon are fused entirely with the silk lining of the pupal shelter, the interstices between the rock fragments are closed, and water circulates through the enclosure mainly by means of the anterior and posterior perforations (Wiggins and Wichard, 1989, figs. 3-6). Among the Integripalpia, a closed cocoon made as part of the pupal case is known only in the Asian family Phryganopsychidae (Fig. 28).

Based upon outgroup comparison with Micropterigidae, other primitive Lepidoptera, and Hymenoptera, Wiggins and Wichard (1989) concluded that construction of a closed parchmentlike cocoon by larvae of Spicipalpia is plesiomorphic for Trichoptera. Additional evidence is that the cocoon of Caurinus dectes Russell (Mecoptera: Boreidae), the only Mecopteran that is known to spin a cocoon, is also closed and parchmentlike (Russell, 1982). A qualification about the cocoon of Micropteryx calthella (Micropterigidae) is that "in the head end a hole remains open, only slightly spun and not with an external covering of soil particles on the outer side. This is the emergence hole of the future adult" (Lorenz, 1961:19, translated by N. P. Kristensen).

A related issue concerns the mechanism of osmotic regulation by pupae of Trichoptera. The closed parchmentlike cocoon of Rhyacophilidae is osmotically semipermeable (Wiggins and Wichard, 1989; Wichard, Schmidt, and Wagner, 1993). Wiggins and Wichard (1989) inferred that the cocoons of Hydrobiosidae, Glossosomatidae, and Hydroptilidae are also semipermeable because, as in Rhyacophildae, these cocoons are turgid in life (for Hydroptilidae see also Nielsen, 1948:170). They also inferred that the closed cocoon constructed by larvae of Dolophilodes (Philopotamidae) is permeable to all ions because it is flimsy and never turgid. The loose structure of the cocoon in the Phryganopsychidae suggests that it is also fully permeable.

Wiggins and Wichard (1989) and Wichard (1991) 
drew attention to the problem of osmotic regulation by insects in water which had to be solved before the larval and pupal stages could become aquatic. In the larval stage, osmoregulation is achicved by the abdominal chloride epithelia or anal papillae (see section on morphology). The mechanism of osmotic regulation in pupae of Annulipalpia and Integripalpia is unknown, but these authors proposed that in Spicipalpia the closed, osmotically semipermeable cocoon fulfills this function, and that this was the initial adaptation for achieving osmotic regulation that enabled the pupal stage of Trichoptera to become aquatic. This innovation forced the pupa to depend upon diffusion for respiration, which initially restricted larvae of Trichoptera to cool running waters where oxygen levels are relatively high, until the osmotic problem of the pupal stage in Integripalpia and Annulipalpia was solved by other means which are not yet understood. This made possible the appearance of permeable, open cocoons, and the subsequent spread of Integripalpia and Annulipalpia into lentic waters, since water could flow directly over the pupa, allowing for more efficient respiration.

The osmotic properties of the terrestrial cocoon of Micropterigidae are unknown; nor is there experimental evidence that respiration of caddis pupae in closed semipermeable cocoons is less efficient than in an open permeable one (Weaver, 1992a). However, there is theoretical evidence provided by Krogh's diffusion equation, and there is the fact that nearly all Trichoptera with closed semipermeable cocoons (i.e., Spicipalpia) are restricted to cool running waters (Wiggins and Wichard, 1989; Wichard, 1991). The few exceptions are some apomorphic genera of Hydroptilidae (Wiggins and Wichard, 1989).

There are four possibilities: either the micropterigid cocoon is semipermeable and there is (1) or is not (2) a respiratory advantage in water to having a permeable cocoon, or the micropterigid cocoon is permeable and there is (3) or is not (4) a respiratory advantage to having a permeable cocoon in water. From either of the first two possibilities the conclusion would be that a semipermeable cocoon is plesiomorphic for Trichoptera. The conclusion from the third possibility would be that the semipermeable cocoon is an innovation for Trichoptera and thus a synapomorphy for the order, unless an advantage to having this type of cocoon is discovered that outweighs any respiratory disadvantage; then one could conclude from the third possibility that the semipermeable cocoon is a synapomorphy for Spicipalpia. The conclusion from the fourth possibility would be that a semipermeable cocoon is a synapomorphy for Spicipalpia. If so, it would be necessary also to postulate that the ancestral Trichopteran had a closed parchmentlike cocoon that was permeable. No extant caddisfly has a pupal cocoon with this combination of traits; nor is there any evidence for an advantage of a closed permeable cocoon over an open one in Trichoptera.
We concur with the interpretation that all available evidence indicates that the closed parchmentlike cocoon of the ancestral Trichopteran was semipermeable (Wiggins and Wichard, 1989; Wichard, 1991).

From intermediate stages represented by the philopotamid genera Wormaldia and Chimarra and the Stenopsychidae, Wiggins and Wichard (1989) inferred that through changes in construction behaviour of the larvae, the ends of the closed permeable cocoon of Dolophilodes became perforate and fused to the ends of the pupal enclosure, admitting water into the cocoon to bathe the pupa directly. Thus, these three genera of Philopotamidae reveal a series of behavioural stages whereby closed permeable cocoons free from the pupal enclosure of rock fragments (Dolophilodes) became open cocoons fused to the ends of the enclosure (Chimarra). Independent support that Dolophilodes exhibits the plesiomorphic behaviour comes from phylogenetic analysis of the philopotamid genera based on morphology by Ross (1956).

\section{Construction of a Pupal Shelter}

The cocoons of Rhyacophilidae, Hydrobiosidae, Glossosomatidae, and virtually all Annulipalpia are constructed within a dome of rock fragments held together by silk (Wiggins and Wichard, 1989). Larvae of Dipseudopsidae are a specialized exception, constructing a discrete, flimsy pupal cocoon within the subterranean dwelling tube (Wallace, Woodall, and Stats, 1976). Pupation in most genera of Hydroptilidae takes place in the closed larval case (actually a precocious pupal case, as noted above).

In Rhyacophilidae, Hydrobiosidae, and Glossosomatidae, some of the spaces between the rock fragments of the pupal shelter are entirely open. Among Annulipalpia (Fig. 28), in Philopotamidae the spaces between the rock fragments of the shelter are restricted with silken meshes (Wiggins and Wichard, 1989, figs. 13, 15). in other Annulipalpia, the interstices between the fragments are closed.

Among Integripalpia, larvae of Phryganopsychidae and the genus Yphria (Phryganeidae: Yphriinae) build a new and different case for pupation (Fig. 28; Wiggins and Wichard, 1989, fig. 2). Larvae of other Integripalpia close off both ends of the case with perforate silk membranes, add some silk to the interior lining of the case, and then pupate. Flow of water through this pupal cell is regulated by the abdominal undulations of the pupa.

Larvae of primitive Lepidoptera spin their cocoon either in an earthen cell or on the food plant, or in the larval mine. As far as is known, larvae of Mecoptera do not do any more than this before pupating (Russell, 1982). Thus, construction of a pupal shelter out of rock fragments or other material is apomorphic for Trichoptera. We consider construction of an open dome of rock fragments held together by silk to be the ancestral condition of this beha- 
vioural trait in Trichoptera because all families that exhibit this behaviour are also the ones that have free-living larvae (or at most use a precocious pupal case), and construct a closed semipermeable parchmentlike cocoon (Fig. 28). These behaviours are confined to Spicipalpia, and, as shown above, are plesiomorphic for Trichoptera.

We regard use of the larval case for pupation by most Integripalpia to be apomorphic relative to the behaviour of Phryganopsychidae and Yphria (Phryganeidae). We interpret this behaviour as a more efficient use of silk and of the requisite nutrients and energy, than is pupation in Annulipalpia where the investment made by the larva in constructing a retreat is abandoned at pupation.

\section{Behavioural Groundplan for Trichoptera}

Based on the above analysis, we recognize three behavioural traits as ancestral for Trichoptera.

1.) Larva free-living, constructs no fixed retreat or portable case; larval construction confined to making a shelter for the cocoon at close of final instar.

2.) For pupation, mature larva constructs closed cocoon of parchmentlike silk that is osmotically semipermeable (Wiggins and Wichard, 1989; Wichard, 1991).

3.) Pupal cocoon spun in a domed shelter of rock fragments, free from cocoon wall, shelter open-i.e., spaces between rock fragments free of silk, enabling water to flow through.

From this behavioural groundplan, and our inferences about subsequent changes in behaviour outlined above and in Fig. 28, we propose behavioural character transformation series for larval case construction (Table 2, character 1), and for the nature of the pupal cocoon (character 2) and construction of the pupal shelter (character 3 ).

\section{Cladistic Analysis of the Behavioural Data}

Parsimony and compatibility analyses of the behavioural data yielded just one arrangement (Fig. 29). In this arrangement the Annulipalpia and Integripalpia are treated as sister groups. Relationships of the Rhyacophilidae, Hydrobiosidae, and Glossosomatidae + Hydroptilidae are unresolved because a behavioural synapomorphy for Spicipalpia is lacking.

\section{Evaluation of Results Based upon Morphology and Behaviour}

When the behavioural data are analysed together with the data on larval and adult morphology using parsimony and compatibility methods, the results are about the same as when the morphological data are analysed alone. If one of

TABLE 2. Characters of larval construction behaviour, and their distribution in Trichoptera.

\section{character 1}

a larva free-living

Rhyacophilidae,

Hydrobiosidae

b larva constructs precocious pupal shelter

Glossosomatidae, Hydroptilidae

$\mathrm{Ca}$ larva constructs stationary tube Annulipalpia

d larva constructs portable tube Integripalpia

\section{character 2}

a cocoon closed, parchmentlike, semipermeable

Rhyacophilidae Hydrobiosidae, Glossosomatidae, Hydroptilidae cocoon closed, flimsy, permeable

Dolophilodes (Philopotamidae), Parecnomina (Ecnomidae), Phryganopsychidae

c cocoon open, incorporated into wall of pupal shelter

remaining

Annulipalpia, Integripalpia

character 3

a cocoon free of pupal shelter, pupal shelter dome-shaped, gaps between stones of pupal shelter entirely open

b cocoon free of pupal shelter or just fused at ends, pupal shelter dome-shaped, gaps between stones of pupal sheiter restricted with silk mesh

c cocoon fused to pupal shelter, pupal shelter dome-shaped, gaps between stones of pupal shelter closed

Da cocoon free of pupal shelter, pupal shelter dome-shaped, or coconn fused to pupal shelter. pupal shelter consisting of two appressed domes, fastened at base; shelter entirely sealed

Ea cocoon fused to pupal shelter, pupal shelter tube-shaped

f pupation in larval tube, cocoon fused to tube
Rhyacophilidae, Hydrobiosidae, Glossosomatidae

Philopotamidae, Stenopsychidae remaining Annulipalpia

Leucotrichiini and other Hydroptilidae, respectively

Phryganopsychidae, Yphriinae (Phryganeidae)

remaining lntegripalpia 


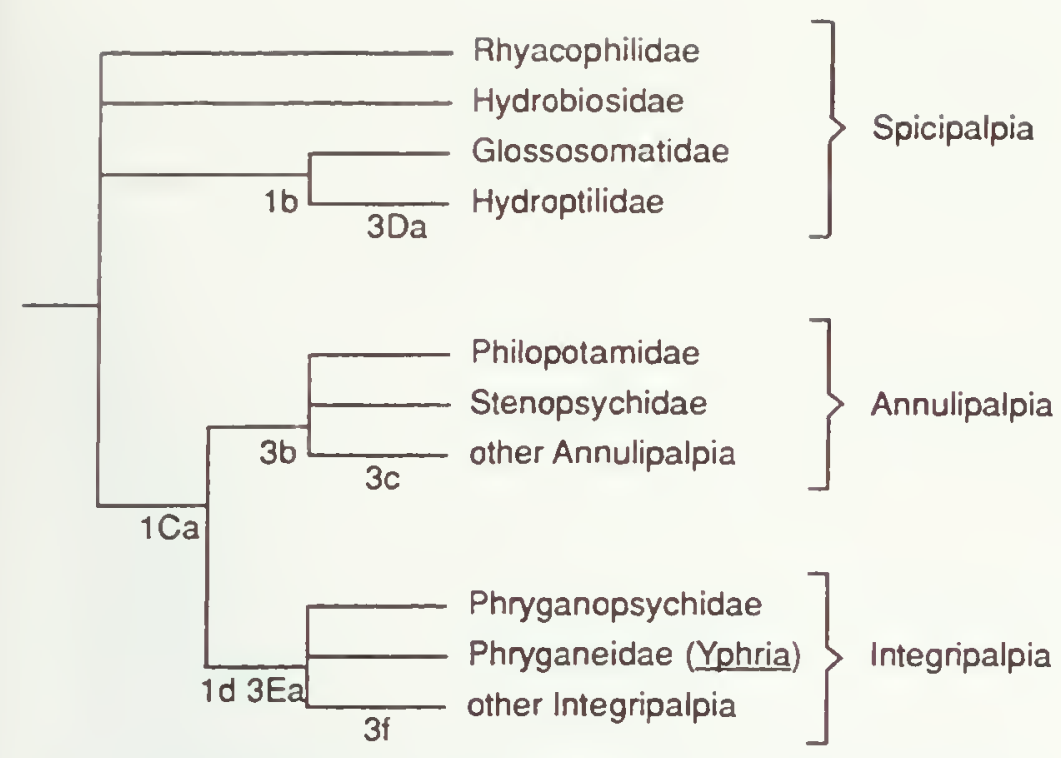

FIG. 29. Minimum-length tree obtained using the HENNIG86 computer program on a data set for characters of larval construction behaviour, showing all character states that are uniquely derived.

the minimum-length trees obtained using the morphological data (e.g., Fig. 24) is modified by moving the Annulipalpia, Rhyacophilidae, Hydrobiosidae, Glossosomatidae, and Hydroptilidae to positions consistent with the behavioural data alone, i. e., the Rhyacophilidac + Hydrobiosidae together with the Glossosomatidae + Hydroptilidae are the sister group of the Annulipalpia + Integripalpia, the result is an additional eight instances of homoplasy. Moving the Phryganopsychidae and Yphriinae (Phryganeidae) to a basal position in Integripalpia on the minimum-length tree increases the length of the tree by another 15 steps. Moreover, we do not know of a morphological character that can be interpreted as a synapomorphy for Annulipalpia + Integripalpia. This shows that the morphological data do not provide support for the arrangement based on behavioural data. However, the relationships between the families of Spicipalpia indicated by the morphological data, with some significant exceptions (i.e., relationship of the Hydrobiosidae to the Rlyyacophilidae, and relationship of these two families and the Glossosomatidae to the Annulipalpia, or relationship of all the families of Spicipalpia to Integripalpia), are largely or entirely supported by characters that are homoplasious or for which the polarity is questionable; moreover, different kinds of numerical analyses give different results. Hence, the results of the numerical analyses for families of the Spicipalpia based on morphological data are themselves not conclusive.

Despite these problems, the morphological and behavioural data both show that the Spicipalpian families retain a large array of plesiomorphic morphological and behavioural traits, compared to even the most primitive families of Annulipalpia and Integripalpia.

\section{Ancestral Habitat of Trichoptera}

The Spicipalpia are restricted to cool running water, except for some apomorphic genera of Hydroptilidae that occur in lentic waters. The Annulipalpia mostly occur in running waters of all kinds, while some are found along wave-washed shorelines of lakes. The Integripalpia occur in various lotic habitats, but also in many lentic ones, including lakes, marshes, and temporary pools.

The question of the aquatic habitat in which Trichoptera first entered fresh water cannot be investigated by outgroup comparison because most Lepidoptera, including the most primitive families, are terrestrial, as are most Mecoptera. However, based on our conclusion that the ancestral Trichopteran constructed a semipermeable cocoon, it follows that cool running water was the ancestral habitat because virtually all of the Trichoptera that construct such a cocoon (i.e., the Spicipalpia) live in this habitat, and because a respiratory constraint, at least theoretically, accounts for the restriction of Trichoptera with closed semipermeable cocoons to cool running water. Secondly, if the habitats of extant Trichoptera are superimposed upon the various arrangements that we obtained using the morphological data (Figs. 23-27), in each instance it is most parsimonious to attribute running water as the ancestral habitat for Trichoptera. Additional evidence for the origin of Trichoptera in cool lotic waters is the analysis of Ross (1956), showing that habitats of the morphologically primitive genera in most families of Trichoptera are cool running waters, and that the more derived genera are characteristic of warmer lotic and lentic waters.

As already noted, Weaver and Morse (1986) proposed a scenario in which the ancestral trichopteran larvae lived in silk-lined burrows in water-saturated detritus at the edge of slow-moving streams. Their scenario was based on the phylogeny for Trichoptera proposed by Weaver (1983, 1984) and on experiments done by Hanna (1960) and Tomaszewski (1981). Weaver and Morse (1986) postulated that the ancestor of Annulipalpia modified the burrow as a stationary tube on the surface of the substrate, and that the ancestral Integripalpian evolved a portable tube case by severing the tube posteriorly; larvae of Rhyacophilidae and allies evolved later to become free-living in cool running water.

There are several difficulties with Weaver and Morse's scenario. Our analyses of data from larval and adult morphology do not support the phylogeny upon which their scenario is based. Also, the tube-building behaviour attributed by Weaver and Morse (1986) to ancestors of the Trichoptera is not shared by the most primitive family of Lepidoptera or by Mecoptera. Instead, based on outgroup comparison, we conclude above that larvae of the ancestral Trichopteran were free-living, as are larvae of most Spicipalpia; the others construct at most a precocious domed pupal shelter. Moreover, there is no evidence that closed, parchmentlike, semipermeable 
cocoons are constructed by Trichoptera larvae living in water-saturated detritus; larvae that do live in these habitats, i.e., various Integripalpia (s.s.), have open cocoons that permit water to flow directly over the pupa, which we have shown above to be a derived trait in Trichoptera.

Osmotic regulation by the terrestrial ancestors of Trichoptera in their invasion of fresh water was not considered by Weaver and Morse (1986); yet this appears to be a fundamental biological problem that had to be solved by every group of insects that now has one or more aquatic life stages (Wichard, 1991). Any hypothesis concerning the ancestral habitat of Trichoptera must address this issue and must also account for the construction of closed semipermeable cocoons by larvae of Spicipalpia.

Considering ecological diversification, it is evident that larvae of the Spicipalpian families have radiated only to a limited extent beyond cool lotic habitats in comparison to Annulipalpia and Integripalpia. Weaver (1992a) compared the total number of species in each of the three suborders as a measure of ecological success, and concluded that the Spicipalpia are as successful as the other two suborders; but in terms of diversification into different habitats, this statistic is irrelevant. The behaviour of constructing semipermable cocoons was a constraint to expansion into other habitats by Spicipalpia. The far broader range of aquatic habitats exploited by
Annulipalpia and Integripalpia can be attributed to two fundamental changes in behaviour: construction of open cocoons that permit freshly oxygenated water to flow directly over the pupa, and the building of tubes at the beginning of larval life.

The portable tube-case constructed by larvae of Integripalpia would have provided protection from predators, enabling them to forage actively for food; and it seems reasonable to infer that as they penetrated depositional areas, there would have been an increase in feeding by shredding accumulations of leaves and other coarse organic matter. By means of their fixed tubular retreats and filter nets, larvae of Annulipalpia were able to harvest the fine particulate organic material produced by Integripalpian larvae. Diversification of the Integripalpia and Annulipalpia may well have coincided with the radiation of angiosperms in the late Jurassic and Cretaceous (Wootton, 1988), as fallen leaves provided new and abundant organic substrates for the aquatic fungi and bacteria on which larvae of both suborders largely depend. There is also the intriguing possibility that exploitation of the resources of depositional areas would have placed selective advantage on increased efficiency of respiration in lentic habitats; and under these circumstances, the larva's ability to generate a current of water through the case would have been an asset.

\section{Higher Classification of Trichoptera}

The analysis of phylogenetic relationships in this study bears on several aspects of higher classification in Trichoptera.

First, additional evidence is advanced in support of the Annulipalpia (s.s.) and Integripalpia (s.s.) as highly corroborated monophyletic groups, based on an array of morphological and behavioural characters. These two suborders comprise the large majority of families in the Trichoptera.

Second, we find little evidence to support monophyly of the four remaining families: Rhyacophilidae, Hydrobiosidae, Glossosomatidae, and Hydroptilidae. There is morphological evidence that the Rhyacophilidae and Hydrobiosidae are sister groups, and for relationship of Glossosomatidae and Rhyacophilidae + Hydrobiosidae to the Annulipalpia, and of Hydroptilidae to the Integripalpia; other morphological evidence indicates relationship of all the families of Spicipalpia to Integripalpia. Behavioural data provide evidence that the Integripalpia and Annulipalpia are sister groups, as are the Glossosomatidae and Hydroptilidae. Under these circumstances, we believe the best option in classification is to treat this group of four families as a separate and coordinate suborder, Spicipal- pia, while recognizing that this does not necessarily reflect the phylogenetic affinities of these families. This same classification of three suborders was proposed previously by Wiggins and Wichard (1989).

The Spicipalpia were proposed originally as an infraorder of the Annulipalpia by Weaver $(1983,1984)$. This action was derived from proposals by Martynov (1924, $1930)$ and was largely supported by Schmid $(1980,1989)$. Weaver $(1983,1984)$ advanced six putative synapomorphic characters to support this relationship. Our study shows that none of these characters is substantive, and that not one of the 70 morphological or three behavioural characters which we use in our analysis provides support for Annulipalpia sensu Martynov-Schmid-Weaver. Therefore, we reject the phylogenetic basis for including the Spicipalpia within the Annulipalpia as proposed by Weaver $(1984,1992 \mathrm{c})$, which also underlies the behavioural scenario by Weaver and Morse (1986) and the critical commentaries by Weaver (1992a, 1992b). Our analysis provides support for Annulipalpia sensu Wiggins and Wichard (1989), i.e., excluding Spicipalpia.

Third, our analysis supports the view that the Spicipalpia, even if they might not be monophyletic, are a set of 
primitive families. In this, our findings are opposed to those of Weaver $(1983,1984)$, who concluded that the Spicipalpia were derived from ancestral tube-making Annulipalpia. Our evidence from the families of the Spicipalpia reveals plesiomorphic states in a wide range of morphological characters, although not all families necessarily exhibit the plesiomorphic condition for any particular character. Congruent with the morphological data, our analysis shows that there is independent behavioural evidence that the Spicipalpia comprise the most primitive extant families of Trichoptera (Wiggins and Wichard, 1989; Wichard, 1991). This preponderance of plesiomorphic character states in the Spicipalpia underlies the difficulty in finding even a single synapomorphy to establish monophyly of the group.

Monophyly for each of the two largest suborders is well founded, and all three groups represent unique alliances of morphological and bchavioural attributes, providing a basis for generalizing about Trichoptera at higher levels-an important role for classification. Therefore, we conclude from our study that a classification of three suborders effectively reflects present understanding of the phyletic relationships among the families of Trichoptera, and also takes into account the relative primitiveness of families of Spicipalpia. The superfamilies proposed by Ross (1967)-Rhyacophiloidea, Hydropsychoidea, and Limnephiloidea-are equivalent to these three suborders; but we concur with Weaver $(1983,1984)$ and Weaver and Morse (1986) that the category of superfamily is more effectively employed in Trichoptera at a lower hierarchic level.

Some systematists might choose to treat the Spicipalpia as families incertae sedis, or to recognize each family as a separate suborder. We believe that recognition of Spicipalpia as a suborder is more useful to the biological community as a whole for the reasons presented above. Details about the relationships of the Spicipalpian families can be examined by systematists, while the higher classification of Trichoptera remains stable for general use.

The infraorders Brevitentoria and Plenitentoria (Weaver 1983, 1984; Weaver and Morse, 1986) are retained here, although monophyly of the Brevitentoria seems doubtful. Even so, our inability to determine how the families of Brevitentoria are related to the Plenitentoria leads us to conclude that it is less disruptive to the current classification to recognize both groups for the present. For the same reason, we retain Leptoceroidea and Sericostomatoidea, even though evidence is lacking for monophyly of the former group. We refrain from proposing a classification of the families belonging to the Plenitentoria because a more intensive study of the relationships among these families has been made (Gall and Wiggins, in press).

Thus, we offer the following classification of the order Trichoptera (an asterisk denotes that representatives were not studicd in our analysis; assignment to Sericostomatoidea of certain families not examined by us is based on Scott, 1993):

Suborder Spicipalpia

Family Rhyacophilidae

Hydrobiosidae

Glossosomatidae

Hydroptilidae

Suborder Annulipalpia

Superfamily Philopotamoidea

Family Philopotamidae

Stenopsychidae

Superfamily Hydropsychoidea

Family Hydropsychidae

Ecnomidae

Psychomyiidae

Xiphocentronidae

Polycentropodidae

Dipseudopsidae

Suborder Integripalpia

Infraorder Plenitentoria

Family Brachycentridae

Goeridae

Lepidostomatidae

Limnephilidae

Oeconesidae*

Phryganeidae

Phryganopsychidae

Pisuliidae*

Plectrotarsidae

Uenoidae

Infraorder Brevitentoria

Superfamily Leptoceroidea

Family Calamoceratidae

Kokiriidae

Leptoceridae

Limnocentropodidae

Molannidae

Odontoceridae

Philorheithridae

Tasimiidae

Superfamily Sericostomatoidea

Family Anomalopsychidae

Antipodoeciidae*

Barbarochthonidae*

Beraeidae

Calocidae

Chathamiidae*

Conoesucidae*

Helicophidae

Helicopsychidae

Hydrosalpingidae*

Petrothrincidae*

Sericostomatidae 
The suborders Spicipalpia, Annulipalpia, and Integripalpia are defined below.

The Spicipalpia are closed-cocoon makers. Larvae in some families are free-living, constructing a shelter for pupation at the close of the final instar (Rhyacophilidae, Hydrobiosidae). Larvae in other families construct a pupal shelter precociously, in the first instar in the Glossosomatidae where a ventral plastron is added and the shelter becomes portable, but at the beginning of the final instar in Hydroptilidae where the shelter is fixed (e.g., Leucotrichiini) or portable as in most other hydroptilids. Pupation usually occurs within an open domelike enclosure of rock fragments, where larvae construct a closed parchmentlike cocoon that is osmotically semipermeable. The cocoon is free from the enclosure, permitting a current of water to flow through spaces between the rock fragments and over the surface of the cocoon. Respiration of the pupa is sustained by diffusion through the cocoon wall. Cocoon and enclosure are not differentiated in many genera of Hydroptilidae, but the two are distinct in the Leucotrichiini.

Eggs are deposited singly or in small groups, and, at least in some species, they lack a gelatinous covering, but the few observations on egg laying in Spicipalpia are not consistent. Some Rhyacophilidae and Hydroptilidae are said to deposit their eggs in large groups in a matrix, as in the Annulipalpia (Silfvenius, 1906), but the eggs are deposited singly or in small groups and lack the matrix in Rhyacophila kiyosumiensis (Kuranishi, 1993) and in the hydroptilid Ptilocolepus granulatus (Ito and Higler, 1993). Eggs are placed on the underside of wet leaves just above the water surface (Palaeagapetus), or in rock crevices just beneath the water surface where the female can extend her abdomen while remaining above the water. Larvae in most families occur in cool lotic waters, but some Hydroptilidae occur in warm lentic waters.
The Annulipalpia are fixed-retreat makers. Larvae construct stationary tubular retreats, in some groups with filter nets of silk; larvae are campodeiform with a prognathous head; the anal prolegs are elongate and the lateral sclerites tubular. Pupation usually occurs in a domeshaped enclosure constructed separately from the larval retreat; the cocoon is permeable and, except in some Philopotamidae, is open at each end, allowing water to circulate directly over the pupa. Adults usually have the terminal segment of the maxillary palpi annulate and flexible, although not in Paduniella (Psychomyiidae). Females enter the water for oviposition, often going to considerable depths; eggs are deposited under water in a layer and encased in a cementlike material. For the most part, larvae exploit food resources transported by lotic waters.

The Integripalpia are portable-case makers. Larvae construct tubular cases, which they carry with them as they forage; most larvae are eruciform with hypognathous heads, but some are suberuciform and tend to be prognathous (e.g., Phryganeidae, Limnocentropodidae); the first abdominal segment usually bears two or three fleshy humps; the pleural region of one or more of the next seven abdominal segments has at least a lateral fringe of slender bifid filaments, or a row of forked or serrate lamellae; the anal prolegs are short and closely appressed to segment X, and the lateral sclerites are usually broad and triangular. Pupation usually occurs within the larval case, but a new tubular pupal enclosure is constructed in Phryganopsychidae and Yphria (Phryganeidae); the cocoon is incorporated as part of the larval case and is usually open, although it is closed in the Phryganopsychidae. Adults usually have separate genital and anal openings. Eggs are enclosed within a hygroscopic gelatinous matrix of spumalin and are deposited either above or beneath the water surface; females of some groups crawl beneath the surface to deposit eggs. Larvae live in lotic or lentic waters. 


\section{Acknowledgements}

This study was carried out using the collections and other facilities of the Department of Entomology, Royal Ontario Museum. Postdoctoral support for the senior author was made possible through an operating grant to G. B. Wiggins (G5707) from the Natural Sciences and Engineering Research Council of Canada. Use of unpublished morphological information from C. R. Parker and R. N. Vineyard is acknowledged with appreciation, as is access to manuscript information from A. Neboiss. For responding to some inquiries about Trichoptera, we thank V. D. Ivanov and W. Wichard, and about Lepidoptera, N. P. Kristensen. For gifts or loans of specimens, we thank L. Botoşăneanu, D. R. Davis, O. S. Flint, W. Mey, A. Neboiss, and A. Wells.
Finally, we express our appreciation to P. W. Schefter and the reviewers of our manuscript, N. P. Kristensen and J. C. Morse, for their helpful and extensive comments.

The manuscript for this study was submitted to the ROM Life Sciences Editorial Board in April 1993. Revisions and other responses to reviewers' comments were returned in March 1994; the work was accepted and publication scheduled for 1995 by the ROM Publications Office. On that basis, the study was cited elsewhere as published in 1995. However, because of budgetary constraints the projected publication date was twice deferred between 1995 and 1997. 


\section{Appendix}

\section{Morphological Characters of Larvae}

1. a) Larval development normal, all instars with about the same proportions.

b) Larvae exhibiting hypermetamorphosis, first four instars with abdomen of about normal proportions, last instar showing hypertrophy of the abdomen.

2. Antennae located
a) far cephalad,
b) cephalad,
c) caudad.

3. a) Antennal segment cylindrical, sides sclerotized.

b) Antennae vestigial, largely or entirely membranous.

\section{Antenna with}

a) two large basiconic sensilla,

b) one large basiconic sensillum,

c) no large basiconic sensilla.

\section{Antenna with}

a) two long trichoid sensilla, located laterally;

b) three long trichoid sensilla, located laterally;

$\mathrm{Ca}$ ) one long trichoid sensillum, located laterally;

d) no long trichoid sensilla;

Ec) one large trichoid sensillum, located medially between the large basiconic sensilla.

The proposal that state $5 \mathrm{~d}$ is derived from state $5 \mathrm{Ca}$ is based on the observation (Nielsen, 1942; Denis, 1984b) that in Limnephilidae and Goeridae a trichoid sensillum is present and located laterally at the apex of the antennal segment in the first instar, but is lost in the second instar.

6. Prelabio-hypopharyngeal lobe

a) relatively short, apex broadly rounded;

b) elongate, tapered to apex.

7. a) Prelabio-hypopharyngeal lobe largely membranous, except for palpiger and associated sclerites, and prementum. b) At least basal portion of dorsal surface of lobe and most or all of ventral surface heavily sclerotized, prementum not distinguishable.

8. Labial palp

a) prominent,

b) appressed to sides of prelabio-hypopharyngeal lobe.

9. Postlabium with

a) pair of setae

b) many setac.

10. Frontoclypeus with seta 1

a) curved mesad, colourless;

b) straight, dark in colour.
11. Anterior tentorial pits

a) in contact with anterior arms of dorsal ecdysial line,

b) arising on dorsal apotome some distance mesad of cleavage line.

12. Venter of head

a) with one ecdysial line, which is forked anteriorly but not posteriorly;

b) with one ecdysial line, which is forked both anteriorly and posteriorly, posterior apotome not extending anteriorly beyond postoccipital ridge;

c) as condition $12 \mathrm{~b}$ except posterior apotome extending further anteriorly, postoccipital ridge extending across apotome; d) with two subparallel ecdysial lines, postoccipital ridge extending across apotome;

Ea) with two ecdysial lines joined at occipital foramen or subparallel, postoccipital ridge not extending across apotome.

13. a) Venter of head uniformly tanned.

b) Posterior third of venter of head lightly tanned.

14. Pronotum

a) with anterolateral margin entire,

b) incised anterolaterally to accommodate propleuron.

15. Anterior margin of pronotum
a) without internal flange,
b) with small internal flange anteriorly,
c) with large internal flange.

16. Pronotum

a) without tergal ridge, posterior external ridge entire;

b) with tergal ridge present and entire, posterior external ridge entire

c) with tergal ridge obsolete dorsally, posterior external ridge obsolete ventrally;

d) with tergal ridge obsolete dorsally, external ridge extending anteriorly.

17. a) Pronotum uniformly and strongly tanned.

b) Posterior third of pronotum lightly tanned.

18. Pronotum with hind angles

a) not prominent, separated by entire width of sternum;

b) extending ventrally and coming into contact on sternum behind procoxae.

19. Prosternum

a) without gland of Gilson or prosternal horn;

b) with gland of Gilson; prosternal horn present or absent.

20. Mesonotum

a) membranous;

b) with several small to large sclerites;

c) with a single large sclerite, dorsal ecdysial line present or absent. 
21. Mesonotum with

a) setal area 1 ( $\mathrm{sal}$ ), sa2, and sa3 having one, one, and two setac, respectively;

b) sa3 having more than two setae.

22. Metanotum
a) membranous;
b) with several small to large sclerites;
c) with a single large sclerite, dorsal ecdysial line present or absent.

23. Metanotum with
a) setal area 1 (sal), sa2, and sa3 having one, one, and two setac, respectively;
b) sa3 having more than two setae.

\section{Prothorax with}
a) pleural sclerite 1 separate from sclerite 2 , mesal or ven- tral portion membranous;
b) propleural sclerite I fused to sclerite 2, shape various, mesal or ventral portion membranous;
c) sclerite 1 fused to sclerite 2 , hatchet-shaped, entirely scle- rotized.

25. Propleural ridge with
a) a vertical orientation,
b) an oblique orientation.

26. Mesepisternum and metepisternum
a) without anteriorly directed apodeme,
b) with anteriorly directed apodeme.

27. Mesocoxae and metacoxae with
a) slight emargination at point of articulation with pleuron;
b) large prominence at point of articulation with pleuron.

28. a) Trochanter short on all legs.

b) At least mesotrochanter and metatrochanter long.

29. a) All legs with trochanter open dorsally.

b) Distal part of protrochanter closed, proximal part open, mesotrochanter and metatrochanter open.

c) All legs with distal and proximal parts of trochanter closed.

Da) One or more legs with proximal part of trochanter closed, distal part open.

e) Metatrochanter with distal as well as proximal part closed.

30. Trochanter with

a) proximal and distal parts divided lengthwise dorsally (open condition) or not at all (i.e., trochanter composed of two sclerites);

b) proximal or proximal and distal parts of trochanter divided lengthwise ventrally as well as dorsally (i.e., trochanter composed of three or four sclerites).

31. a) Femur entire.

b) Anterior face of femur separated basally from rest of femur.
32. Middle and hind pair of legs with tarsal claw
a) entire,
b) divided.

33. Abdominal terga I-VIII
a) membranous,
b) each with large sclerite in first four instars.

34. Abdominal tergum $I X$

a) with two small sclerites, at least one long seta arising at posterior margin of each sclerite;

b) with one large sclerite, at least one pair of long setae arising at posterior margin of sclerite;

c) membranous, at least one pair of long setae arising at posterior margin of tergum;

Da) membranous, all setae inconspicuous.

35. Abdominal segment I
a) without lateral or dorsal humps,
b) with lateral humps,
c) with lateral and dorsal humps.

36. Pleural region of abdominal segments II-VIII:

a) with primary setae only; secondary setae, if present, restricted to a small area;

b) each segment with patch of secondary setae that covers most of the pleural region;

Ca) one or more segments with lateral fringe, forked lamellae present or absent, no serrate lamellae present;

d) with serrate lamellae, with or without forked lamellae.

37. Abdomen

a) without chloride epithelia;

b) with chloride epithelia, with appearance of ovid area bordered by thin sclerotized line.

38. a) All instars with anal proleg slightly prominent, claw pointing downwards, or in mature last instar larva slightly outwards.

b) All instars with anal proleg very prominent but segment IX entire, claw pointing downwards.

c) All instars with anal proleg very prominent, incorporating part of segment IX, otherwise as in state b.

$\mathrm{Da}$ ) All instars with anal proleg not prominent, claw pointing outwards.

Ea) Instars $1-1 V$ with anal proleg prominent, claw pointing downwards, last instar with anal proleg not prominent, claw pointing outwards.

39. Ventral sole plate of anal proleg
a) smooth,
b) with a large field of short stout spines.

40. Anal prolegs with seta 7 located

a) at or near ventral margin of lateral plate, about in line with the junction of the claw and ventral sole plate;

b) near the ventral articulation of the ventral sole plate with the lateral plate. 


\section{Morphological Characters of Adults}

\section{Mandibles}

a) large, partly hidden under labrum in repose;

b) reduced in size, largely or completely exposed in repose;

c) vestigial.

42. Labial palps in female

a) with sensilla on terminal segment generally distributed,

or if localized, then not forming pad;

b) with large pad of sensilla mesally.

43. Maxillary palps in male
a) five-segmented,
b) four-segmented,
c) three-segmented,
d) two-segmented,
e) one-segmented,
Fa) six-segmented.

44. Maxillary palps with apex of terminal segment

a) drawn out to a point, glabrous except for one or more coniform sensilla;

b) rounded, covered with setae, sensilla setiform.

45. Maxillary palps with segment 2
a) cylindrical, longer than segment 1 ;
b) ovoid, as long as segment 1 .

46. Maxillary palps with terminal segment
a) not annulate, flexible or not;
b) annulate and flexible.

47. Haustellum

a) with or without a system of parallel channels; channels, if present, lined with simple or symmetrical pectinate microtrichia;

b) largely covered with a system of parallel channels, walls of channels with asymmetrical pectinate microtrichia.

48. Head
a) with ocelli,
b) without ocelli.

49. Head with lateral ocelli separated
a) by more than their diameter from eye,
b) by not more than half their diameter from eye.

50. Head with temporal suture
a) closed or not evident
b) open.

51. Tentorium

a) having shape of $\mathrm{H}$ or $\mathrm{X}$, with posterior arms + tentorial bridge arched, posterior arms long;

b) U-shaped, with posterior arms obsolete, anterior arms and tentorial bridge joined at head capsule.

52. Tentorium with anterior arms
a) separate
b) contiguous,
c) fused basally.

53. Tentorium with
a) dorsal arms entire,
b) apical portion of anterior arms filamentous or arms short,
c) dorsal arms tiny or entirely absent.

\section{Tentorial bar}

a) with single or paired anteromedian prominence,

b) lacking anteromedian prominence.

55. Prosternum with posterior border

a) lightly sclerotized medially, dividing the sides of the mesal point into an almost membranous central area;

b) entirely sclerotized and terminating in a narrow mesal point.

56. Forewing with crossvein $m$
a) present
b) absent.

57. Forewing with vein M4
a) evident
b) not evident in male,
c) not evident in either sex.

58. Forewing with

a) thyridial cell contiguous with medial cell or nearly so;

b) thyridial and medial cells separated by least one-quarter length of thyridial cell.

59. Mesoscutellum
a) rounded,
b) with sides elevated.

60. Mesopleuron with

a) short ridge that runs downwards in front of pleurocoxal articulation ( $\mathrm{r} 4$ in Fig. 6; suture Y of mesopleuron, Ross, 1967); b) $\mathrm{r} 4$ absent

61. Mesofurca
a) with anteromedial tendon membranous;
b) with anteromedial tendon sclerotized, e.g., mesofurca beaked, beak short;
c) as state $61 \mathrm{~b}$ except beak long.

62. Mesofurca with ventrolateral arm
a) tapered to a point
b) forked.

63. Metafurca with
a) lateral arms only,
b) lateral arms and median process.

64. Mesotibia with
a) two preapical spurs,
b) one preapical spur,
c) no preapical spurs. 
65. Middle leg of female with

a) tibia and tarsus slender;

b) tibia swollen apically, tarsus slender;

Ca) tibia and tarsus flattened laterally.

66. Female with

a) terminal segment of abdomen bearing one- or two-segmented papillate cerci;

b) cerci lacking.

67. Female with

a) pair of rodlike apodemes arising from anterolateral margin of each of segments VIII and IX and extending cephalad, both pairs at least half the length of segment VIII;

b) anterior pair of apodemes short, about one-third to onehalf length of segment VIII, posterior pair long;

c) anterior pair of apodemes vestigial, posterior pair long; d) anterior pair of apodemes vestigial; posterior pair short;

e) both pairs of apodemes vestigial.

68. Female with terminal segment of abdomen

a) without lateral papillae;

b) with lateral papillae present, subequal in length, and adjacent to cerci.

69. Phallus with
a) paired parameres,
b) single paramere,
c) no parameres.

70. Male genitalia with inferior appendages
a) two-segmented,
b) one-segmented 


\section{Literature Cited}

BADCOCK, R. M.

1963 The morphology of some parts of the head and maxillolabium in larval Trichoptera with special reference to the Hydropsychidae. Transactions of the Royal Entomological Society of London 113:217-248.

BETTEN, C.

1902 The larva of the caddis fly, Molanna cinerea Hagen. Journal of the New York Entomological Society 10:147-154.

BICCHIERAI, M. C., and G. P. MORETTI

1986 Prosternal horn and Gilson's gland in certain limnephilid larvae. In M. Bournaud and H. Tachet, eds., Proceedings of the Fifth International Symposium on Trichoptera. Series Entomologica 39. The Hague, Junk, pp. 3-9.

BITSCH, J.

1979 Morphologie abdominale des insectes. In P. P. Grassé, ed., Traité de Zoologie: anatomie, systématique, biologie. Tome VIII. Fasc. Il. Paris, Masson, pp. 291-578.

BOHLE, H. W., and M. FISCHER

1983 Struktur und Entstehung der Larven- und Puppengehäuse einiger Glossosomatidae und Rhyacophilidae, insbesondere bei Synagapetus iridipennis (Trichoptera: Rhyacophiloidea). Entomologia Generalis 9:17-34.

BORROR, D. J., C. A. TRIPLEHORN, and N. F. JOHNSON

1989 An introduction to the study of insects. 6th ed. Philadelphia, Saunders. $875 \mathrm{pp}$.

BOWLES, D. E., and R. T. ALLEN

1988 Description of the female of Paduniella nearctica (Trichoptera: Psychomyiidae). Entomological News 99:7-9.

BYERS, G. W.

1987 Order Mecoptera. In F. W. Stehr, ed., Immature insects. Dubuque, Iowa, Kendall/Hunt, pp. 246-252.

CHAPIN, J. W.

1978 Systematics of Nearctic Micrasema (Trichoptera: Brachycentridae). Ph.D. Thesis, Clemson University. $136 \mathrm{pp}$.

CHAUVIN, G., and M. FAUCHEUX

1981 Les pièces buccales et leurs récepteurs sensoriels chez l'imago de Micropterix calthella L. (Lepidoptera: Micropterigidae). International Journal of Insect Morphology and Embryology $10: 425-439$.

CRICHTON, M. I.

1957 The structure and function of the mouth parts of adult caddis flies (Trichoptera). Philosophical Transactions of the Royal Society of London, B 241:45-91.
DAVIS, D. R.

1978 A revision of the North American moths of the superfamily Eriocranioidea with the proposal of a new family, Acanthopteroctetidae (Lepidoptera). Smithsonian Contributions to Zoology 251:1-131.

1987a Order Lepidoptera (in part). In F. W. Stehr, ed., Immature insects. Dubuque, Iowa, Kendall/Hunt, pp. 341-343.

1987 b Order Lepidoptera (in part). In F. W. Stehr, ed., Immature insects. Dubuque, Iowa, Kendall/Hunt, pp. 456-460.

1990 First record of a bagworm moth from Hawaii: description and introduction of Brachycyttarus griseus De Joannis (Lepidoptera: Psychidae). Proceedings of the Entomological Society of Washington 92:259-270.

DENIS, C.

1983 Differenciation de certains organes larvaires des Rhyacophiloidea et des Limnephiloidea (Trichoptera). Bulletin de la Société scientifique de Bretagne 55:5-14.

1984a Les antennes larvaires des Hydropsychoidea. Considérations générales sur la morphologie antennaire des larves de Trichoptères. Bulletin de la Société scientifique de Bretagne 56:117-124.

1984b Fine structure of case-making larvae (Trichoptera). In J. C. Morse, ed., Proceedings of the Fourth International Symposium on Trichoptera. Series Entomologica 30. The Hague, Junk, pp. 105-114.

DENIS, J. R., and J. BITSCH

1973 Structure céphalique dans les ordres des insectes. In P. P. Grassé, ed., Traité de Zoologie: anatomie, systématique, biologie. Tome VIII. Fasc. I. Paris, Masson, pp. 101-593.

DENIS, C., and J. LE LANNIC

1991 Les pièces buccales des Trichoptères adultes et leurs microstructures. Bulletin de la Société scientifique de Bretagne 62:37-72.

DETHIER, V. G.

1941 The antennae of lepidopterous larvae. Bulletin of the Museum of Comparative Zoology, Harvard $87: 455-507$.

DUGDALE, J. $\mathrm{S}$.

1974 Female genital configuration in the classification of Lepidoptera. New Zealand Journal of Zoology 1:127-146.

FLINT, O. S.

1960 Taxonomy and biology of Nearctic limnephilid larvae (Trichoptera), with special reference to species in the eastern United States. Entomologica Americana 40:1-117.

1962 Larvae of the caddis fly genus Rhvacophila in eastern North America (Trichoptera: Rhyacophilidae). Proceedings of the United States National Museum 113:465-493. 
1967 The first record of the Paduniellini in the New World (Trichoptera: Psychomyiidae). Proceedings of the Entomological Society of Washington 69:310-311.

1981 Studies of Neotropical caddisflies, XXVII: Anomalopsychidae, a new family of Trichoptera. I $n$ G. P. Moretti, ed., Proceedings of the Third International Symposium on Trichoptera. Series Entomologica 20. The Hague, Junk, pp. 75-85.

\section{FOTIUS-JABOULET, $M$.}

1961 Squelette et musculature céphaliques de la larve de Drusus trifidus MacLachlan (TrichopteraLimnophilidae). Travaux du Laboratoire de Zoologie et de la Station Aquicole Grimaldi de la Faculté des Sciences de Dijon 40:1-54.

1963 Anatomie des glandes céphaliques de la larve de Rhyacophila septentrionis (Trichoptera-Rhyacophilidae). Travaux du Laboratoire de Zoologie et de la Station Aquicole Grimaldi de la Faculté des Sciences de Dijon 46:1-25.

\section{FRIEDLÄNDER, $M$.}

1983 Phylogenetic branching of Trichoptera and Lepidoptera: an ultrastructural analysis on comparative spermatology. Journal of Ultrastructure Research 83:141-147

1993 Phylogenetic position of rhyacophilid caddisflies (Insecta: Trichoptera): a spermatological analysis of Rhyacophilidae and Glossosomatidae. Zoologica Scripta 22:299-304.

FRIEDLÄNDER, M., and R. E. JEGER

1990 Phylogenesis of spermatogenesis in Annulipalpia caddisflies: an ultrastructural analysis on Philopotamidae spermiogenesis. Journal of Ultrastructure Research 105:75-79.

FRIEDLÄNDER, M., and J. C. MORSE

1982 The aberrant spermatozoa of Hydropsychidae caddisflies (Trichoptera): an electron microscope analysis of spermiogenesis. Journal of Ultrastructure Research 78:84-94.

FULLER, H., C. TOMASZEWSKI, and B. MARCINIAK

1991 The homological relations in the musculature of the protuberances of the first abdominal segment in caddis larvae (Trichoptera). In C. Tomaszewski, ed., Proceedings of the Sixth International Symposium on Trichoptera. Poznań, Adam Mickiewicz University Press, pp. 291-298.

GALL, W. K., and G. B. WIGGINS

in press Phylogeny and classification of the families of the Limnephiloidea (Trichoptera). Bulletin of the Buffalo Society of Natural Sciences 35.

GILSON, G.

1896 On segmentally disposed thoracic glands in the larvae of the Trichoptera. Journal of the Linnean Society of London 25:407-412.

HANNA, H. M.

1960 Methods of case-building and repair by larvae of caddis flies. Proceedings of the Royal Entomolo- gical Society of London, A 35:97-106.

HENSEVAL, $M$.

1896 Étude comparée des glandes de Gilson. La Cellule 11:329-354.

HEPBURN, R. H.

1969 The skeleto-muscular system of the Mecoptera: the head. University of Kansas Science Bulletin 48:721-765.

HICKIN, N. E.

1967 Caddis larvae. London, Hutchison. 476 pp. HINTON, H. E.

1955 On the structure, function, and distribution of the prolegs of the Panorpoidea, with a criticism of the Berlese-Imms theory. Transactions of the Royal Entomological Society of London 106:455-556.

1958 The phylogeny of the panorpoid orders. Annual Review of Entomology 3:181-206.

1963 The ventral ecdysial lines of the head of endopterygote larvae. Transactions of the Royal Entomological Society of London 115:39-61.

ISSIKI, S. T.

1931 On the morphology and systematics of Micropterygidae (Lepidoptera Homoneura) of Japan and Formosa, with some considerations on the Australian, European, and North American forms. Proceedings of the Zoological Society of London 66:999-1039.

ITO, T., and L. W. G. HIGLER

1993 Biological notes and description of little known stages of Ptilocolepus granulatus (Pictet) (Trichoptera: Hydroptilidae). In C. Otto, ed., Proceedings of the Seventh International Symposium on Trichoptera. Leiden, Backhuys, pp. 177-181.

IVANOV, V. D.

1985 Structure and function of wing articulation of caddisflies. I. Ground-plan. Herald of Leningrad University 10:3-12. [in Russian]

1990 Structure and evolution of setose warts of caddisflies. Latvijas Entomologs 33:96-110.

JACQUEMART, S., and Y. COINEAU

1962 Missions S. Jacquemart dans les Pyrénées Orientales ( $2^{\text {ème }}$ note). Les Trichoptères Hydroptilides des Albères. Bulletin Institut royal des Sciences naturelles de Belgique 38:1-81.

KALTENBACH, A.

1978 Mecoptera. In W. Kukenthal, ed., Handbuch der Zoologie, 2nd ed., vol. 4, pt. 2, no. 28, pp. 1-111.

KERR, J. D., and G. B. WIGGINS

1995 A comparative morphological study of the lateral line systems in larvae and pupae of Trichoptera. Zoological Journal of the Linnean Society 115:165-184.

KIMMINS, D. E.

1950 Indian caddis flies (Trichoptera). 1. New species of the genus Limnocentropus Ulmer. Annals and Magazine of Natural History, ser. 12, 3:590-603. 
KLEMM, $N$.

1966 Die Morphologie des Kopfes von Rhyacophila Pict. (Trichoptera). Zoologische Jahrbücher, Abteilung für Anatomie und Ontogenie der Tiere 83:1-51.

KORAYASHI, Y., and H. ANDO

1981 The embryonic development of the primitive moth, Neomicropteryx nipponensis Issiki (Lepidoptera, Micropterygidae): morphogenesis of the embryo by external observation. Journal of Morphology 169:49-59.

KOZLOV, M. V., V. D. IVANOV, and D. L. GRODNITSKY

1986 Wing mechanism evolution and wing kinematics of Lepidoptera. Advances in Modern Biology 101:291-305.

KRAFKA, J.

1923 Morphology of the head of trichopterous larvae as a basis for the revision of the family relationships. Journal of the New York Entomological Society $31: 31-52$.

1924 Morphology of the prolegs of trichopterous larvae. Annals of the Entomological Society of America 17:97-103.

KRISTENSEN, N. P.

1984a Studies on the morphology and systematics of primitive Lepidoptera (Insecta). Steenstrupia 10:141-191.

1984b The larval head of Agathiphaga (Lepidoptera, Agathiphagidae) and the lepidopteran ground plan. Systematic Entomology 9:63-81.

1990 Cladistics and the ecological scenario of early evolution in the Lepidoptera/Trichoptera complex. Ninth meeting of the Willi Hennig Society, Canberra. Abstracts, p. 27.

KRISTENSEN, N. P., and E. S. NIELSEN

1979 A new subfamily of micropterigid moths from South America. A contribution of the morphology and phylogeny of the Micropterigidae, with a generic catalogue of the family (Lepidoptera: Zeugloptera). Steenstrupia 5:69-147.

1983 The Heterobathmia life history elucidated: immature stages contradict assignment to suborder Zeugloptera (Insecta, Lepidoptera). Zeitschrift für zoologische Systematik und Evolutionsforschung 21:101-124.

KUKALOVA-PECK, J.

1991 Fossil history and the evolution of hexapod structures. In The Insects of Australia. 2nd ed., Commonwealth Scientific and Industrial Research Organization. Ithaca, Cornell University Press, pp. 141-179.

KURANISHI, R. B

1993 Oviposition behaviour of Rhyacophila kiyosumiensis (Trichoptera: Rhyacophilidae) in a small mountain stream, central Japan. In C. Otto, ed., Proceedings of the Seventh International Symposium on Trichoptera. Leiden, Backhuys, pp. 261-262.
LEPNEVA, S. G.

1964 Fauna of the U.S.S.R.; Trichoptera, vol. 2, no. 1. Larvae and Pupae of Annulipalpia. Israel Program for Scientific Translations, 1970.

LORENZ, R. E.

1961 Biologie und morphologie von Micropterix calthella (L.) (Lep. Micropterygidae). Deutsche Entomologische Zeitschrift, N.F. 8:1-23.

MACKAY, R. J., and G. B. WIGGINS

1979 Ecological diversity in Trichoptera. Annual Review of Entomology 24:185-208.

MADDISON, D. R.

1991 The discovery and importance of multiple islands of most-parsimonious trees. Systematic Zoology 40:315-328.

MARSHALL, J. E.

1979 A review of the genera of the Hydroptilidae. Bulletin of the British Museum (Natural History), Entomology Series 39:135-239.

MARTYNOV, A. V.

1924 Rucheiniki. In N. N. Bogdanova Kat'kova, ed., Prakticheskaya entomologie, vyp. 5. Leningrad, Gosudarstvennoe Izdatelstvo. 384 pp.

1930 On the trichopterous fauna of China and eastern Tibet. Proceedings of the Zoological Society (London) 5:65-112.

MATSUDA, R.

1965 Morphology and evolution of the insect head. Memoirs of the American Entomological Institute 4:1-334.

1976 Morphology and evolution of the insect abdomen with special reference to developmental patterns and their bearings upon systematics. Oxford, Pergamon Press. 534 pp.

MIYAKAWA, K.

1973 The embryology of the caddisfly Stenopsyche griseipennis (Trichoptera: Stenopsychidae) I. Early stages and changes in external form of embryo. Kontyu 41:413-425.

MIYAMOTO, M. M.

1985 Consensus cladograms and general classifications. Cladistics 1:186-189.

MORETTI, G. P., F. CLANFICCONI, and M. C. BICCHIERAI

1975 The structure of the abdominal fork-bearing plates in the larva of Granmotaulius atomarius Fbr. (Trichoptera: Limnephilinae). Bollettino Zoologia 42:423-425.

MORSE, J. C., and R. W. HOLZENTHAL

1987 Higher classification of Triplectidinae (Trichoptera: Leptoceridae). In M. Bournaud and H. Tachet, eds., Proceedings of the Fifth International Symposium on Trichoptera. Series Entomologica 23. The Hague, Junk, pp. 139-144.

MUTUURA, A.

1972 Morphology of the female terminalia in Lepidoptera, and its taxonomic significance. Canadian Entomologist 104:1055-1072.

1980 Morphological relations of sclerotized and pig- 
mented areas of lepidopterous larvac to muscle attachments, with applications to larval taxonomy. Canadian Entomologist 112:697-724.

NEBOISS, $\mathrm{A}$

1986 Atlas of Trichoptera of the SW Pacific-Australian Region. Series Entomologica 37. The Hague, Junk. $286 \mathrm{pp}$.

1987 Immature stages of Plectrotarsus gravenhorsti Kolenati (Trichoptera: Plectrotarsidae) and comments on likely family relationships. Proceedings of the Royal Society of Victoria 99:135-140.

1991 Comparative study of tentorial structures in caddisflies (Trichoptera). In C. Tomaszewski, ed., Proceedings of the Sixth International Symposium on Trichoptera. Poznan, Adam Mickiewicz University Press, pp. 283-290.

NIELSEN, A.

1942 Über die Entwicklung und Biologie der Trichopteren mit besonderer Berucksichtigung der Quelltrichopteren Himmerlands. Archiv für Hydrobiologie, supplement 17:255-631.

1948 Postembryonic development and biology of the Hydroptilidae. Det Kongelige Danske Videnskabernes Selskab Biologiske Skrifter 5:1-200.

$1957 \mathrm{a}$ On the evolution of the genitalia in male insects. Entomologiske Mcddelelser 28:27-57.

1957b A comparative study of the genital segments and their appendages in male Trichoptera. Det Kongelige Danske Videnskabernes Selskab Biologiske Skrifter 8:1-159.

1980 A comparative study of the genital segments and the genital chamber in female Trichoptera. Det Kongelige Danske Videnskabernes Selskab Biologiske Skrifter 23:1-200.

NIELSEN, E. S.

1989 Phylogeny of the major lepidopteran groups. In B. Fernholm, K. Bremer, and H. Jörnvall, eds., The Hierarchy of life. Amsterdam, Elsevier, pp. 281-294.

NÜSKE, H., and W. WICHARD

1971 Die Analpapillen der Köcherfliegenlarven. 1. Feinstruktur und histochemischer Nachweis von Natrium und Chlorid bei Philopotamus montanus Donov. Cytobiologie 4:480-486.

PATTEN, W.

1884 The development of Phryganids, with a preliminary note on the development of Blatta germanica. Quarterly Journal of Microscopical Science 24:449-602.

PAULUS, H. F., and M. SCHMIDT

1978 Evolutionswege zum Larvalauge der Insekten: die Stemmata der Trichoptera und Lepidoptera. Zeitschrift für zoologische Systematik und Evolutionforschung 16:188-216.

PILGRIM, R. I. C.

1972 The aquatic larva and the pupa of Choristella philpotti Tillyard, 1917 (Mecoptera: Nannochoristidae). Pacific Insects 14:151-168
PRYOR, M. G. M.

1951 On the abdominal appendages of the larvae of Trichoptera, Neuroptera and Lepidoptera, and the origins of jointed limbs. Quarterly Journal of Microscopical Science 92:351-376.

ROSS, $\mathrm{H} . \mathrm{H}$

1944 The caddis flies, or Trichoptera, of Illinois. Bulletin of the Illinois Natural History Survey 23(1):1-326.

1956 Evolution and classification of the mountain caddisflies. Urbana, University of Illinois Press. $213 \mathrm{pp}$.

1964 Evolution of caddisworm cases and nets. American Zoologist 4:209-220.

1967 The evolution and past dispersal of the Trichoptera. Annual Review of Entomology 12:169--206.

RUSSELL, L. K.

1982 The life history of Caurinus dectes Russell, with a description of the immature stages (Mecoptera: Boreidae). Entomologica Scandinavica 13:225-235.

SAETHER, O. A.

1979 Underlying synapomorphies and anagenetic analysis. Zoologica Scripta 8:305-312

SCHMID, F.

1969 La famille des Stenopsychides (Trichoptera). Canadian Entomologist 101:187-224.

1970 Le genre Rhyacophila et la famille des Rhyacophilidae (Trichoptera). Mémoires de la Société entomologique du Canada 66:1-230.

1980 Genera des Trichoptères du Canada et des États adjacents. Ottawa, Agriculture Canada. 296 pp.

1982a Revision des Trichoptères canadiens Il. Les Glossosomatidae et Philopotamidae (Annulipalpia). Mćmoires de la Société entomologique du Canada 122:1-76.

1982b La famille des Xiphocentronides (Trichoptera: Annulipalpia). Mémoires de la Société entomologique du Canada 121:1-76.

1989 Les Hydrobiosides (Trichoptera, Annulipalpia). Bulletin de l'Institut royal des sciences naturelles de Belgique 59 (suppl.):1-154.

SCHMID, F, and L. BOTOŞANEANU

1966 Le genre Himalopsyche Banks (Trichoptera, Rhyacophilidae). Annales de la Société entomologique du Québec 11:123-176.

SCOTT, K. M. F.

1993 Three recently erected Trichoptera families from South Africa, the Hydrosalpingidae, Petrothrincidae and Barbarochthonidae (Integripalpia: Sericostomatoidea). Annals of the Cape Provincial Museums (Natural History) 18:293-354.

SHARPLIN, J. E.

1963 Wing base structure in Lepidoptera I. Fore-wing base. Canadian Entomologist 95:1024-1050.

SILFVENIUS, A. J.

1906 Trichopterologische Untersuchungen II. Über den Laich der Trichopteren. Acta Societatis pro Fauna et Flora Fennica 28:1-128. 
SILTALA, A. J.

1907 Über die postembryonale Entwicklung der Trichopteren-Larven. Zoologische Jährbücher, Suppl. 9(2):309-626.

SNODGRASS, R. E.

1935 Principles of insect morphology. New York, McGraw-Hill. 667 pp.

STEHR, F. W.

1987 Order Lepidoptera (in part). In F. W. Stehr, ed., Immature insects. Dubuque, lowa, Kendall/Hunt, pp. 288-305.

TESKEY, H. J.

1981 Morphology and terminology-larvae. In J. F. McAlpine, B. V. Peterson, G. E. Shewell, H. J. Teskey, J. R. Vockeroth, and D. M. Wood, coordinators. Manual of Nearctic Diptera. Vol. 1. Ottawa, Agriculture Canada Monograph 27, pp. 65-88.

TINDALL, A. R.

1963 The skeleton and musculature of the thorax and limbs of the larva of Limnephilus sp. (Trichoptera: Limnephilidae). Transactions of the Royal Entomological Society of London 115:409-477.

1964 The skeleton and musculature of the larval thorax of Triaenodes bicolor Curtis (Trichoptera: Limnephilidae[sic] Leptoceridae). Transactions of the Royal Entomological Society of London 116:151-210.

1965 The functional morphology of the thorax of Limnephilus marmoratus Curtis (Trichoptera: Limnephilidae). Transactions of the Royal Entomological Society of London 117:127-166.

TOMASZEWSKI, C.

1981 The principles of case building behaviour in Trichoptera. In G. P. Moretti and M. Tachet, eds., Proceedings of the Third International Symposium on Trichoptera. Series Entomologica 20. The Hague, Junk, pp. 365-373.

TUXEN, S. L.

1970 Part II, Glossary. In S. L. Tuxen, ed., Taxonomist's glossary of genitalia in insects. 2nd ed. Munksgaard, Copenhagen, pp. 215-359.

ULMER, G.

1951 Köcherfliegen (Trichopteren) von den SundaInseln. 1. Archiv für Hydrobiologie, Suppl. 19:1-528.

VINEYARD, R. N., and G. B. WIGGINS

1988 Further revision of the caddisfly family Uenoidae (Trichoptera): evidence for inclusion of Neophylacinae and Thremmatidae. Systematic Entomology 13:361-372.

WALLACE, J. B., W. R. WOODALL, and A. A. STATS

1976 The larval dwelling-tube, capture net and food of Phylocentropus placidus (Trichoptera: Polycentropodidae). Annals of the Entomological Society of America 69:149-154.
WEAVER, J. S.

1983 The evolution and classification of Trichoptera, with a revision of the Lepidostomatidae and a North American synopsis of this family. $\mathrm{Ph} . \mathrm{D}$. Thesis, Clemson University. 411 pp.

1984 The evolution and classification of Trichoptera, part 1: the groundplan of Trichoptera. In J. C. Morse, ed., Proceedings of the Fourth International Symposium on Trichoptera. Series Entomologica 30. The Hague, Junk, pp. 413-419.

1992a Remarks on the evolution of Trichoptera: a critique of Wiggins and Wichard's classification. Cladistics 8:171-180.

1992b Further remarks on the evolution of Trichoptera: a reply to Wiggins. Cladistics 8:187-190.

1992c Evolution and classification of Trichoptera: the diversification of Trichoptera. Seventh International Symposium on Trichoptera, Leiden, Abstracts, p. 34.

WEAVER, J. S., and J. C. MORSE

1986 Evolution of feeding and case-making behavior in Trichoptera. Journal of the North American Benthological Society 5:150-158.

WICHARD, W.

1976 Morphologische Komponenten bei der Osmoregulation von Trichopterenlarven. In H. Malicky, ed., Proceedings of the First International Symposium on Trichoptera. The Hague, Junk, pp. 171-177.

1991 The evolutionary effect of overcoming osmosis in Trichoptera. In C. Tomaszewski, ed., Proceedings of the Sixth International Symposium on Trichoptera. Poznań, Adam Mickiewicz University Press, pp. 337-342.

WICHARD, W., and H. KOMNICK

1973 Fine structure and function of the abdominal chloride epithelia in caddisfly larvae. Zeitschrift für Zellforschung 136:579-590.

WICHARD, W., H. H. SCHMIDT, and R. WAGNER

1993 The semipermeability of the pupal cocoon of Rhyacophila (Trichoptera: Spicipaipia). In C. Otto, ed., Proceedings of the Seventh International Symposium on Trichoptera. Leiden, Backhuys, pp. 25-27.

WICHARD, W., and M. SCHMITZ

1980 Anpassungsmechanismen der osmoregulatorischen Ionenabsorption bei Limnephilidae-Larven (Insecta, Trichoptera). Gewässer und Abwässer 66/67: 102-118.

WIGGINS, G. B.

1954 The caddisfly genus Beraea in North America (Trichoptera). Contributions of the Royal Ontario Museum of Zoology and Palaeontology 39:1-13.

1969 Contributions to the biology of the Asian caddisfly family Limnocentropodidae (Trichoptera). Life Sciences Contributions, Royal Ontario Museum $74: 1-29$.

1977 Larvae of the North American caddisfly genera. Toronto, University of Toronto Press. $401 \mathrm{pp}$. 
1992 Comments on the phylogeny of pupation behavior in Trichoptera: a response to Weaver. Cladistics 8:181-185.

WIGGINS, G. B., and W. K. GALL

1993 The Asian caddisfly family Phryganopsychidae: phylogenetic novelty or relict? In C. Otto, ed., Proceedings of the Seventh International Symposium on Trichoptera. Leiden, Backhuys, pp. 149-154.

WIGGINS, G. B., and J. S. RICHARDSON

1982 Revision and synopsis of the caddisfly genus Dicosmoecus (Trichoptera: Limnephilidae; Dicosmoccinae). Aquatic lnsects 4:181-217.

WIGGINS, G. B., and W. WICHARD

1989 Phylogeny of pupation in Trichoptera, with proposals on the origin and higher classification of the order. Journal of the North American Benthological Society $8: 260-276$.
WILLIAMS, N. E.

1983 A comparative study of chactotaxy in larval Trichoptera with special reference to the Limnephilidac. Ph.D. Thesis, University of Toronto. $168 \mathrm{pp}$.

WILLIAMS, N. E., and G. B. WIGGINS

1981 A proposed setal nomenclature and homology for larval Trichoptera. In G. P. Moretti, ed., Proceedings of the Third International Symposium on Trichoptera. Series Entomologica 20. The Hague, Junk, pp. 421-429.

WOOTTON, R. J.

1988 The historical ecology of aquatic insects: an overview. Palaeogeography, Palaeoclimatology, and Palacoccology 62:477-492. 


\section{ROYAL ONTARIO MUSEUM LIFE SCIENCES PUBLICATIONS INSTRUCTIONS TO AUTHORS}

Authors should prepare their manuscripts carefully according to the following instructions; failure to do so will result in the manuscript's being returned to the author for revision. All manuscripts are considered on the understanding that they are not currently offered for publication elsewhere.

1. General Papers for publication are accepted from ROM staff members and research associates, and from researchers reporting on work done with ROM collections. Monographs on the flora and/or fauna of Ontario by authors not affiliated with the ROM may be considered for publication. Financial contributions towards publication may be required. Authors are expected to write clearly and concisely and to omit any material not essential for an understanding of the main theme of the paper.

2. Formal Manuscripts (including captions, synonymies, literature cited, and tables) should be provided in WordPerfect (for DOS) 5.1/5.2, doublespaced, with corresponding hard copy, to the Head of Publications. The submission should include a separate sheet giving the names and affiliations of the author(s), the title of the publication, the series if applicable, the number of typed pages, the number of tables, and the number of plates and figures. Manuscripts should normally be organized in the following order: contents, abstract, introduction, materials and methods, results, discussion, conclusions, summary (if manuscript is long), acknowledgements, appendices, and literature cited. Authors are encouraged to include foreign-language translations of the summary, if appropriate. Main headings should be centred; subheadings should be left-justified to the text margin. The first line of the first paragraph in each new section should not be indented. A single space only should be left between sentences. Material intended to be typeset as italic must be provided as italic, not as underlined roman type. Literature citations in the text should be in one of the following forms: "Jones (1994)" or “(Jones, 1994)" or "(Smith, 1990:71-79, fig. 17)."

3. Standard Sources The primary authority on questions of format and style is the Guide to Authors and Editors, available from ROM Publications. For mat- ters not covered in the guide, consult the CBE Style Manual. Other standard sources are as follows: for English spelling, The Concise Oxford Dictionary; for Canadian place names and coordinates, Canada Gazetteer Atlas; for the spelling of geographic names, The Times Atlas of the World.

4. Abstract All papers must be preceded by a short, factual abstract, about one per cent of the text in length. The abstract may be followed by four to six key words in parentheses.

5. Taxonomy The name of a taxon should be given in full in headings, at the beginnings of paragraphs, and at its first occurrence in the text. Give the authority and date, if appropriate, with the first mention of each taxon, but not thereafter. Taxonomic papers, particularly synonymies, should follow the layout in the Guide to Authors and Editors.

6. Literature Cited A complete list of references, in alphabetical order of authors, must be given at the end of the paper. When two or more works of one author are cited, they should be listed chronologically. The names of journals should not be abbreviated. For correct bibliographic form, see the Guide to Authors and Editors.

7. Tables All tables should be typed on separate sheets and numbered consecutively in arabic numerals in the order of their first mention in the text. Mark the location of each table in the margin of the text.

8. Plates, Figures, and Text-figures Illustrations may be designated according to the conventions of the author's discipline; in some disciplines grouped photographs of scientific subject matter are commonly termed Plates, while line drawings and locality and other illustrations that occupy a full page or less are Text-figures. Usage must be consistent throughout the paper. A full-page illustration with its caption should be sized to fit an area of $17.3 \times 22.75 \mathrm{~cm}\left(6.8^{\prime \prime} \times 9^{\prime \prime}\right)$ for a Contribution; for Occasional Papers, the area is $14.1 \times 21.2 \mathrm{~cm}\left(5.5^{\prime \prime} \times 8.3 "\right)$. If captions are lengthy, they may be placed on the facing page. A scale or magnification factor should be included. Authors are reminded that when illustrations are reduced, magnification factors will change, and that they are responsible for the conversion. For details, see the Guide to Authors and Editors. 



\section{ROYAL ONTARIO MUSEUM LIFE SCIENCES CONTRIBUTIONS}

Life Sciences Contributions are a numbered series of scientific publications of varied subject matter. Most recent contributions include the following:

159 Revision, Plyylogeny, and Discussion of Biology and Biogeography of the Fish Genus Plesiops (Percifornies: Plesiopidac)

Randall D. Mooi

1995, 112 pp., ill., $\$ 24.95$

ISBN 0-88854-414-6

158 Breeding-Bird Populations in Jack Pine and Mixed Jack Pine/Deciduous Stands in Central Ontario

Ross D. James and Mark K. Peck

1995, 40 pp., ill., \$14.95

ISBN 0-88854-413-8

157 Classification and Evolution of the Oraseminae in the Old World, Including Revisions of Two Closely Related Genera of Eucharitinae (Hymenoptera: Eucharitidae)

John Michael Heraty

1994, 184 pp., ill., $\$ 24.95$

ISBN 0-88854-412-X

156 Conodonts of the Lower Border Group and Equivalent Strata (Lower Carboniferous) in Northern Cumbria and the Scottish Borders, U.K. Mark A. Purnell

1992, 80 pp., ill., $\$ 19.95$

ISBN 0-88854-405-7

155 Revision of the World Species of Spalangiopelta (Hymenoptera: Clialcidoidea: Pteromalidae: Ceinae)

D. Christopher Darling

1991, 48 pp., ill., \$11.00

ISBN 0-88854-395-6

154 Shallow-Water Hydroids of Bermuda:

The Thecatae. Exclusive of Plumularioidea

Dale R. Calder

1991,144 pp., ill., $\$ 24.50$

ISBN 0-88854-354-9

153 Silurian Trilobites from the Northern Yukon Territory

Rolf Ludvigsen and Ronald P. Tripp

1990, 64 pp., ill., \$12.95

ISBN 0-88854-349-2

152 The Type Species of the Ordovician Trilobite Genus Isotelus: I. gigas Dekay, 1824

David M. Rudkin and Ronald P. Tripp

1989, 24 pp.. ill., \$10.25

ISBN 0-88854-345-X
151 The Structure of the Call Note System of the Warbling Vireo

Daryl Howes-Jones and Jon C. Barlow

I988, 40 pp., ill., $\$ 11.00$

ISBN 0-88854-343-3

150 Late Cretaceous-Early Tertiary

Dinoflagellates and Acritarchs from the Kashi

Area, Tarim Basin, Xinjiang Province, China

Mao Shaozhi and Geoffrey Norris

1988, 100 pp., ill., $\$ 25.00$

ISBN 0-88854-334-4

149 Occurrence of the Cladid Inadunate Crinoid

Thalamocrinus in the Silurian (Wenlockian) of New York and Ontario

George C. Mclntosh and Carlton E. Brett 1988, 20 pp., ill., $\$ 7.75$

ISBN 0-88854-342-5

148 Shallow-Water Hydroids of Bermuda:

The Athecatae

Dale R. Calder

1988, 112 pp., ill., $\$ 24.50$

ISBN 0-88854-339-5

147 Biostratigraphy and Palaeontology of the Scollard Formation, Late Cretaceous and Paleocene of Alberta

Loris S. Russell

1987,23 pp., ill., $\$ 7.00$

ISBN 0-88854-338-7

146 Stipatocrinus, a New and Unusual Camerate Crinoid from the Lower Silurian of Western

New York

James D. Eckert and Carlton E. Brett

1987, 17 pp., ill., $\$ 6.00$

ISBN 0-88854-336-0

145 An Annotated Checklist of the Fishes of the Chagos Archipelago, Central Indian Ocean

Richard Winterbottom, Alan R. Emery, and Erling Holm

1987, 240 pp., ill., $\$ 50.00$

ISBN 0-88854-329-8

A catalogue of $\mathrm{ROM}$ publications in print is available from

University of Toronto Press

10 St. Mary Street, Suite 700

Toronto, Ontario M4Y 2W8

Canada

Tel. (416) 978-2239

Fax (416) 978-4738 